\title{
Ontogeny of the Osteocranium in the African Catfish, Clarias gariepinus Burchell (1822) (Siluriformes: Clariidae): Ossification Sequence as a Response to Functional Demands
}

\author{
DOMINIQUE ADRIAENS* AND WALTER VERRAES \\ Institute of Zool ogy, University of Ghent, Ghent, Bel gium
}

\begin{abstract}
The ontogeny of the bony skull of the African catfish, Clarias gariepinus, is studied from initial ossification until a complete skull is formed. The ossification sequence in C. gariepinus seems to be related to the functional demands that arise in a developing larva. Early ossification of the opercular bone coincides with the initiation of opercular skin movements. Early ossifications invol ve several dentul ous bones, formed shortly before the transition phase from endogenous to exogenous feeding. The enlarging branchiostegal membrane becomes supported by the gradual adding of branchiostegal rays. Parasphenoid ossification may be related to protection of the brain during prey transport, whereas the several hyoid bones, including the parurohyal, are formed in relation to the increasing loads exerted onto the tendons of the sternohyoideus and consequently onto the hyoid bar. Overall skull reinforcement occurs al most simultaneously, with a whole set of perichondral bones arising especially at places of high mechanical load. The suspensorium becomes protected against dislocation in an anteroposterior direction through a ligamentous connection, which even becomes partially ossified, forming the sesamoid entopterygoid. Later, the cranial lateral-line system becomes enclosed by a set of gutters, which close, frequently becoming platelike later in ontogeny. The brain also becomes covered dorsally. Additional dentition (prevomeral tooth plates) formation seems to coincide with formation of the opercular four-bar system, as well as with the time the digestive system becomes completely functional. Eventually, unossified regions between the bones become closed off, fortifying and completely covering the skull. J . Morphol. 235:183-237, 1998. @ 1998 Wiley-Liss, Inc.
\end{abstract}

The osteol ogy of catfishes has been a basis for several studies, especially for taxonomy and phylogeny. In the present study, the taxonomy follows that of Fink and Fink ('96), in which the Siluriformes, or catfish, represent the sister group of the Gymnotiformes, or knife-fish. Both are grouped within the Siluriphysi, which together with the Characiphysi and Cypriniphysi comprise the otophysan group of the Ostariophysi. An extensive literature has been produced on the descriptive cranial osteology of siluriform fish, mostly on adult forms (e.g., McMurrich, 1884; Bhimachar, '33; Merriman, '40; Hubbs and Miller, '60; Tilak, '61, '63a,b, '64, '65a,b, '67, '71; Rastogi, '63; Gauba, '66; '70; Taverne and Aloulou-Triki, '74; Lundberg, '75, '82; Srinivasa Rao and Lakshmi, '84; Vignes and Garcia, '87; de Pinna, '88; Howes and Fumi- hito, '91; Teugels et al., '91; Kobayakawa, '92; Chen and Lundberg, '95; de Pinna and Vari, '95; Ferraris, '96). Special attention has been paid to some clariid species (Nawar, '54; Greenwood, '56; Poll, '57, '77; Tilak, '63c). Much confusion concerning homologies is being cleared up, as data from several studies and several catfish groups are put together (Fink and Fink, '81, '96; Arratia and Gayet, '95; Arratia and Huaquin, '95). For a general review of bone nomenclatural synonymies, we also refer to Harrington ('55).

Contract grant sponsor: Institute for Science and Technology (D.A.); contract grant sponsor: National Funds for Scientific Research (W.V.)

*Correspondence to: Dominique Adriaens, University of Ghent, Zoological Institute, K.L. Ledeganckstraat 35, B-9000 Gent, Belgium. E-mail: Dominique.Adriaens@rug.ac.be 
The main purposes of the present work are, first, to describe the ontogeny of the cranial bones in order to observe the presence or absence of cranial bones. Additionally, ontogenetic stages provide information concerning fusions or reductions of certain skeletal elements, of which no trace can be seen in adults. Further, we attempt to consider the ontogeny of skeletal elements from a functional morphological point of view. Why do certain bones develop at a certain moment, and why do some develop simultaneously while others do not? Such attempts (Weisel, '67; Verraes, '74, '75, '77; Verraes and Ismail, '80; Hunt von Herbing et al., '96b; Mabee and Trendler, 1996) can yield important information on the adaptations of structures present at a certain stage. Additionally, as indicated by Arratia ('87), "detailed ontogenetic studies of different structures in different groups are needed as base for a future phylogenetic interpretation of the relationships of the families of Siluroidei."

\section{MATERIALS AND METHODS}

Observations were made on 30 different ontogenetic stages of theAfrican catfish Clarias gariepinus, originally described by Burchell (1822) and synonymized by Teugels ('82). Specimens ranged from $4.1 \mathrm{~mm} \mathrm{SL}$ (standard length) (=1 day posthatching) to $174.5 \mathrm{~mm} \mathrm{SL}$ (age unknown) (Table 1). Eggs were obtained from the Laboratory of E cology and Aquaculture (Catholic University of Leuven) and raised at a temperature of $25^{\circ} \mathrm{C}$. Most juveniles (100 days posthatching) were commercially raised and obtained from $\mathrm{W}$. Fleure (Someren, The Netherlands). At different time intervals, the devel oping larvae were sedated in MS-222 and fixed in 4\% buffered formal dehyde or paraformaldehydeglutaraldehyde. Clearing and staining followed H anken and Wassersug ('81) with trypsin being replaced by a $1 \% \mathrm{KOH}$ solution. Thesespecimens werestudied using a stereoscopic microscope (WILD M5). Eight specimens were used for serial sectioning after

TABLE 1. Specimens used for present study

\begin{tabular}{|c|c|c|c|c|c|c|c|}
\hline $\mathrm{nr}$ & $\mathrm{SL}^{1}(\mathrm{~mm})$ & $\mathrm{TL}^{2}(\mathrm{~mm})$ & $\operatorname{PAL}^{3}(\mathrm{~mm})$ & $\mathrm{Age}^{4}$ & Method & Staining ${ }^{5}$ & Used for \\
\hline 1 & 4.1 & 4.4 & 2.3 & 1 & clearing & $A B+A R S$ & drawing \\
\hline 2 & 5.9 & 6.4 & 3.3 & 2 & serial sections & $\mathrm{T}$ & 3D reconstructions \\
\hline 3 & 6.0 & 6.4 & 2.7 & 1 & clearing & $A B+A R S$ & drawing \\
\hline 4 & 6.6 & 7.0 & 3.2 & 2 & clearing & $A B+A R S$ & drawing \\
\hline $5^{6}$ & 6.8 & 7.4 & 3.1 & 3 & clearing & $A B+A R S$ & observations \\
\hline 6 & 7.2 & 7.8 & 3.8 & 7 & serial sections & $\mathrm{T}$ & 3D reconstructions \\
\hline 7 & 7.3 & 7.9 & 3.3 & 7 & clearing & ARS & observations \\
\hline 8 & 7.7 & 8.7 & 3.7 & 9 & clearing & $A B+A R S$ & drawing \\
\hline $9^{6}$ & 8.2 & 8.6 & 4.1 & 17 & clearing & $A B+A R S$ & observations \\
\hline 10 & 8.3 & 9.2 & 4.4 & 10 & clearing & ARS & observations \\
\hline $11^{6}$ & 8.4 & 9.1 & 4.2 & 13 & serial sections & $\mathrm{T}$ & observations \\
\hline $12^{6}$ & 9.3 & 10.7 & 4.9 & 21 & clearing & $A B+A R S$ & observations \\
\hline $13^{6}$ & 10.0 & 11.3 & 5.0 & 21 & clearing & $A B+A R S$ & drawing \\
\hline $14^{6}$ & 11.1 & 12.4 & 5.5 & 21 & serial sections & $\mathrm{T}$ & observations \\
\hline $15^{6}$ & 11.6 & 13.0 & 5.0 & 26 & clearing & $A B+A R S$ & drawing \\
\hline $16^{6}$ & 12.0 & 13.5 & 6.2 & 26 & clearing & ARS & drawing \\
\hline $17^{6}$ & 12.7 & 15.0 & 6.1 & 26 & clearing & $A B+A R S$ & drawing \\
\hline $18^{6}$ & 13.0 & 14.7 & 6.4 & 31 & serial sections & $\mathrm{T}$ & observations \\
\hline $19^{6}$ & 14.8 & 16.4 & 8.1 & 31 & clearing & ARS & drawing \\
\hline $20^{6}$ & 15.2 & 16.9 & 8.0 & 26 & serial sections & $\mathrm{T}$ & observations \\
\hline $21^{6}$ & 15.4 & 16.7 & 7.7 & 31 & clearing & ARS & observations \\
\hline $22^{6}$ & 15.5 & 17.8 & 8.3 & 31 & clearing & $A B+A R S$ & observations \\
\hline $23^{6}$ & 18.7 & 20.9 & 9.2 & 31 & serial sections & $\mathrm{T}$ & observations \\
\hline $24^{6}$ & 19.0 & 21.1 & 11.1 & 31 & clearing & $A B+A R S$ & drawing \\
\hline $25^{6}$ & 21.5 & 24.7 & 11.7 & 31 & clearing & $A B+A R S$ & drawing \\
\hline 26 & 46.8 & 50.2 & 23.9 & 119 & serial sections & $\mathrm{T}$ & 3D reconstructions \\
\hline 27 & 125.5 & 144.9 & 67.1 & 100 & clearing & $A B+A R S$ & drawing \\
\hline 28 & 127.0 & 143.6 & 65.5 & 100 & clearing & $A B+A R S$ & drawing \\
\hline 29 & 140.1 & 158.4 & 72.4 & 100 & clearing & ARS & drawing \\
\hline 30 & 174.5 & 187.7 & 90.9 & $?$ & clearing & $A B+A R S$ & drawing \\
\hline
\end{tabular}

$\mathrm{IT}=$ improved trichromous staining, $\mathrm{T}=\mathrm{T}$. Standard length.

2Total length.

3Pral length.

${ }^{4} \mathrm{Number}$ of days posthatching.

${ }^{5} \mathrm{AB}=$ alcian blue; $\mathrm{ARS}=$ alizarine reds.

${ }^{6} \mathrm{Gynogenetic} \mathrm{specimens.}$ 
embedding using Epon and Paraplast. The obtained $2 \mu \mathrm{m}$ and $5 \mu \mathrm{m}$ thick sections, respectively, werestained with toluidineand an improved trichrome staining according to Mangakis et al. ('64). Sections were studied using a Leitz Diaplan light microscope. Drawings of both cleared and sectioned material were created using a camera lucida. Three-dimensional reconstructions of serial sections were done using a commercial software package (PC3D, J andel Scientific).

The examined specimens were obtained from different egg batches. However, 17 of them belong to one single batch of gynogenetical eggs, obtained by and according to Volckaert et al., ('94) (Table 1).

The present study uses body length as an indicator of developmental stage. As several factors such as temperature, prey size, prey type, or water qual ity, may influence growth rate, independent from age, growth itself is a better indication of maturity. Also, coupled to body size is the fluctuation in spatial constraints in a developing larva. Arratia and Schultze ('90) noted that "the sequence of appearance of bones is maintained intraspecifically and interspecifically within extant neopterygians despite age differences." An epigenetic control of bone formation has been demonstrated by several experiments, from which it could be derived that once a certain bone is formed (genetic differentiation), its growth is regulated through the mechanical load (and other factors as hormones and metabolic factors) (epigenetic differentiation) (Herring, '93). Therate of development of other structures like the suprabranchial organ, and consequently the coupled behavior of air breathing, depends on the water temperature during ontogeny (Haylor and Oyegunwa, '93). The fact that the embryological and early larval period of Clarias gariepinus occurs extremely fast, in which the uptake of yolk resources occurs in a very efficient way (Kamler et al., '94), implies that skull formation also must be fast. However, a devel oping larva has to deal with a varying set of demands in order to survive, with most of these demands related to body size. Consequently, skull formation will be coupled to the developmental needs that arise, where those apparatuses, which can satisfy thoseneeds, have to devel op prior to their corresponding needs.

RESULTS

In some cleared specimens, especially the smallest ones, staining was insufficient to make a clear distinction between certain bones and their margins. Serial microscopic sections, however, revealed clearly the presence or absence of bones. The drawings were based on cleared material, so drawings of certain stages may not show the presence of a certain bone, although that bone was already observed in serial sections of a smaller specimen. Despitethis, the drawings do give a good representation of the morphology, as well as the chronol ogy of ossification.

For anatomical references of the chondrocranium, we refer to Adriaens and Verraes ('97c), wheretherelation of the cranial bones with the cranial lateral-line system is dealt with separately (Adriaens et al., '97). The initiation of ossification of the cranial bones, grouped per region, is given in Table 2 . The ontogeny of the Weberian apparatus is given in the figures, but is not discussed here. For that, we refer to Radermaker et al. ('89).

The 4.1-6.0 mm SL stage(Fig. 1)

\section{Neurocranium}

No signs of any ossification.

\section{Splanchnocranium}

The first signs of bony elements involve the opercular bone. At $4.1 \mathrm{~mm} \mathrm{SL}$, where the chondrocranium is still in a primordial phase (Adriaens and Verraes, '97c), a condensation of what appears to be a bony matrix (although still unstained in the specimen), at the level of the opercular process of the hyosymplectic could be observed. In the $5.9 \mathrm{~mm}$ $\mathrm{SL}$ serial sections, a condensation of cells could be observed at that spot, although no bony matrix could be distinguished. Presumably, this condensation concerns the initiation of opercular bone formation. At $5.9 \mathrm{~mm}$ $\mathrm{SL}$, dentition is present in the lower jaw, borne by a dentary. The latter is a dermal plate covering the lateral face of Meckel's cartilage. The rostral tips of that cartilage, however, are still unossified at that stage. They will ossify perichondrally, forming the mentomeckelian bone (somewhere between 5.9 and $6.0 \mathrm{~mm} \mathrm{SL}$ ). This ossification seems to initiate at the anterior tip of the dermal dentary, which is fused to it from the moment it arises. This bony lower jaw at this stage is referred to as the os dento-mentomeckelium (Fig. 2B). No signs of other ossifications could be discerned. 


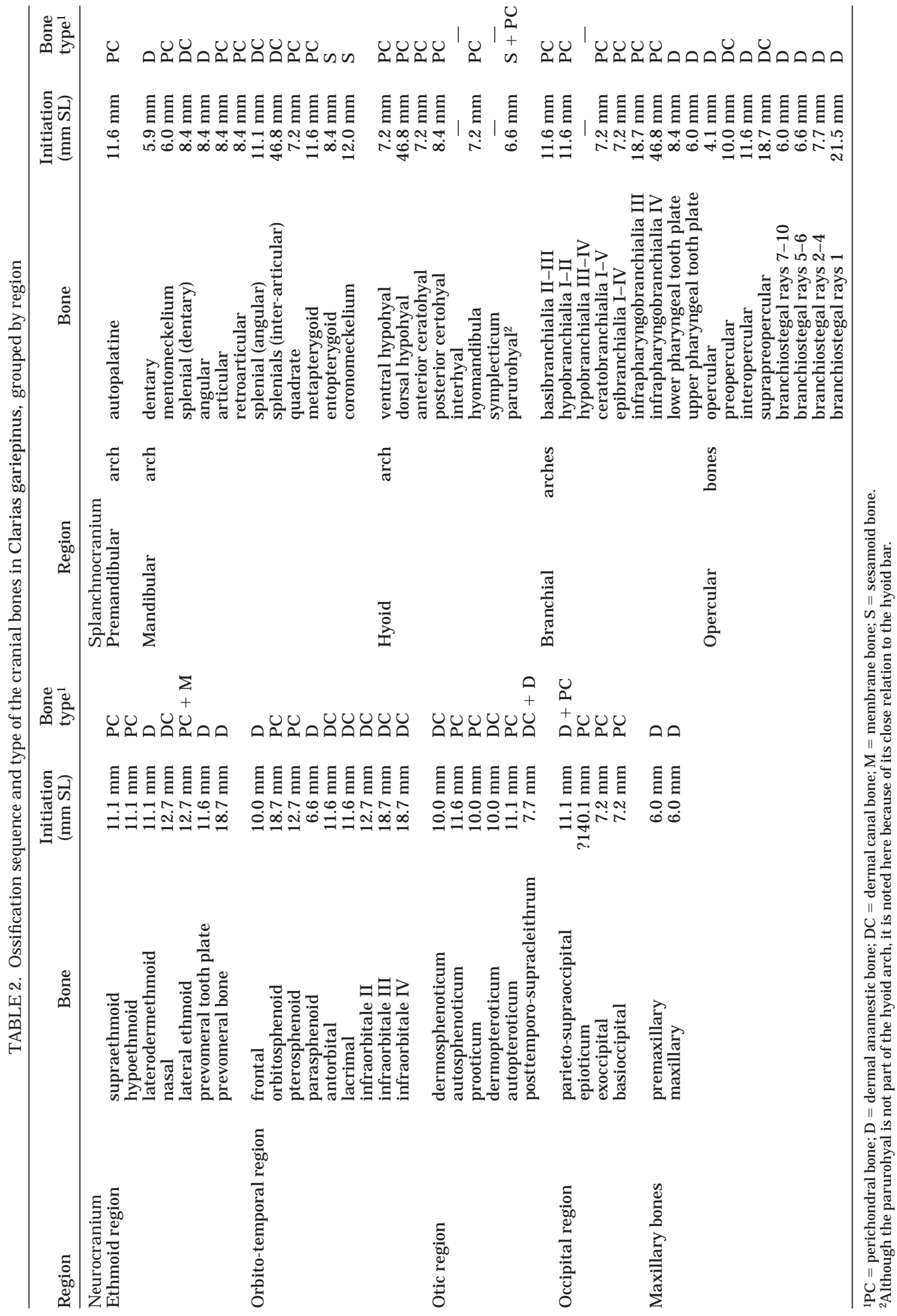


The 6.0-6.6 mm SL stage (Fig. 2) Neurocranium

Several bones are present at this stage. Rostrally, a paired, rudimentary premaxillary bone lies at the ventral surface of the ethmoid plate. Although rudimentary, they al ready bear several teeth (Fig. 2B). The two premaxillaries do not yet meet in the midline (Fig. 2A). At the rostral tip of the palatine, a maxillary bone is formed, al ready enclosing the base of the maxillary barbel. The articulation of the maxillary bone with the palatine is improved by an additional cartilagi nous element, the submaxillary cartilage.

\section{Splanchnocranium}

The opercular bone has clearly ossified now. It consists of a horizontal rod bearing a ventral, triangular membranous plate. The articular facet is more differentiated. Along the caudoventral margin of the posterior part of the ceratohyal, four branchiostegal rays have devel oped. Based on their position and the further development of these rays, it is clear that those four involve the posterior four branchiostegal rays of adults (radii branchiostegi VII-X). During further ontogeny they become enlarged, whereas other branchiostegal rays are added in front of them. At the ventral face of the fourth infrapharyngobranchial element, a tooth plateis formed. This plate corresponds to the tooth bearing part of the upper pharyngeal jaws.

The 6.6-7.7 mm SL stage (Figs. 3, 4A) Neurocranium

Whereas in the previous stages the neurocranial floor is reinforced by cartilaginous elements only, a bony support is present at $6.6 \mathrm{mmSL}$. The parasphenoid arises as what appears to be a U-shape bone, following the curvature of the trabecular bars and the acrochordal cartilage. Although the hypophysial fenestra is open almost completely, the foramen for the internal carotid artery is al ready cut off ( $\mathrm{Fig}$. $3 \mathrm{~A}$ ). The serial sections of the $5.9 \mathrm{~mm} \mathrm{SL}$ stage reveal no sign of a parasphenoid, whereas the $6.8 \mathrm{~mm} \mathrm{SL}$ stage already has a parasphenoid closing off the hypophysial fenestra almost completely. At that stage, the parasphenoid is no longer $\mathrm{U}$-shaped. The premaxillary bones have become more el ongated. At 7.2 mm SL, ossification at the anterior tip of the notochord has started, corresponding to the basioccipital. Exoccipitals arise as perichondral ossifica- tions of the inner side of cranial walls surrounding the lagena and the sacculus.

\section{Splanchnocranium}

At $6.6 \mathrm{~mm} \mathrm{SL}$, the dento-mentomeckel ian complex reaches up to the coronoid process of M eckel's cartilage. In the middle, the left and right mentomeckel ian parts of the complexes are separated from each other by the fused tips of the Meckelian cartilages. At the caudal face of the hypohyals, two ossicles have formed, separated from each other by the anterior copula (Figs. 3C, 4A). These paired el ements correspond to the sesamoid, unfused parts of the future median parurohyal bone. Two more branchiostegal rays have been added, as six of them border the ceratohyal. At $7.2 \mathrm{~mm} \mathrm{SL}$, most of the splanchnocranial perichondral bones have formed. The hyoid bar bears an anterior ceratohyal bone, as well as a ventral hypohyal one. The cartilaginous hyosymplecticpterygoquadrate plate bears an ossification at its articular facets with the mandibula and the opercular bone, i.e., the quadrate and opercular process of the hyomandibular bones, respectively (the latter was overlooked in a previous study by Adriaens and Verraes, '97a). The ventral plate of the opercular bonenow reaches the level of the interhyal, whereas the horizontal rod is extended posteriorly. The bone is still triangularly shaped. Serial sections of a $7.2 \mathrm{~mm} \mathrm{SL}$ specimen indicate the differentiation of a dorsal process at the lateral face of the articulatory facet of the opercular bone with the hyosymplecticum. At this stage, a very indistinct tendon of the dilatator operculi inserts onto this process. The branchial basket bears most of its ossifications at this $7.2 \mathrm{~mm} \mathrm{SL}$ stage. All five ceratobranchials and all four epibranchials are present. Ossification seems to start at the anterior half of the cartilaginous elements. The ceratobranchials V, however, do not seem to possess any teeth yet.

The 7.7-10.0 mm SL stage (Figs. 5, 6A, 7A) Neurocranium

At $7.7 \mathrm{~mm} \mathrm{SL}$, the parasphenoid now completely covers the hypophyseal fenestra, leaving only a paired foramen for the entrance of the internal carotid artery (Figs. 5A, 6A). Posteriorly it becomes extended and al most contacts with the basioccipital, which now has an extracranial ossified part also (Fig. 5C). The exoccipital bones cover the bases of the pilae occipitales (Fig. 5A). Posterior to 

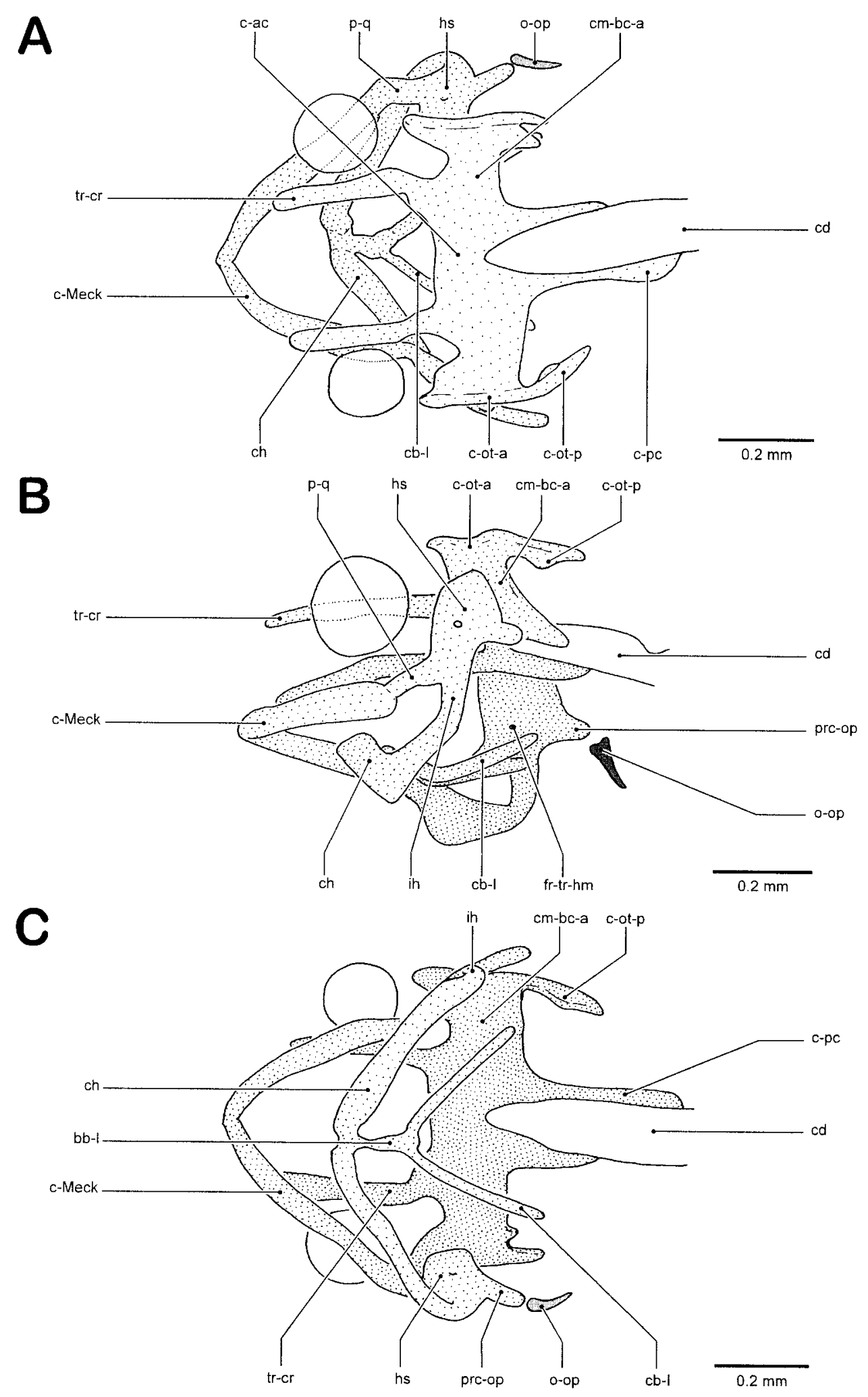

Figure 1 
the chondrocranium, two small ossicles are formed, which lie between the caudal margin of the otic capsules and the parapophysis of the fourth vertebra (Figs. 5B, 6A). Based on its position, in relation to the cleithral bone, as well as evidence from further ontogeny, this bone must correspond to the dorsal process of the posttemporal part of the future posttemporo-supracleithral bone complex. A discussion on the true nature of this bone complex in siluriform fishes is given by Arratia and Gayet ('95). The premaxillaries now al most meet in the midline.

\section{Splanchnocranium}

Both processes, i.e., the lateral and ventral processes, of the future dentospleniomentomeckelian complex can al ready be distinguished at $7.7 \mathrm{~mm} \mathrm{SL}$. A total of nine branchiostegal rays is present. The left and right parurohyal parts have become forked at their caudal tip, whereas both are connected with their rostral tip to the ventral hypohyals through a ligament (Fig. 4B). The upper pharyngeal tooth plate is enlarged and heavily toothed, but is still supported by the fourth infrapharyngobranchial el ement only (Figs. 5C, 7A). At $8.4 \mathrm{~mm} \mathrm{SL}$, a gutter has formed, covering the posterior part of the dental bone laterally. This gutter corresponds to the dental splenial, but whether or not one or more of these splenial bones are involved could not be discerned. As expected, the initiation of this gutter formation is at the level of a superficial neuromast, which has started to sink in. More anteriorly, the neuromasts al so have started to invaginate, although not so deeply, and are not yet supported by a gutter. At this stage, a perichondral ossification surrounding the articulation between M eckel's cartilage and the pars quadrata of the pterygoquadratum indicates the presence of the articular bone (Fig. 8B). Observations of sev-

Fig. 1. Skull of Clarias gariepinus (4.1 mm SL stage). A, dorsal view; B, lateral view; C, ventral view. (Grey indicates bone, shaded areas indicate cartilage.) bb-l, basibranchiale I; c-ac, cartilago acrochordalis; c-Meck, cartilago Meckeli; c-ot-a, cartilago otical is anterior; cot- $p$, cartilago oticalis posterior; c-pc, cartilago parachordalis; cb-I, ceratobranchiale I; cd, chorda dorsalis; ch, ceratohyale; cm-bc-a, commissura basicapsularis anterior; fr-tr-hm, foramen truncus hyomandibularis nervus facialis; hs, hyosymplecticum; ih, interhyale; o-op, os operculare; $p-q$, pars quadrata of the palatoquadratum; prc-op, processus opercularis; tr-cr, trabecula cranii. eral stages indicate that the perichondral articular and retroarticular bones and the dermal angular bonearise at about the same moment (Adriaens et al., '97). The retroarticular bone is formed as an ossification of the ventral face of the cartilagi nous retroarticular process of Meckel's cartilage. The angular bone is plate-like, bordering the posterior part of Meckel's cartilage ventrolaterally. At the ventromedial face of the, still cartilaginous, palatinea thin, plate-likebone is formed. At this stage $(8.4 \mathrm{~mm} \mathrm{SL})$, this bone seems to be surrounded by ligamentous tissue. Based on its morphology, position, and data from further ontogeny, this bone must correspond to the sesamoid "entopterygoi d" type 4 (Arratia, '92). The hyoid bar now bears a posterior ceratohyal ossification (frequently referred to as the epihyal). The paired, sesamoid part of the parurohyal bone has become fused to what seems to be a perichondral ossification of the ventral face of the anterior basibranchial element. The complex nature of this bone, which has the position and function of the pure dermal urohyal bone of teleosts, led to the designation of the name "parurohyal" for that bone in Siluriformes (see Discussion) (Arratia and Schultze, '90). Teeth were observed at this stage on the dorsal face of the fifth ceratobranchial bone. Both pharyngeal jaws are thus present from $8.4 \mathrm{~mm} \mathrm{SL}$.

The 10.0-11.6 mm SL stage (Figs. 6B, 7B, 8) Neurocranium

The ossification of the skull roof has started. The ossification centers of the frontal bones are situated at the branching point of the taenia marginalis posterior in the epiphysial bridge, the lamina orbito-nasal is, and the commissura spheno-septalis. Apparently, this ossification initiates by the formation of the neurodermal component of the frontal bone, as a gutter-like bone follows the taenia marginal is posterior and the commissura spheno-septalis. Apparently, this ossification initiates by the formation of the neurodermal component of the frontal bone, as a gutter-like bone follows the taenia margi nalis posterior and the commissura sphenoseptalis. At the level of the epiphysial bridge, a medial opening of that gutter is present, corresponding to the future epiphysial branch of the supraorbital canal (Adriaens et al., '97). Posterior to the frontal bone, two paired and consecutive gutter-like bones border the otic capsules laterally (Fig. 8A). The anterior one represents the neurodermal 

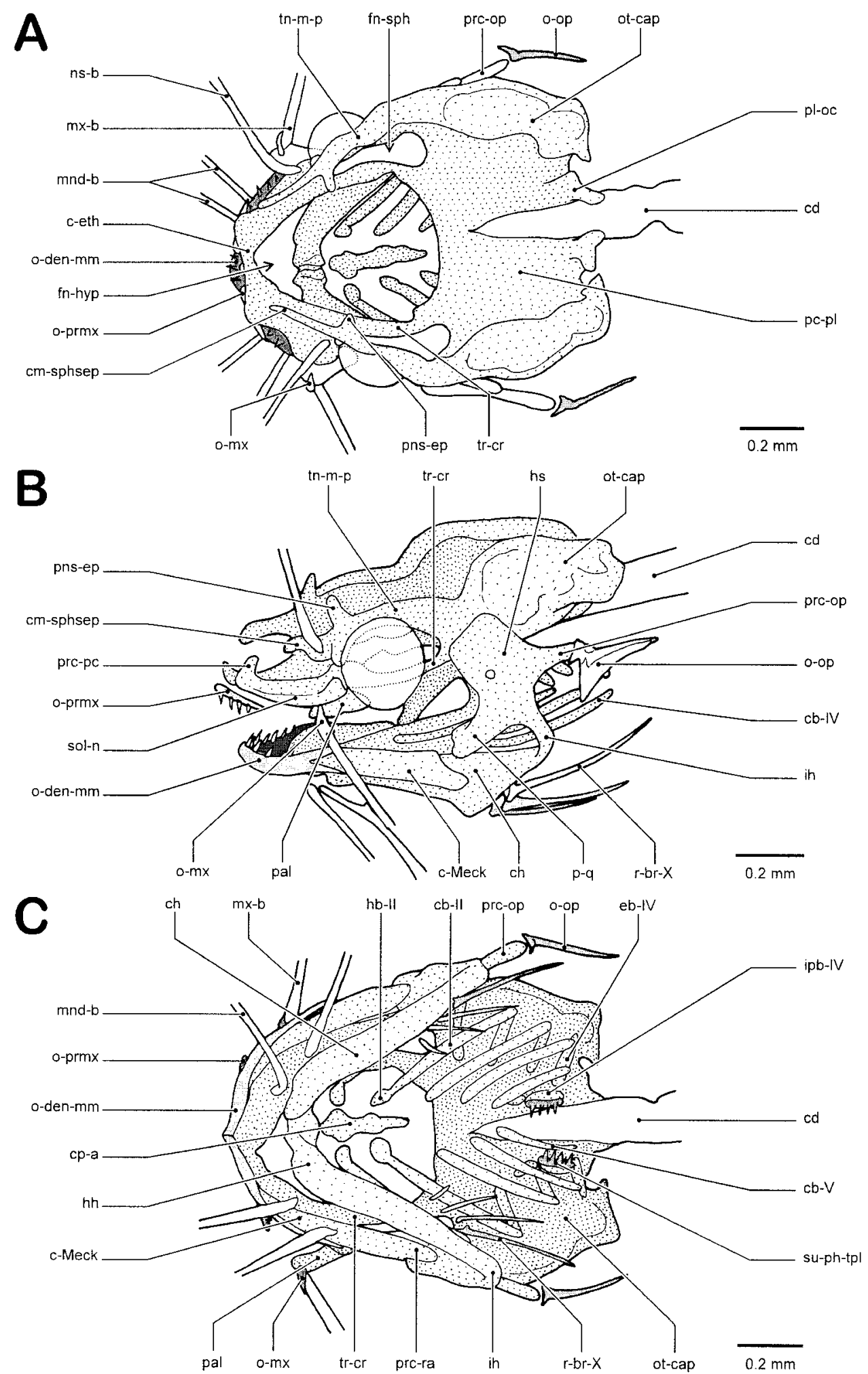

Figure2 
component of the dermosphenotic bone, whereas the posterior one corresponds to the neurodermal component of the dermopterotic bone. Apparently the supraorbital canal is al ready el ongated into the otic and temporal canals at this stage. Both neurodermal components are still separated from each other, although the dermopterotic bone already reaches the posttemporo-supracleithral complex.

Based on its morphology, the latter complex is represented by both the posttemporal and supracleithral parts at this stage. Three processes can be distinguished: (1) a dorsal one, which reaches the dorsocaudal margin of the neurocranium, medial to the pterotic bone, (2) a ventral one, which runs to the lateroventral face of the pterotic bone, and (3) a ventromedial process, which runs toward the parapophysis of the fourth vertebra. Most probably, the two anteriorly directed processes represent the dorsal and ventral processes of the posttemporal bone, and the ventromedial one corresponds to the transscapular ligament of the supracleithral bone, which has become ossified (see Discussion). In the skull floor, the parasphenoid has reached the basiocci pital, and even overlaps it (Fig. 6B). The foramina for the internal carotid arteries have shifted laterally, coupled to the ongoing excavation of the trabecular bars. At that level the parasphenoid has formed two conspicuous lateral wings that reach up to the posterior margin of the sphenoid fenestra (Fig. 6B). At the anteromedial face of the otic capsules, the initiation of the prootic bone covers both the

Fig. 2. Skull of Clarias gariepinus ( $6.0 \mathrm{~mm} \mathrm{SL} \mathrm{stage).}$ A, dorsal view; B, lateral view; C, ventral view. (Grey indicates bone, shaded areas indicate cartilage.) c-eth, cartilago ethmoideum; c-Meck, cartilago Meckeli; cb-II, ceratobranchiale II; cb-IV, ceratobranchiale IV; cb-V, ceratobranchiale V; cd, chorda dorsalis; ch, ceratohyale; cm-sphsep, commissura spheno-septalis; cp-a, copula anterior; eb-IV, epibranchiale IV; fn-hyp, fenestra hypophysea; fn-sph, fenestra sphenoidea; hb-II, hypobranchiale II; hh, hypohyale; hs, hyosymplecticum; ih, interhyale; ipb-IV, infrapharyngobranchiale IV; mnd-b, mandibular barbel; mx-b, maxillary barbel; ns-b, nasal barbel; o-den-mm, os dento-mentomeckelium; o-mx, os maxillare; o-op, os operculare; o-prmx, os praemaxillare; ot-cap, otic capsule; p-q, pars quadrata of the palatoquadratum; pal, palatinum; pc-pl, parachordal plate; pl-oc, pila occipitalis; pns-ep, pons epi physialis; prc-op, processus opercularis; prc-pc, processus praecerebral is; prc-ra, processus retroarticularis; r-br, radius branchiostegus; sol-n, solum nasi; su-ph-tpl, superior pharyngeal tooth plate; tn-m-p, taenia marginalis posterior; tr-cr, trabecula cranii. ventral and dorsal surface of the cartilaginous floor ( $F$ igs. 6B, 8A). At this stage the bone is rather slender and broadens at its posterior half. The basioccipital now covers the exposed notochord completely. The exoccipital expands along the dorsal face of the pila occipitalis (Fig. 6B). At $11.1 \mathrm{~mm} \mathrm{SL}$, additional skull roof bones are formed. In the ethmoid region, two dermal plates come to cover the pre-ethmoid cornua and the ethmoid cartilage, which have already started to become ossified perichondrally, both ventrally and dorsally. At the dorsal face, however, this bone bears a distinct lateral, plate-like extension, which indicates a possible dermal origin. The ventral and dorsal perichondral ossification must correspond to the hypo- and supraethmoid bones, respectively, whereas the dermal component probably represents the laterodermethmoid bones (Taverne, pers. comm.). Consequently, this bony complex is referred to as the mesethmoid (Adriaens et al., '97). The posterior part of the skull roof has also started to ossify. As is the case for the ethmoid region, the roof of the occi pital region seems to consist of two dermal plates covering an unpaired, perichondral bone. This perichondral supraoccipital covers the tectum posterius, as well as the roof of the posterior part of the otic capsules. The dermal plates overlap with the whole supraoccipital bone, but are extended anteriorly, up to the anterior part of the otic capsule. Apparently, what seems to correspond to the parietals becomes fused to the supraoccipital at the moment they are formed, as has been observed in several siluriform fishes (see Discussion). This complex is further referred to as the parieto-supraoccipital bone. However, what part of this complex exactly corresponds to the supraoccipital would require some more detailed research. At the level of the dermopterotic bone, the otic cartilage has begun to ossify perichondrally, corre sponding to the autopterotic bone. A corre sponding ossification of the autosphenotic bone, however, is still lacking.

\section{Splanchnocranium}

Suspensorial ossifications, like the quadrate and hyomandibular bone, can be discerned on the cl eared specimens of $10.0 \mathrm{~mm}$ $\mathrm{SL}$, whereas no sign of a symplectic bone is present (Fig. 8B). The latter bone does not develop at all in Clarias gariepinus, which is a general feature for Siluriformes (Fink and Fink, '81, '96). The hyomandibular bone en- 

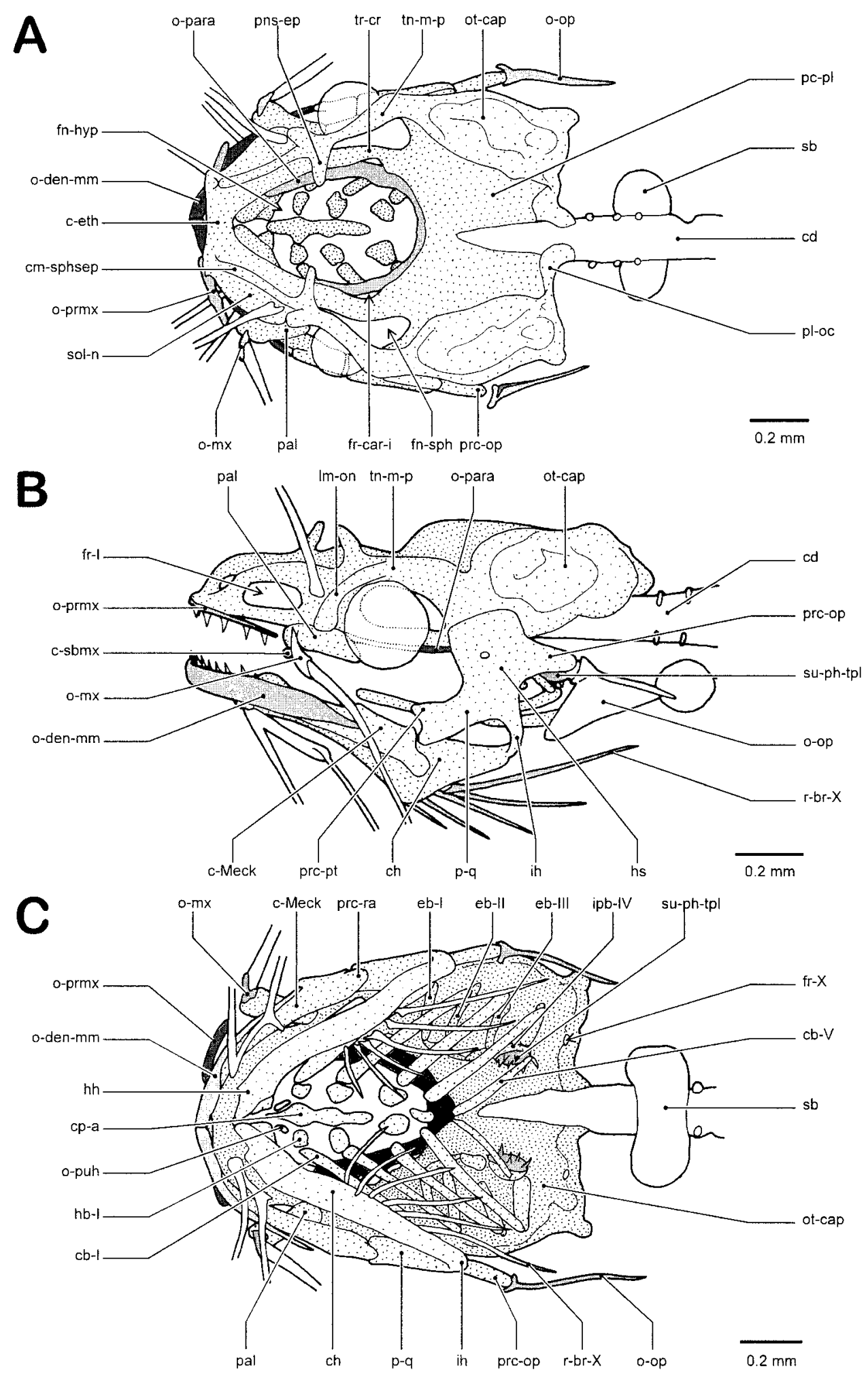

Figure 3 
closes the foramen for the truncus hyomandibularis of the nervus facialis (VII), as well as the base of the opercular process (Fig. $8 B)$. Between the hyomandibular and quadrate bones, a gutter-like preopercular bone follows the ventrolateral border of the suspensorium, thereby partially covering the cartilaginous interhyal. The anterior ceratohyal bone is now apparent in the cleared specimen as well. The forked branches of the parurohyal bones have become extended, both in an anterior and posterior direction. Their medial tips now have fused with each other posteriorly (Fig. 4C). Ceratobranchial ossifications are observed in the cleared specimen. Both their articular facets, with the hypobranchials and epibranchials, remain unossified. Apart from an increase in number of teeth, no striking difference can be observed in the upper pharyngeal tooth plate (Fig. 7B). No more branchiostegal rays have been added since the previous stage; thus nine are present. At $11.1 \mathrm{~mm} \mathrm{SL}$, the angular bone bears a lateral gutter, which indicates the fusion with at least one splenial bone. Consequently, a complex angulo-splenio-articulo-retroarticular bone is formed.

The 11.6-12.7 mm SL stage (Figs. 6C, 7C, 9) Neurocranium

Ventral to the ethmoid plate, the premaxillaries become more and more platelike, as a posterior extension is noted. The membranodermal component of the frontal bone can

Fig. 3. Skull of Clarias gariepinus ( $6.6 \mathrm{~mm} \mathrm{SL} \mathrm{stage).}$ A, dorsal view, B, lateral view, C, ventral view. (Grey indicates bone, shaded areas indicate cartilage.) c-eth, cartilago ethmoideum; c-Meck, cartilago Meckeli; csbmx, cartilago submaxillaris; cb-I, ceratobranchiale I; cb-V, ceratobranchiale V; cd, chorda dorsalis; ch, ceratohyale; cm-sphsep, commissura spheno-septalis; cp-a, copula anterior; eb-I, epibranchiale I; eb-II, epibranchiale II; eb-III, epibranchiale III; fn-hyp, fenestra hypophysea; fn-sph, fenestra sphenoidea; fr-car-i, foramen arteria carotis interna; fr-I, foramen fila ol factoria; $\mathrm{fr}-\mathrm{X}$, foramen nervus vagus; hb-I, hypobranciale I; hh, hypohyale; hs, hyosymplecticum; ih, interhyale; ipb-IV, infrapharyngobranchiale IV; I m-on, lamina orbitonasalis, sensu latu; o-den-mm, os dento-mentomeckelium; o-mx, os maxillare; o-op, os operculare; o-para, os parasphenoideum; o-prmx, os praemaxillare; o-puh, os parurohyale; ot-cap, otic capsule; $p-q$, pars quadrata of the palatoquadratum; pal, palatinum; pc-pl, parachordal plate; pl-oc, pila occi pital is; pns-ep, pons epi physial is; prc-op, processus opercularis; prc-pt, processus pterygoideus; prc-ra, processus retroarticularis; r-br, radius branchiostegus; sb, swimbladder; sol-n, solum nasi; su-ph-tpl, superior pharyngeal tooth plate; tn-m-p, taenia marginal is posterior; tr-cr, trabecula cranii. now beclearly distinguished from the neurodermal, gutter-like one, as it has started to cover the postpineal foramen and, consequently, the brain. Posterolaterally, the frontal bone gutter has reached that of the dermosphenotic bone. The latter bone, as well as the dermopterotic bone, has started to form the membranodermal component as well. Additionally, a perichondral ossification covers the taenia marginalis posterior at the level of these dermosphenotics, especially at the ventral side (Fig. 6C). Apparently, the autosphenotic has also formed. It is directly fused to the dermal counterpart, as is the case for the dermopterotics, and autopterotic bones. This fused bony complex of double origin is consequently referred to as the sphenotic bone (=dermosphenotic and autosphenotic bones) and the pterotic bone (dermopterotic and autopterotic bones).

At the posterior corners of the chondrocranium, contacting the pterotics, lies the posttemporo-supracleithral bone, bearing a foramen for the temporal canal (Fig. 9B). The latter feature is an additional argument for stating that the posttemporal is present and part of the bony complex. From this stage on, the parasphenoid plays an important rol ein the reinforcement of the skull floor, as the trabecular bars have become split in two by the continued lateral expansion of the foramen for the internal carotid artery (Fig. 9A). At this stage, the parasphenoid consequently establishes the ventral connection between the anterior part of the neurocranium (anteri or to the sphenoid fenestra) and the posterior part (posterior to the fenestra). The previously slender, lateral wings have consequently become broader. The basiocci pital has formed two longitudinal ridges between which the posterior extension of the parasphenoid comes to lie (Fig. 6C). At this stage, the basioccipital supports the otoliths of the lagena and the sacculus, i.e., the asteriscus and the sagitta, respectively. Lateral to the basioccipital, the exocci pitals have enclosed the foramen of the nervus vagus $(\mathrm{X})$. The latter bones form the lateral margins of the foramen magnum, thus encl osing the pilae occipitales, until they contact the parieto-supraoccipital bone complex dorsally. The prootics have become enlarged and ovally shaped and take part in the ossification of the border of the sphenoid fenestra (Fig. 6C). They support the otolith of the utriculus, i.e., the lapillus. Anteriorly, behind the premaxillary bones, two small, 


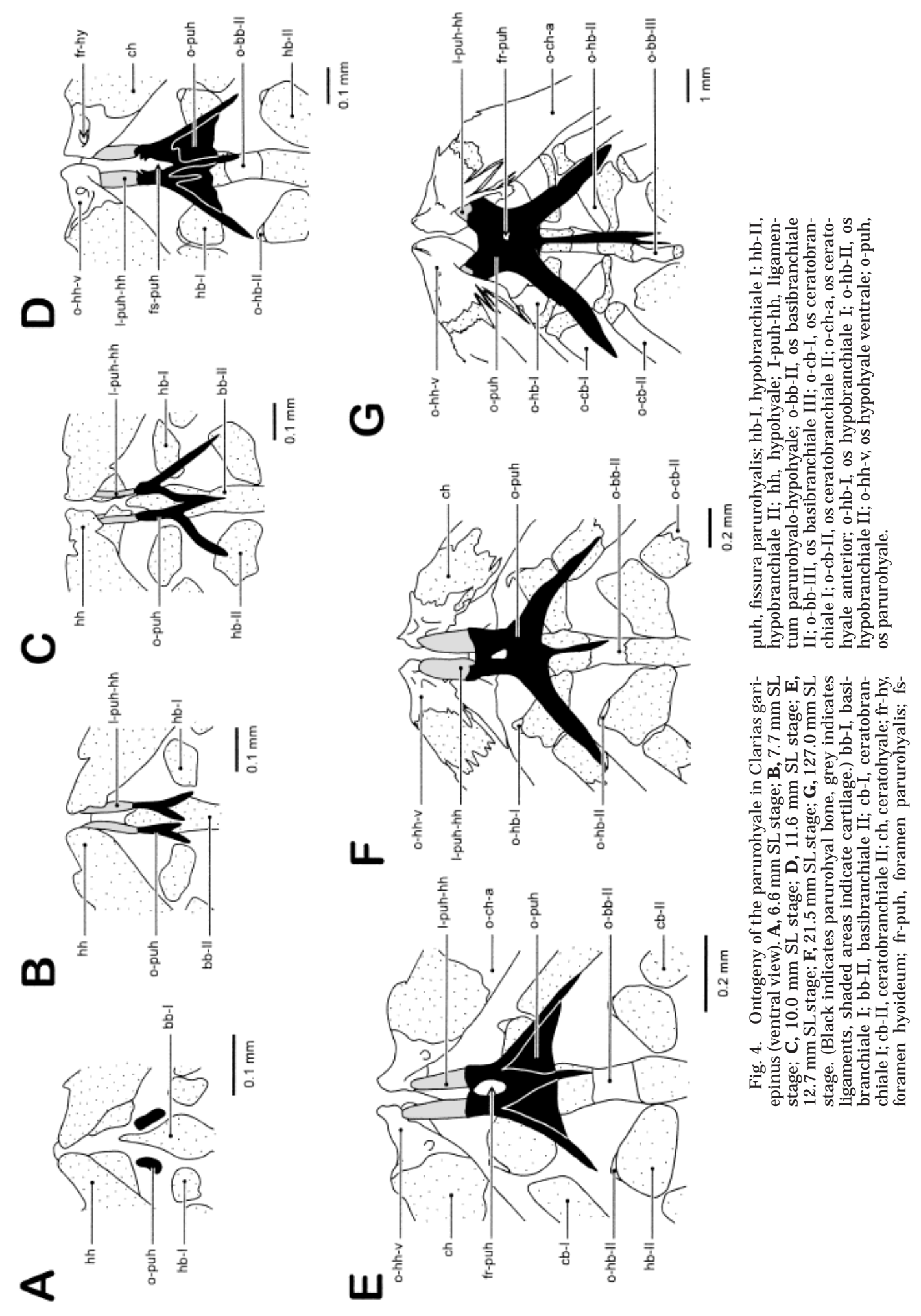


splint-like bones arise on the ventral face of the ethmoid plate (Fig. 6C). As can be derived from further ontogeny, these bones correspond to the prevomeral tooth plates that are formed prior to the median prevomeral bone itself. Dentition, however, could not yet be discerned. At this stage, the first signs of the dermal bones bordering the rigid skull laterally are present. At the level of the palatine, two small ossicles have formed, enclosing the anterior part of the infraorbital canal. These ossicles correspond to the neurodermal component of the antorbital bone and lacrimal bone (=os infraorbitalel) (Fig. 9B).

\section{Splanchnocranium}

The previously cartilaginous lower jaw has now become al most completely encl osed with bone. An anterol ateral process of the angulosplenio-retroarticular complex fits between the ventral and lateral processes of the dentosplenio-mentomeckelian complex. At this interdigitating surface, the coronoid process, as well as almost the complete medial face of Meckel's cartilage is still exposed (Fig. 7C). At thelevel of its articulation with the orbitonasal Iamina, the palatine has become ossified perichondrally, thus forming the autopalatine bone (Fig. 6B). The articular facet of the autopalatine itself is still cartilaginous, although surrounded by bone. The entopterygoid is now a small, triangular bone, bordering the autopalatine ventrally (Figs. $6 C, 7 C, 9 B$ ). The anterior tip of the pterygoid process of the suspensorium has also started to ossify, forming the metapterygoid bone. This perichondral bone, however, is still separated from the quadrate bone. The latter has become expanded dorsal ly and caudally, compared with the previous stage. Dorsally, the initiation of the membranous outgrowth of thequadratehas started. Although still separated from the quadrate, the hyomandibular bone has formed the corresponding membranous outgrowths as well, at its anterior border. The preopercular bone has becometubelike now, as the gutter has closed. This bone still follows the ventrocaudal margin of the hyosymplecticum, with its anterior part lying horizontally and its posterior part vertically. At thelevel of thearticulation with the neurocranium, the hyomandibular bone bears a cartilaginous rim. Compared to the previous stage, the opercular bone has extended even more ventrally. In this cleared and stained specimen, three ossifications of the hyoid bar are discernable: the anterior ceratohyal in the middle, and the newly formed posterior ceratohyal and ventral hypohyal (Fig. 7C). The latter bone is penetrated by a foramen, through which passes the hyoid artery (Fig. 4D). The articulation of the nine branchiostegal rays occurs with the anterior ceratohyal bone and the cartilaginous part separating the latter from the posterior ceratohyal bone. The parurohyal bone now clearly forms one single unit, as a horizontal bony lamella has formed between the median and two lateral processes (Fig. 4D). The ligamentous connection of the parurohyal with the hyoid bar occurs at the level of the ventral hypohyals. Theanterior copula bears two ossified rings at the position of the second and third basibranchial bones. At their anterolateral tips, the hypobranchials I and II have started to ossify as well (Fig. 7C). All the epibranchial bones are observed in the cleared specimen of $11.6 \mathrm{~mm} \mathrm{SL}$. The upper pharyngeal tooth plate has enlarged rather isometrically, but is still supported mainly by the unossified, fourth infrapharyngobranchial element. At $12.0 \mathrm{~mm} \mathrm{SL}$, all mandibular ossifications are present. The last to develop is the coronomeckelian bone, which is formed at the medial face of the coronoid process, between the dento-spleniomentomeckelian and the angulo-splenioarticulo-retroarticular bone complexes (Fig. 10A). At this stage, the splenial gutter of the dental boneis still open anteriorly, but gradually becomes closed off and incorporated in the bone compl ex (Fig. 10).

\section{The 12.7-21.5 mm SL stage}

(Figs. 4E, 11, 12A)

\section{Neurocranium}

The bones of the skull roof have started to close up the unossified regions in the skull as they make contact with the surrounding bones. The laterodermethmoids follow the commissura spheno-septalis as they grow posteriorly. Serial sections of a $13.0 \mathrm{~mm} \mathrm{SL}$ specimen show that the laterodermethmoids are fused to the perichondral supraethmoid, up to the level of the precerebral lamina. Posterior to that level, the supraethmoid is missing, whereas the dermal bones have extended above the posterior part of this Iamina and the sphenoseptal commissures, separated from it by connective tissue. This configuration supports a possible dermal origin of these bones. The plate-like part of the frontal bone becomes extended anteriorly, medially and posteriorly. Posteriorly, the frontals have contacted the parietals (thus 

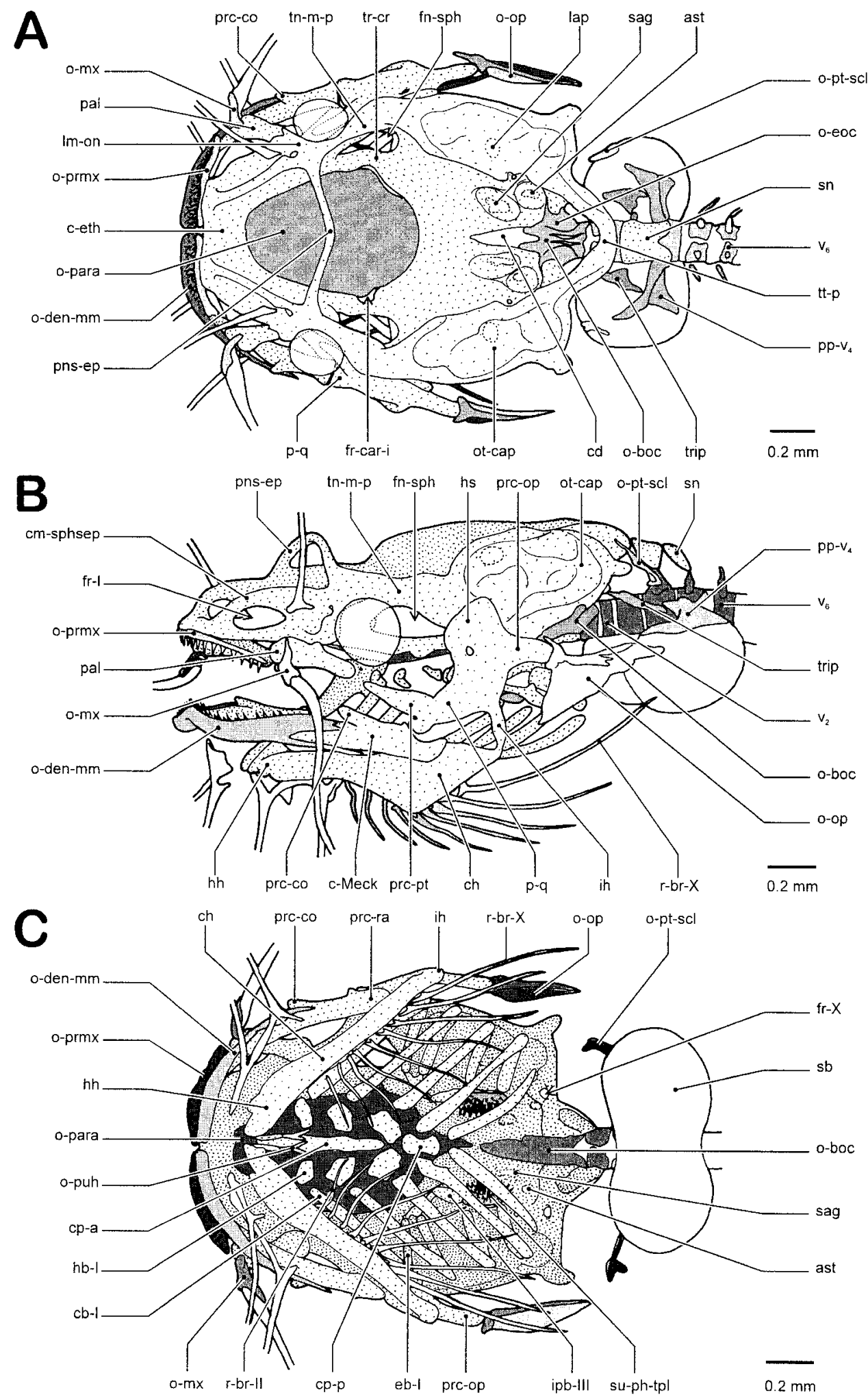

Figure 5 
fused to the supraoccipital bone), and the initiation of an interdigitation can be observed. Medially, the frontals have continued to cover the pre- and postpineal fenestra, as well as enclosing the cartilaginous epiphysial bridge (Fig. 11A). Anterior to the entrance of the supraorbital canal into the frontal bone, a small, gutter-like nasal bone has differentiated. Laterocaudally, the bony skull margin is formed by the sphenotic and pterotic bone, covering the posterior part of the taenia marginalis posterior and the otic capsule. The sphenotic bone is restricted to the taenia marginalis and the anterior part of the otic capsule, whereas the pterotic bone covers about two thirds of that capsule. The perichondral part of both these bones has expanded over the otic capsules, ventrally and dorsally. Posteriorly, the two anterior processes of the posttemporo-supracleithral bone have expanded anteriorly, as the fork between them fits onto the posterior margin of the pterotic bone (Fig. 11B). The ossified transscapular ligament is a stout process, contacting the laterodorsal margin of the parapophysis of the fourth vertebra. In the skull floor, two more bones have been added. Ossification of the lateral ethmoid has started at the level of the articular facet of the lamina orbito-nasalis, for the articulation with the autopalatine (Fig. 12A). It borders the articular facet laterally, and has

Fig. 5. Skull of Clarias gariepinus ( $7.7 \mathrm{~mm} \mathrm{SL} \mathrm{stage).}$ A, dorsal view; B, lateral view; C, ventral view. (Grey indicates bone, shaded areas indicate cartilage.) ast, asteriscus (lagenar otolith); c-eth, cartilago ethmoideum; c-Meck, cartilago Meckeli; cb-I, ceratobranchialel; cd, chorda dorsalis; ch, ceratohyale; cm-sphsep, commissura spheno-septalis; cp-a, copula anterior; cp-p, copula posterior; eb-I, epibranchialel; fn-sph, fenestra sphenoidea; fr-car-i, foramen arteria carotis interna; fr-I, foramen fila olfactoria; fr-X, foramen nervus vagus; hb-l, hypobranchiale I; hh, hypohyale; hs, hyosymplecticum; ih, interhyale; ipb-III, infrapharyngobranchiale III; Iap, Iapillus (utricular otolith); I m-on, lamina orbitonasal is, sensu latu; o-boc, os basioccipitale; o-den-mm, os dentomentomeckelium; o-eoc, os exoccipitale; o-mx, os maxilIare; o-op, os operculare; o-para, os parasphenoideum; o-prmx, os praemaxillare; o-pt-scl, os posttemporosupracleithrum; o-puh, os parurohyale; ot-cap, otic capsule; $p$-q, pars quadrata of the palatoquadratum; pal, palatinum; pns-ep, pons epiphysialis; $p p-v_{4}$, parapophysis of vertebra 4; prc-co, processus coronoideus; prc-op, processus opercularis; prc-pt, processus pterygoideus; prc-ra, processus retroarticularis; r-br, radius branchiostegus; sag, sagitta (saccular otolith); sb, swimbladder; sn, supraneurale; su-ph-tpl, superior pharyngeal tooth plate; tn-m-p, taenia marginalis posterior; tr-cr, trabecula cranii; trip, tripus; tt-p, tectum posterius; $v_{2}$, vertebra $2 ; v_{6}$, vertebra 6 covered the ventral part of the preorbital base. At the anterodorsal border, the pterosphenoid bones have appeared at the ventral part of the taenia marginalis posterior ( $\mathrm{Fig}$. 12A). The prevomeral tooth plates have expanded, and the first teeth can be distinguished. The parasphenoid becomes extended anteriorly, touching the prevomeral tooth plates. Posteriorly, the parasphenoid narrows and terminates in a slender process lying between the longitudinal ridges of the basioccipital. This kind of overlap allows the long and slender interdigitation, which can be observed in later stages. The basi occi pital has enlarged, especially in an anterior direction, as it now forms the complete floor for the saccul us, enclosing the sagitta (Fig. 12A). The exoccipitals now border the foramen for the glossopharyngeus nerve posteriorly. At the lateral face of the skull, a second infraorbital bone has been added, posterior to the lacrimal bone.

As is still the case for the anterior two canal bones, this infraorbital bone is tubular. It borders the eye ball anteroventrally (F ig. 11B). Ventral to the preopercular bone, a triangular interopercular bone is formed, close to the anterior margin of the opercular ventral tip. Serial sections of a $15.2 \mathrm{~mm} \mathrm{SL}$ specimen indicate that the lateral ethmoid consists of a perichondral ossification, bearing a plate-like extension. The lamina orbitonasalis ossifies perichondrally and becomes laterally and dorsally enlarged by a bony plate. However, a separate ossification of the plate-like part could not be discerned. At $18.7 \mathrm{~mm} \mathrm{SL}$, the prevomeral tooth plates are interconnected and have fused to the me dian prevomeral bone. This bone already interdigitates with the parasphenoid. Three more dermal canal bones are added at this stage, covering the skull laterally: the third and fourth infraorbital bones, and the suprapreopercular one. All of them are still tubular or gutter-like. The infraorbital series is completed in this stage. The onset of perichondral ossification of the orbitosphenoid could also be discerned, covering the cartilaginous floor of the ethmo-orbital region.

\section{Splanchnocranium}

The bones of the hyoid arch have expanded, especially the anterior ceratohyal. It is, however, still separated from both the ventral hypohyal and posterior ceratohyal by cartilage (Fig. 11B). The interhyal is still cartilaginous and is continuous with both the hyoid arch and the hyosymplectic carti- 
A

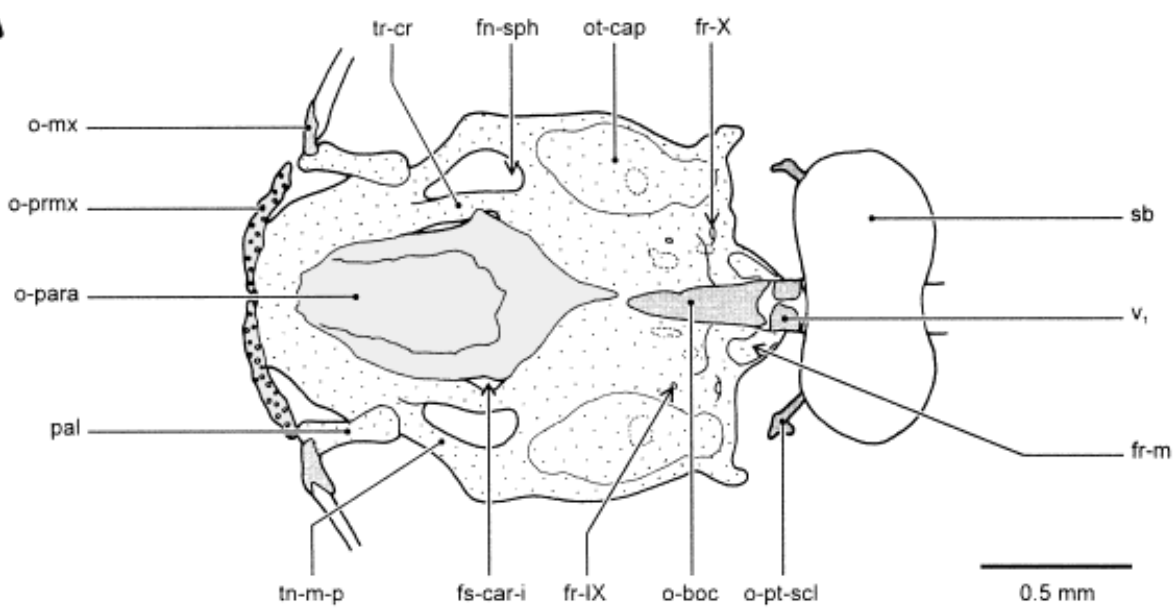

B

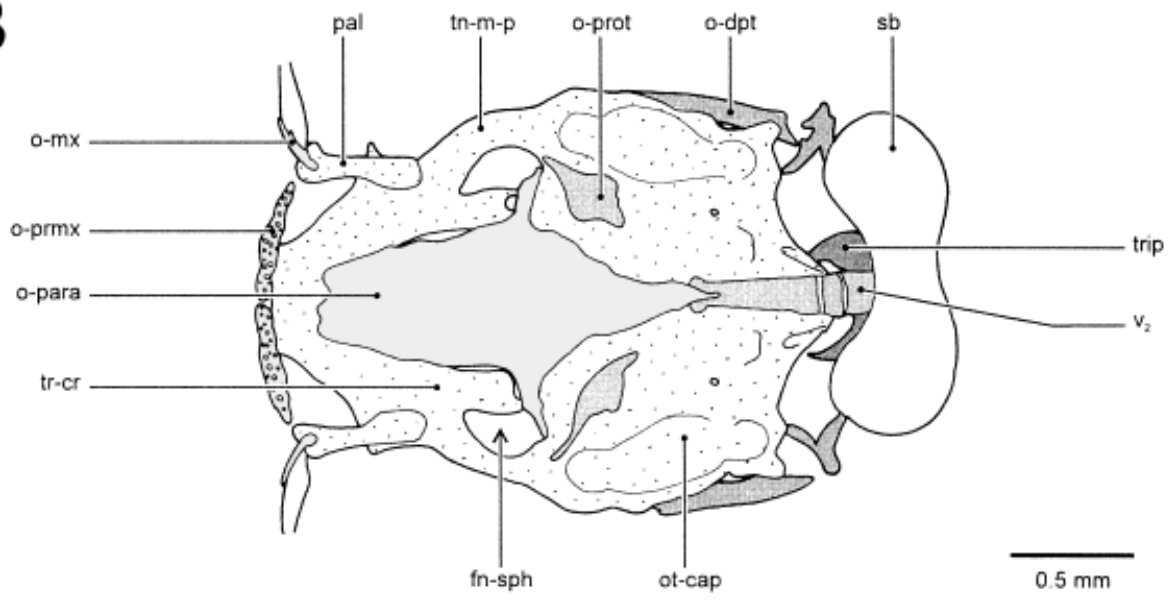

C

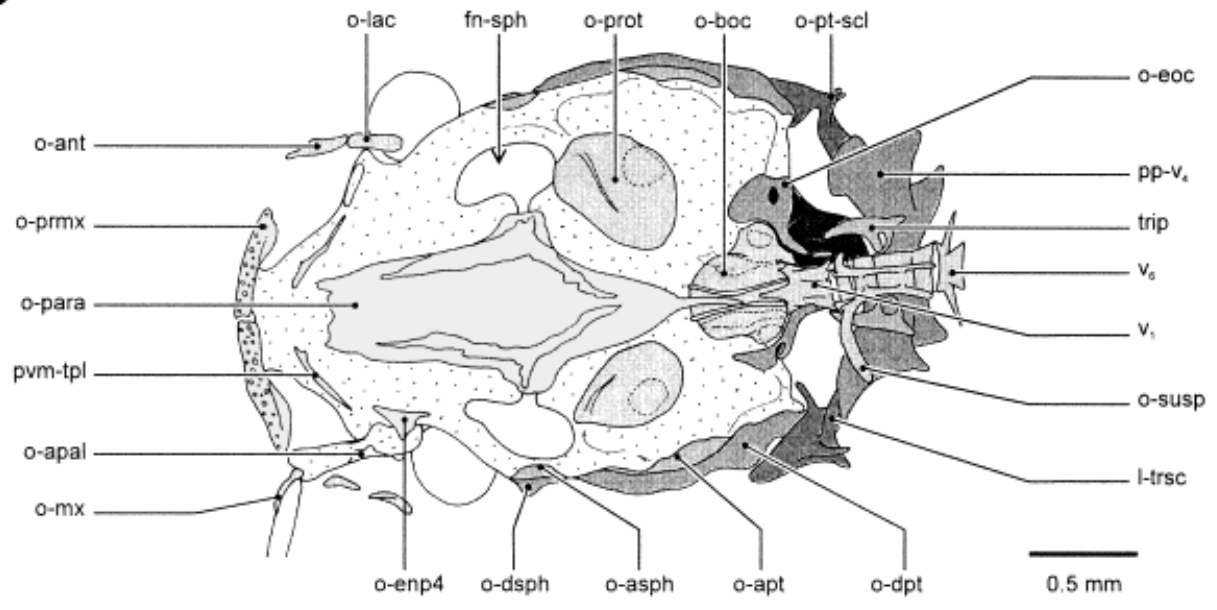

Figure 6 
lage. As is the case for the previous stage, all branchiostegal rays articulate with the anterior ceratohyal and the cartilaginous part between the latter and the posterior ceratohyal. All suspensorial bones have expanded, closing in the cartilaginous parts between them. The membranous outgrowths of the quadrate and hyomandibular are more pronounced, and a distinct articular ridge between the latter and the neurocranium is present (Fig. 11B). The articulation between the suspensorium and the neurocranium is situated at the level of the posterior part of the sphenotic and the anterior part of the pterotic. Evidence of a paired origin of the parurohyal is now lost, as the anterior tips also have fused, leaving a foramen for the passage of the parurohyal artery, as can be derived from serial sections of a $46.8 \mathrm{~mm} \mathrm{SL}$ specimen (Figs. 4E, 13). At $18.7 \mathrm{~mm} \mathrm{SL}$, the third infrapharyngobranchial also becomes ossified.

The 21.5-127.0 mm SL stage (Figs. 4F, 12B, 14)

\section{Neurocranium}

All bones are present. Most of them have started to close off the unossified parts almost completely. In the $21.5 \mathrm{~mm}$ SL specimen, the premaxillaries have expanded posteri orly, thus supporting the nasal sacs. The ethmoid plate and precerebral lamina are almost completely ossified, as the contralateral laterodermethmoid bones have fused medially. Thenasal bones have becometubular, in which the branching of the supraorbital canal can already be distinguished (Adriaens et al., '97). In the cleared speci-

Fig. 6. Neurocranium of Clarias gariepinus (ventral view). A, $7.7 \mathrm{~mm} \mathrm{SL}$ stage; B, $10.0 \mathrm{~mm} \mathrm{SL}$ stage; C, 11.6 $\mathrm{mm} \mathrm{SL}$ stage. (Grey indicates bone, shaded areas indicate cartilage.) fn-sph, fenestra sphenoi dea; fr-car-i, foramen arteria carotis interna; fr-IX, foramen nervus glossopharyngeus (=fenestra basicapsularis posterior); fr-X, foramen nervus vagus; fr-m, foramen magnum; I-trsc, ligamentum transcapularis; o-ant, os antorbitale; oapal, os autopalatinium; o-apt, os autopteroticum; oasph, os autosphenoticum; o-boc, os basioccipitale; o$\mathrm{dpt}$, os dermopteroticum; o-dsph, os dermosphenoticum; o-enp4, sesamoid "os entopterygoi deum" type 4; o-eoc, os exoccipitale; o-lac, os lacrimale (=os infraorbitale I); o-mx, os maxillare; o-para, os parasphenoideum; oprmx, os praemaxillare; o-prot, os prooticum; o-pt-scl, os posttemporo-supracleithrum; o-susp, os suspensorium; ot-cap, otic capsule; pal, palatinum; $\mathrm{pp}-\mathrm{v}_{4}$, parapophysis of vertebra 4; pvm-tpl, prevomeral tooth plate; sb, swimbladder; tn-m-p, taenia marginalis posterior; tr-cr, trabecula cranii; trip, tripus; $v_{1}$, vertebra $1 ; v_{2}$, vertebra 2 ; $v_{6}$, vertebra 6. men, the lateral ethmoid ossification is now observed on the dorsal face of the skull (Fig. 14A). The frontal bones have expanded substantially in all directions. Anterolaterally, they interdigitate with the lateral ethmoid, anteriorly with the mesethmoid, posterolaterally with the sphenotics and the pterotics, caudally with the parieto-supraocci pital complex, and medially the two frontals meet at the level of the epiphysial bridge (Fig. 14A). The parieto-supraoccipital bone has started to close off the postpineal fenestra, as have the frontals. Posteriorly, the former bone complex bears a distinct, pointed supraoccipital process, which reaches up to the fourth vertebra. Rudimentary contact between the parieto-supraoccipital bone and the pterotic bone is al ready established. Anterior expansion of the pterotic bone has deprived the sphenotic bone from any contact with the parieto-supraoccipital bone complex. Medial expansion of the sphenotic bone, at the ventral side of the skull, has resulted in the ossification of thelateral border of the sphenoid fenestra. At its posterior margin, the posttemporo-supracleithral bone has become plate-likeand borders the pterotic bone both laterocaudally and mediocaudally. The lateral-line canal, which exits this bonecomplex, is enclosed by a pair of small ossicles. In the skull floor, the orbitosphenoid is clearly visible(Fig. 12B). It arises as a paired ossification of the ethmoid plate and the preorbital base, lateral to the anterior part of the parasphenoid. The orbitosphenoids are still separated from the surrounding bones and border the sphenoid fenestra anteriorly. The lateral wings of the parasphenoid have expanded extensively, as they contact the ventral extension of the pterosphenoid bones. Consequently, this connection subdivides the sphenoid fenestra into an anterior foramen for the optic nerve and a posterior trigemino-facial foramen. The prootics have come into close contact with the parasphenoid, sphenotics, pterotics, basi occi pital, and exoccipital bones, but notrueinterdigitation has occurred (Fig. 12B). Basioccipital and parasphenoid, however, al ready strongly interdigitate. The second infraorbital bonehas extended caudal ly, as it also now borders the eye ventrally. The third infraorbital bone lies at the posterior margin of the eye. A gap is still present between the third and the second infraorbital bone. All these infraorbital bones are still tubular, apart from the fourth one, which lies at the lateral margin 


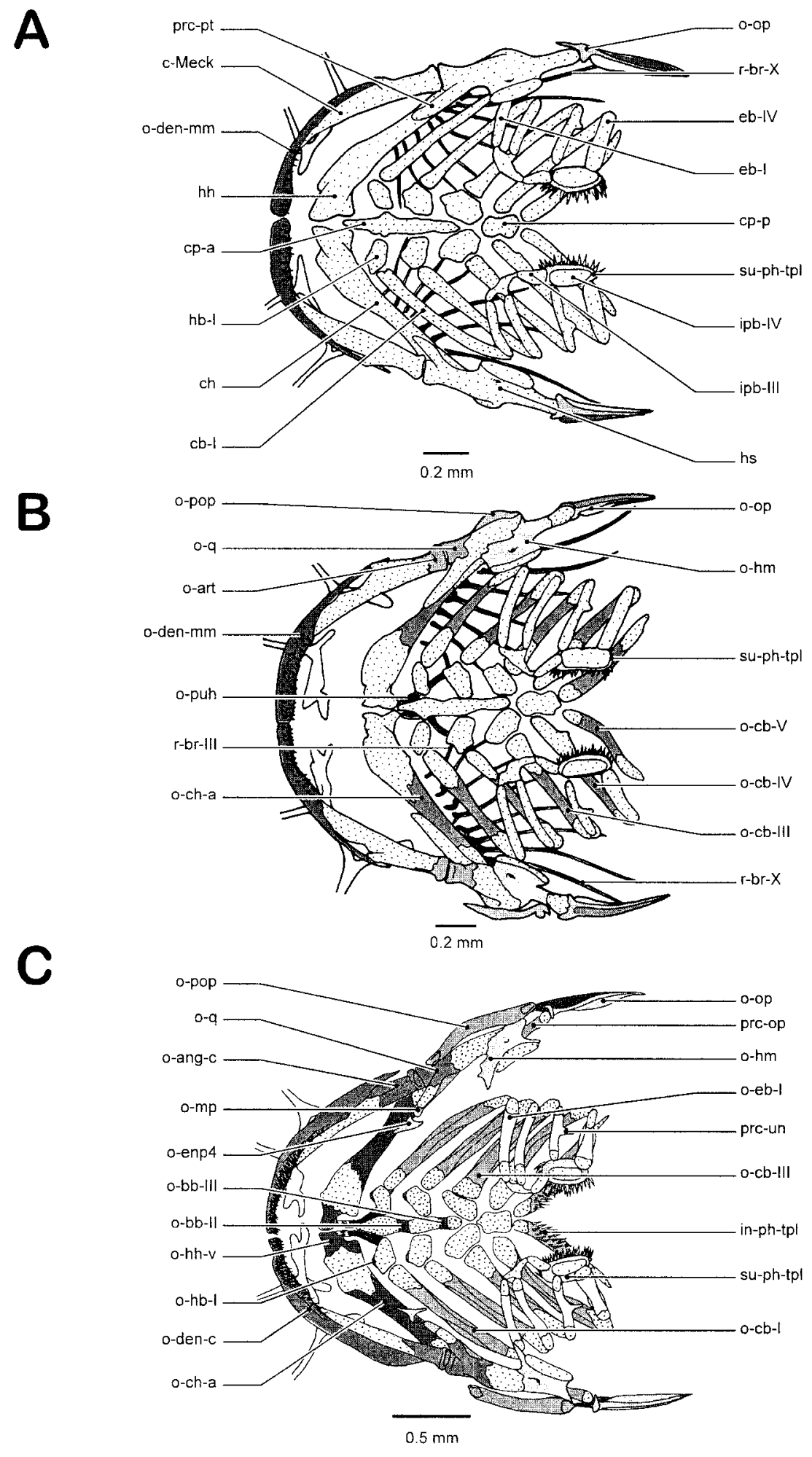

Figure 7 
of the skull, between the frontal and sphenotic bones. Apparently, the fourth infraorbital bone arises last, although it subsequently becomes thelargest one of the series, as can be derived from the later stages. The suprapreopercular bone has become platelike, wheretheneurodermal and membranodermal components already can be clearly distinguished. In the $46.8 \mathrm{~mm}$ SL specimen, a plate-like, nasal, triangular in cross section, could be observed, indicating the presence of the membranodermal component. An articulation is present between the small antorbital bone and a small cartilaginous protuberance of the anterior articular facet of the autopalatine (Fig. 15A). The antorbital bone partially encloses the base of the nasal barbel.

\section{Splanchnocranium}

The mandibula has become more heavily ossified, as the dento-splenio-mentomeckelian complex becomes connected more solidly to the angulo-splenio-articulo-retroarticular complex through an extensive interdigitation (Fig. 10B,C). The splenial bones have closed their gutters completely, leaving only the pores where the mandibular canal exits the bone (Adriaens et al., '97). At its medial face, the coronoid process gradually becomes enclosed as well (Fig. 10C). A well-developed articular facet for articulation with the quadrate is present, bearing a substantial retroarticular process.

Fig. 7. Splanchnocranium of Clarias gariepinus (dorsal view). A, $7.7 \mathrm{~mm}$ SL stage; B, $10.0 \mathrm{~mm}$ SL stage; C, $11.6 \mathrm{~mm}$ SL stage. (Grey indicates bone, shaded areas indicate cartilage.) c-M eck, cartilago Meckeli; cb-I, ceratobranchiale I; ch, ceratohyale; cp-a, copula anterior; cp-p, copula posterior; eb-I, epibranchiale I; eb-IV, epibranchialeIV; hb-I, hypobranchialel; hh, hypohyale; hs, hyosymplecticum; in-ph-tpl, inferior pharyngeal toothplate; ipb-III, infrapharyngobranchiale III; ipb-IV, infrapharyngobranchiale IV; o-ang-C, os angulo-splenioarticulo-retroarticulare complex; o-art, os articulare; obb-II, os basibranchiale II; o-bb-III, os basibranchiale III: o-cb-I, os ceratobranchiale I; o-cb-III, os ceratobranchiale III; o-cb-IV, os ceratobranchiale IV; o-cb-V, os ceratobranchiale V; o-ch-a, os ceratohyale anterior; oden-c, os dento-splenio-mentomeckelium complex; o-den$\mathrm{mm}$, os dento-mentomeckelium; o-eb-l, os epibranchiale I; o-enp4, sesamoid "os entopterygoideum"type 4; o-hb-I, os hypobranchiale I; o-hh-v, os hypohyale ventrale; o$\mathrm{hm}$, os hyomandibulare; o-mp, os metapterygoideum; o-op, os operculare; o-pop, os praeoperculare; o-puh, os parurohyale; o-q, os quadratum; prc-op, processus opercularis; prc-pt, processus pterygoideus; prc-un, processus uncinatus; r-br, radius branchiostegus; su-ph-tpl, superior pharyngeal tooth plate.
The autopalatine is al most completely ossified, except for its rostral and caudal tips (Fig. 12B). Anteriorly, the tip establishes an articular facet for the double-headed maxillary bone, enclosing the maxillary barbel. Although notrue articulation is present with the caudal tip of the autopalatine, an ossification is lacking. The sesamoid entopterygoid bone connects to the metapterygoid bone and the prevomeral bonethrough a ligamentous strap. The metapterygoid bone has started to form its membranous outgrowths, as was al ready the case for the quadrate and the hyomandibular bone. Although more extensively ossified, the latter two bones are still separated from each other by cartilage (Fig. 14B). The preopercular bone has initiated the formation of the membranodermal component, and the branching of the preopercular canal can be recognized in the neurodermal part. The dorsal opening of that canal in the preopercular bone is positioned exactly ventral to the entrance of the canal intothe suprapreopercular bone. Theopercular bone is still triangular, being ligamentously connected to the interopercular bone at its ventral tip. Thelatter bone has become broader compared to the previous stage. The anterior ceratohyal bone now reaches the posterior one.

Interdigitation between these two bones has started only at the dorsal side of the hyoid bar, whereas cartilage separates them ventrally (Fig. 14B). Anteriorly, the anterior ceratohyal bone has reached the ventral hypohyal bone, where the first signs of interdigitation are apparent (Fig. 4F). Thearticulation between the hyoid bar and the branchiostegal rays is still comparable to that in the previous stage, i.e., at the level of the anterior ceratohyal bone and the cartilaginous region posterior to it. At this stage, one branchiostegal ray is added, comprising a total of 10. The parurohyal bone bears a small but distinct foramen, and the three caudal processes have become el ongated (Fig. $4 F$ ). Anteriorly, the double ligamentous connection to the ventral hypohyals is still present. The bones of the branchial basket have not changed substantially compared to the previous stage. Basibranchials of the second and third branchial arches are separated by cartilage on the anterior copula. Very small hypobranchials are present on the first and second branchial arch; all ceratobranchials are well ossified. Their articular facets, with the hypo- and epibranchials, however, re- 

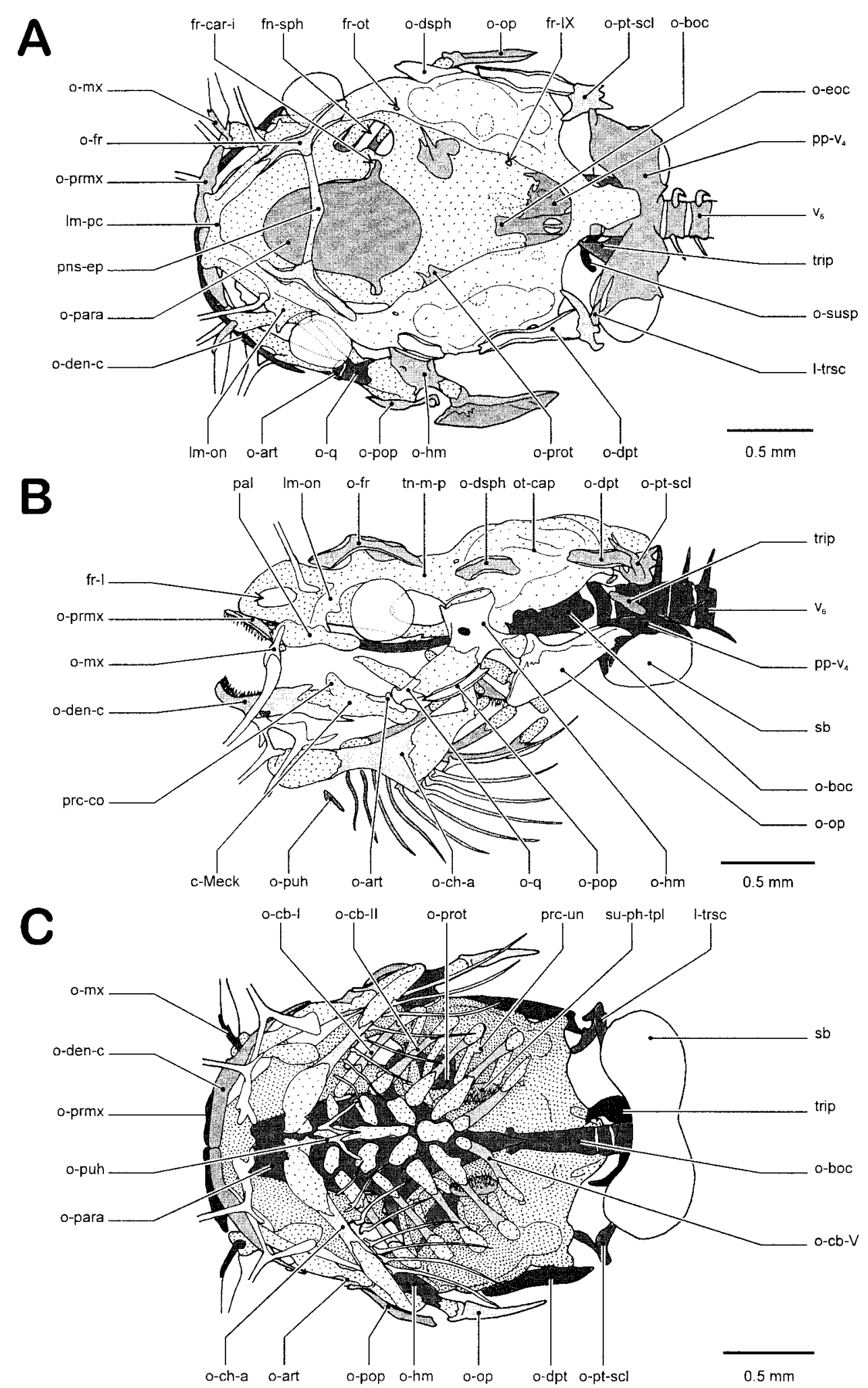

Figure 8 
mains unossified. Although no fifth epibranchial has developed, the corresponding ceratobranchial element bears an unossified head at both ends. The third epibranchial element bears a well-developed, medially directed uncinate process at its caudal margin. At $46.8 \mathrm{~mm} \mathrm{SL}$, the splanchnocranium is compl ete. A small, gutter-like splenial bone is present lateral to the articulation between mandibular and suspensorium. This splenial embraces the sensory canal, at the transition from the mandibular to the preopercular canal. Dorsomedially, the angulosplenio-articulo-retroarticulare complex has become extended rostrally, coming into contact with the dento-splenio-mentomeckelian bone. As a result, the cartilaginous coronoid process is enclosed by bone laterally and medially. At its dorsomedial face, the hypohyal cartilage bears a small, but distinct process, which becomes ossified at this stage. Lying at the dorsal face of the ventral hypohyal, this bone corresponds to the dorsal hypohyal. The fourth infrapharyngobranchial el ement also starts to ossify, bordering the cartilage dorsally, medially and ventrally.

The $127.0 \mathrm{~mm}$ SL stage

(Figs. 4G, 10D, 12C, 15-23)

Neurocranium

This juvenile stage is to some degree a good copy of the adult configuration, although reduced in size. The mesethmoid is relatively broad, bearing two well-developed

Fig. 8. Skull of Clarias gariepinus $(10.0 \mathrm{~mm} \mathrm{SL}$ stage). A, dorsal view; B, lateral view; C, ventral view. (Gray indicates bone, shaded areas indicate cartilage.) c-Meck, cartilago Meckeli; fn-sph, fenestra sphenoidea; fr-car-i, foramen arteria carotis interna; fr-I, foramen fila olfactoria; fr-IX, foramen nervus glossopharyngeus (=fenestra basicapsularis posterior); fr-ot, foramen ramus oticus nervus facial is; I-trsc, ligamentum transcapuIaris; Im-on, Iamina orbitonasalis, sensu latu; Im-pc, lamina praecerebralis; o-art, os articulare; o-boc, os basiocci pital e; o-cb-I , os ceratobranchialel; ; o-cb-II , os ceratobranchiale II; o-cb-V, os ceratobranchiale V; o-ch-a, os ceratohyale anterior; o-den-c, os dento-splenio-mentomeckelium complex; o-dpt, os dermopteroticum; odsph, os dermosphenoticum; o-eoc, os exoccipitale; o-fr, os frontale; o-hm, os hyomandibulare; o-mx, os maxillare; o-op, os operculare; o-para, os parasphenoideum; o-pop, os praeoperculare; o-prmx, os praemaxillare; oprot, os prooticum; o-pt-scl, os posttemporo-supracleithrum; o-puh, os parurohyale; o-q, os quadratum; osusp, os suspensorium; ot-cap, otic capsule; pal, palatinum; pns-ep, pons epiphysialis; $p p-v_{4}$, parapophysis of vertebra 4; prc-co, processus coronoideus; prc-un, processus uncinatus; sb, swimbladder; su-ph-tpl, superior pharyngeal tooth plate; tn-m- $p$, taenia marginalis posterior; trip, tripus; $\mathrm{v}_{6}$, vertebra 6 . preethmoid processes, which correspond to the well-ossified preethmoid cornua (Adriaens and Verraes, '97c). Interdigitation occurs with the lateral ethmoids, Iaterally, and the frontals, posteriorly. Together with the lateral ethmoid, the laterally curved preethmoid processes encl ose the nasal bone. Thelateral ethmoid has become plate-like, enclosing the cartilaginous orbito-nasal lamina. At its ventral face, the initial articular facet between this lamina and the palatine can still be distinguished, as an ossification is lacking (Fig. 17A). Medially thelateral ethmoid bears a funnel through which the olfactory lobes pass. Laterally, it bears a distinct process for the articulation with the dorsal process of the second infraorbital bone (Fig. 15A). Posteriorly, the lateral ethmoid interdigitates with the frontals, but no overlapping could be observed. At its lateral margin, the lateral ethmoid is connected through a connective tissue sheet to the dorsal margin of the anterior part of the fourth infraorbital bone. The frontals are the largest, paired skull bones, which border the anterior fontanella. Compared to the previous stage, both frontals are sutured to each other posteriorly, thus subdividing the postpineal fenestra into a postepiphysial part of the anterior fontanella and the posterior fontanella (Fig. 15A). In small specimens, the anterior fontanella is bordered anteriorly by the mesethmoid.

A second regi on of interdigitation between contralateral frontals occurs at the level of the epiphysial bridge, which has becomecompletely enclosed by a tubular outgrowth of the dermal frontals (Fig. 17B). In the skull roof, the frontals connect through sutures to the sphenotics (posterolaterally), the pterotics (posteriorly) and the parieto-supraoccipital bone complex (posteromedially). Laterally, they connect through connective tissue to the central part of the fourth infraorbital bone. Ventrally, the frontals connect rigidly to the orbitosphenoids and the pterosphe noids (Fig. 12C). The sphenotics have be come plate-likeas well, encl osing the anterolateral part of the otic capsule (Fig. 12C). They are bordered by thefrontals and pterotics, to which they arestrongly sutured. They have lost contact with the parieto-supraoccipital bone (Fig. 15A). Ventrally, they connect to the prootic and pterosphenoid bones. At their ventrolateral margin, they enclose the anterior part of the articular facet for the suspensorium, which is preceded by a stout lateroventral process (Figs. 17C, 21E). 

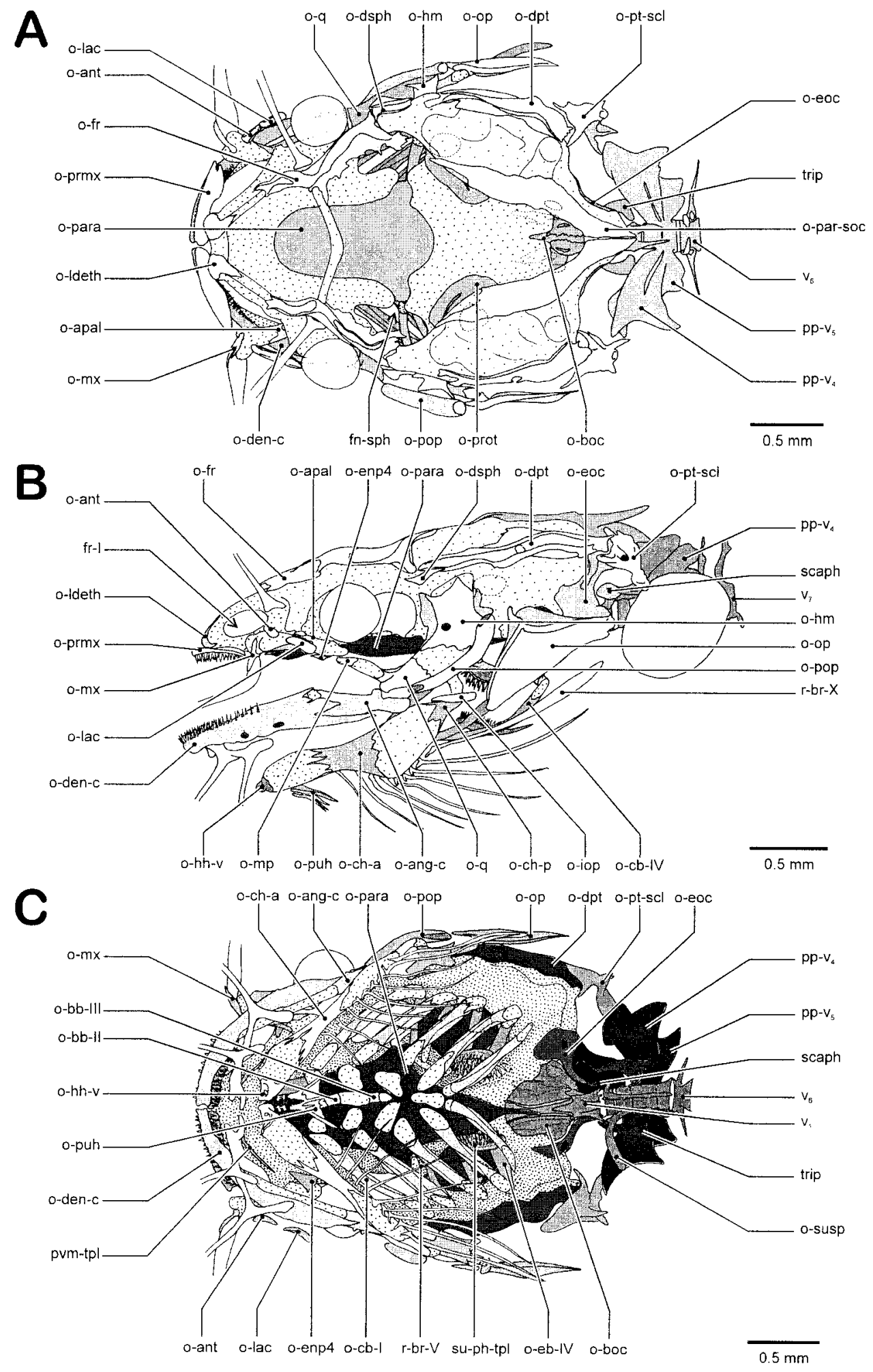

Figure 9 
The pterotics are large bones, enclosing the posterolateral part of the otic capsule, and bearing large, lateral, plate-like extensions. Medially, they are sutured to the parieto-supraocci pital bone. The connection with the posttemporo-supracleithral bone is restricted to the posterolateral part. Consequently, the pterotics form part of the posterior margin of the juvenile skull (Fig. 15A). Ventrally, they connect to the prootics and exoccipitals (Figs. 12C, 17D) and form the posterior part of thearticular facet for articulation with the suspensorium (Fig. 21E). In a specimen of $140.1 \mathrm{~mm} \mathrm{SL}$, however, the pterotic seemed to be separated partially from the parieto-supraocci pital and exocci pital bones (which may be due to insufficient staining), where a very small ossicle was found covering that region (Fig. 16). Based on its position, as well as the fact that it seems to be a perichondral bone, at the level of the posterior semicircular canal, it must correspond to the epiotic, which could not be observed in any previous stage. It is, however, possible that because of its reduced size and insufficient staining, it has been overlooked in the other specimens, as was also the case for Nawar ('54). The parietosupraoccipital bone complex is large, with its previously paired anterior part now fused to each other medially. Apparently, a true fusion has occurred, in contrast with the

Fig. 9. Skull of Clarias gariepinus (11.6 mm SL stage). A, dorsal view. B, lateral view; C, ventral view. (Grey indicates bone, shaded areas indicate cartilage.) fn-sph, fenestra sphenoidea; fr-I , foramen fila ol factoria; o-ang-c, os angulo-splenio-articulo-retroarticulare complex; o-ant, os antorbitale; o-apal, os autopalatinum; o-bb-II, os basibranchiale II; o-bb-III, os basibranchiale III; o-boc, os basioccipitale; o-cb-I, os ceratobranchiale I: o-cb-IV, os ceratobranchiale IV; o-ch-a, os ceratohyale anterior; o-ch-p, os ceratohyale posterior; o-den-c, os dento-splenio-mentomeckelium complex; o-dpt, os dermopteroticum; o-dsph, os dermosphenoticum; o-eb-IV, os epibranchiale IV; o-enp4, sesamoid "os entopterygoideum" type 4; o-eoc, os exoccipitale; o-fr, os frontale; o-hh-v, os hypohyale ventrale; o-hm, os hyomandibulare; o-iop, os interoperculare; o-lac, os lacrimale (= os infraorbitale I); o-ldeth, os latero-dermethmoideum; o-mp, os metapterygoideum; o-mx, os maxillare; o-op, os operculare; o-par-soc, os parieto-supraoccipitale; o-para, os parasphenoideum; o-pop, os praeoperculare; o-prmx, os praemaxillare; o-prot, os prooticum; o-pt-scl, os posttemporo-supracleithrum; o-puh, os parurohyale; o-q, os quadratum; o-susp, os suspensorium; pp- $v_{4}$, parapophysis of vertebra 4; pp- $v_{5}$, parapophysis of vertebra 5; pvm-tpl, prevomeral tooth plate; r-br, radius branchiostegus; scaph, scaphium; su-ph-tpl, superior pharyngeal tooth plate; trip, tripus; $v_{1}$, vertebra $1 ; v_{6}$, vertebra $6 ; v_{7}$, vertebra 7. posterior part of the frontals, as no signs of a suture can be observed anymore (Fig. 17E). The left-right fusion is not complete, as a posterior fontanella remains. Observations of Iarger adults indicate a slow, but progressive closure of both the anterior and posterior fontanella. At its ventral face, the complex bears a median ridge, which is formed in the mediosagittal septum. Caudolaterally, the bone interdigitates with the exoccipitals (Fig. 17E). The posttemporo-supracleithral bone is a plate-like complex, bordering the pterotics laterally and laterocaudally. Ventrally, it bears a mediocaudally directed process for articulation with the parapophysis of the fourth vertebra, as well as an articular facet for articulation with the cleithral bone (Fig. 17F). It does not bear any connection with the basioccipital, which is the case in many siluriform fishes (Fig. 12C). Most presumably, this process corresponds to the ossification of the transcapular ligament (see Discussion).

Anteriorly, two plate-like premaxillaries articulate with the ventral face of the pre ethmoid processes of the mesethmoid. Pre maxillaries, with the exception of the posterior margin, are completely covered with teeth. They lack any differentiations like an ascending process or maxillary process (Fig. 18A). No true articular facet, with secondary cartilage, is present between the premaxillary bone and the mesethmoid. Both connect only through connective tissue. An articulation of the premaxillary with the maxillary bone is also absent. Only a distinct string of ligamentous tissue connects the two. The maxilla is typically advanced siluriform, as it is socket-like, enclosing the base of the maxillary barbel. It bears a double-headed articular facet for articulation with the rostral tip of the palatine (Fig. 18B). As in most siluriform fish, the maxillary bone has been modified to take part in the palatine-maxillary mechanism (Adriaens and Verraes, '97a). The antorbital bone is still small and overlies the rostral tip of the pal atine. Compared to the previous stage, most infraorbital bones have undergone a major transformation in shape, as they are nolonger tubular. The lacrimal bone bears a serrated ventral edge, whereas the second infraorbital bone possesses a massive part for the articulation with the lateral process of the lateral ethmoid (Fig. 15A). Consequently, both these bones form the anterior border of the orbita, whereas the remaining 
A

B
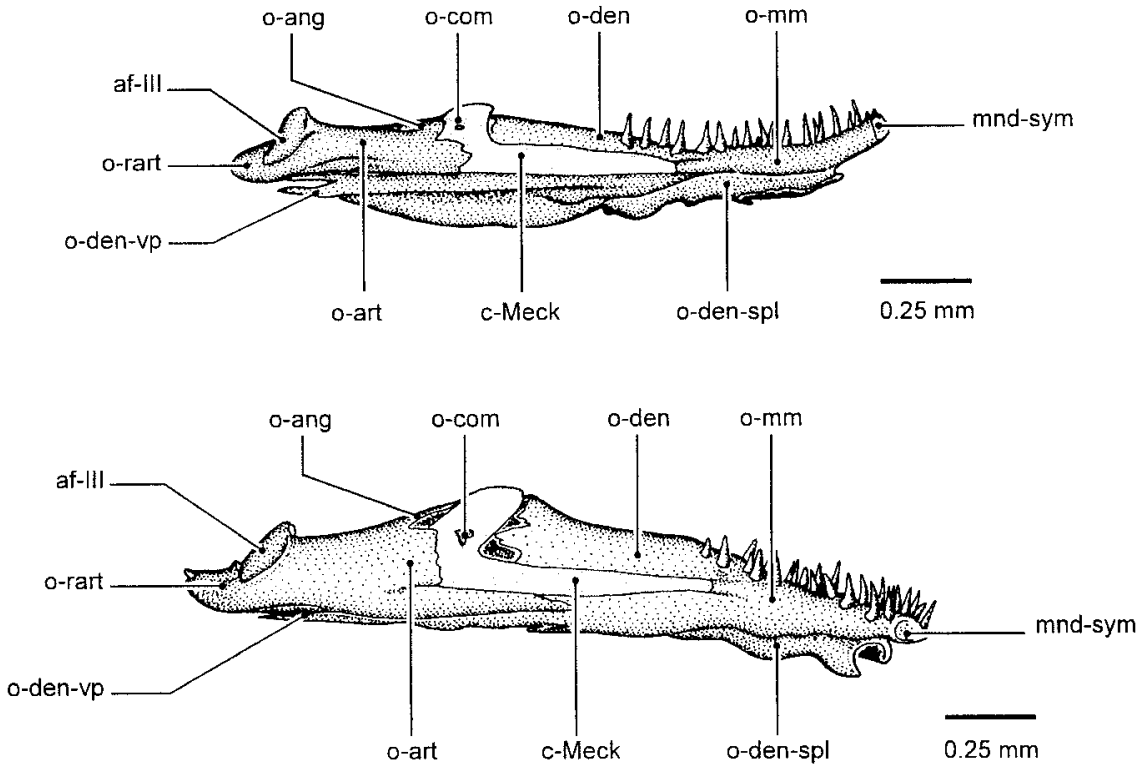

C

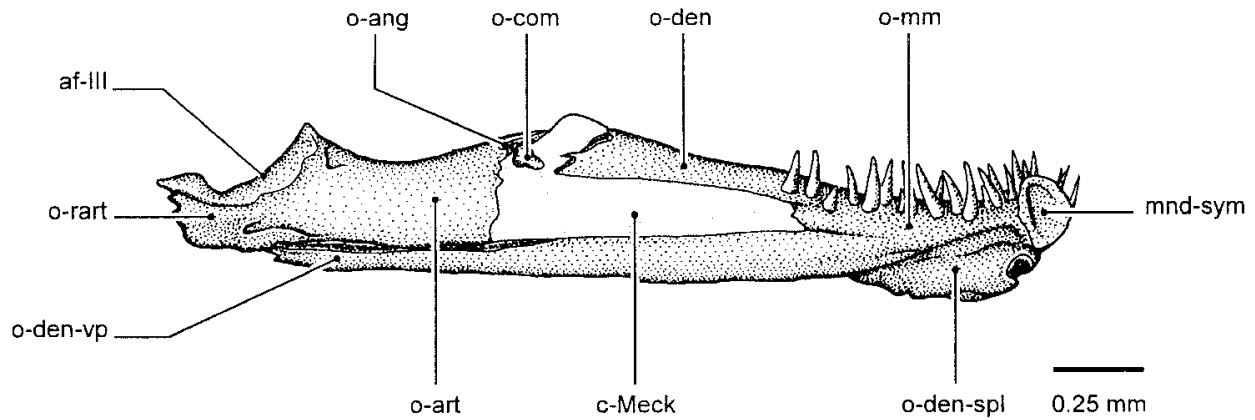

D

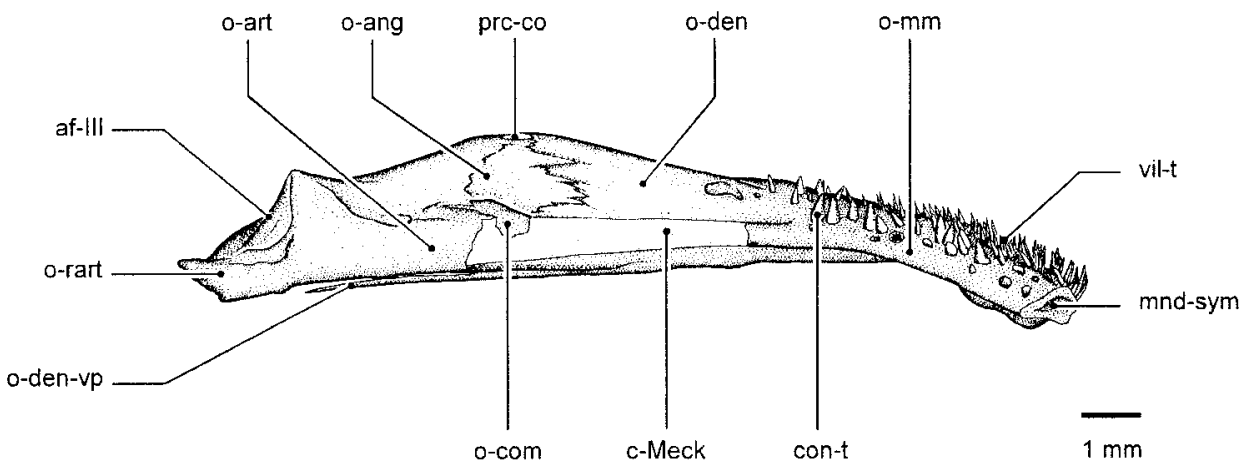

Figure 10 
part of the second infraorbital bone borders the orbita anteroventrally. The posteroventral and posterior border is demarcated by the third infraorbital bone (Fig. 15B). Dorsally, the slender supraorbital process of the fourth infraorbital bone forms the dorsal margin, but is el ongated and much broader prosterior to the eye. In Clarias gariepinus, the fourth infraorbital bone reaches up to the suprapreopercular bone. The latter bone has become plate-like as well, filling up the gap between the fourth infraorbital bone and the posttemporo-supracleithral bone (Fig. 15B).

The skull floor consists of a central, longitudinal and narrow bridge, which becomes broader posteriorly, as it forms the base of the braincase. Anteriorly, the hypoethmoid part of the mesethmoid interdigitates with the prevomeral bone. The latter has become arrow-like, bearing two well-devel oped tooth plates, to which it is fused. Posteriorly, the prevomeral bone interdigitates through a very slender, forked suture with the parasphenoid (Fig. 19A). Dorsally, the prevomeral bone is connected to the lateral ethmoid, more exactly to the part enclosing the ol factory lobes (Fig. 12C). The parasphenoid consists of a small anterior part, which is expanded laterally at the level of the earlier formed lateral wings, which contact the pterosphenoid bones. Posterior to these wings, the parasphenoid becomes narrow again, finally interdigitating posteriorly with the basioccipitals. The interdigitation with the latter occurs through many more sutures than is the case for the prevomeral bone (Fig. 19B). At its dorsal face, the parasphenoid connects rigidly to the orbitosphenoid (in front of thelateral wings), the pterosphenoids (at the lateral wings), and the prootics (posterior to thelateral wings) (Figs. 12C, 19B). The basioccipital no longer forms an articular surface with the first vertebra,

Fig. 10. Ontogeny of the lower jaw in Clarias gariepinus (medial view). A, $12.0 \mathrm{~mm} \mathrm{SL}$ stage; $\mathbf{B}, 14.8 \mathrm{~mm} \mathrm{SL}$ stage; C, $19.0 \mathrm{~mm}$ SL stage; D, $127.0 \mathrm{~mm}$ SL stage. (Grey indicates Meckel's cartilage, shaded areas indicate bone.) af-III, articulatory facet of the os angulosplenio-articulo-retroarticulate with the os quadratum; c-Meck, cartilago Meckeli; con-t, conical teeth; mndsym, mandibular symphysis; o-ang, os angulare; o-art, os articulare; o-com, os coronomeckelium; o-den, os dentale; o-den-spl, os spleniale (dentale); o-den-vp, ventral process of the os dento-splenio-mentomeckelium complex; o-mm, os mentomeckelium; o-rart, os retroarticulare; prc-co, processus coronoideus; vil-t, villiform teeth. but now interdigitates with the complex of vertebrae, formed in relation to the Weberian apparatus (Figs. 16, 19C). Lateroventrally, the basiocci pital connects to the exoccipitals, posteriorly, and to the prootics, anteri orly, both through short sutures. At its dorsal face, the basioccipital bears a bowllike structure housing the sinus impar perilymphaticus of the Weberian complex (Fig. 16) (Chardon, '67; Radermaker et al., '89).

The orbitosphenoids connect to the lateral ethmoids anteriorly, the frontals dorsally, and the parasphenoid posteriorly. They are separated from the pterosphenoids by the foramen for the optic nerve (Fig. 12C). Although the orbitosphenoids are formed as paired ossifications, they have fused to a single, gutter-like bone in the juvenile stage (Fig. 19D). The pterosphenoids, however, remain paired ossifications, which connect to the orbitosphenoids, the parasphenoid, and the sphenotics (Fig. 12C). The prootics form the anterolateral floor of the brain cavity and enclose the utriculus with its otolith (the lapillus) (Fig. 19F). The perichondral prootics are sutured to a whol e set of bones: the pterosphenoid, the parasphenoid, the sphenotics, the pterotics, the exoccipitals, the basioccipital, and the parieto-supraoccipital. It takes part in the bordering of the trigemino-facial foramen (Fig. 12C). Finally, the exocci pitals form the poster ol ateral ossifications of the brain cavity floor and also enclose the otoliths of the sacculus and the lagena (i.e., the sagitta and asteriscus respectively) (Fig. 19G). These bones interdigitate with the basioccipitals, prootics, and the parieto-supraoccipital bone, whereas a synchondrosis seems to be present with the pterotics. The exoccipital bone encloses the foramina for the glossopharyngeus, vagus, and hypoglossus nerves (F igs. 12C, 16, 19G).

\section{Splanchnocranium}

The mandibula is fully ossified, although Meckel's cartilage remains partial ly exposed (Fig. 10D). The coronoid process is well protected by bone, with only its dorsal tip re maining uncovered. Caudally, the retroarticular process is rather short and bears two processes, both for the attachments of ligaments: a ligament running to the interopercular bone and one to the hyoid bar (Fig. 20A). The dento-splenio-mentomeckelian bone complex is provided with a large patch of teeth. Two types of teeth are observed: villiform teeth at the outer margin, and conical teeth at the inner margin (Fig. 20B). The 

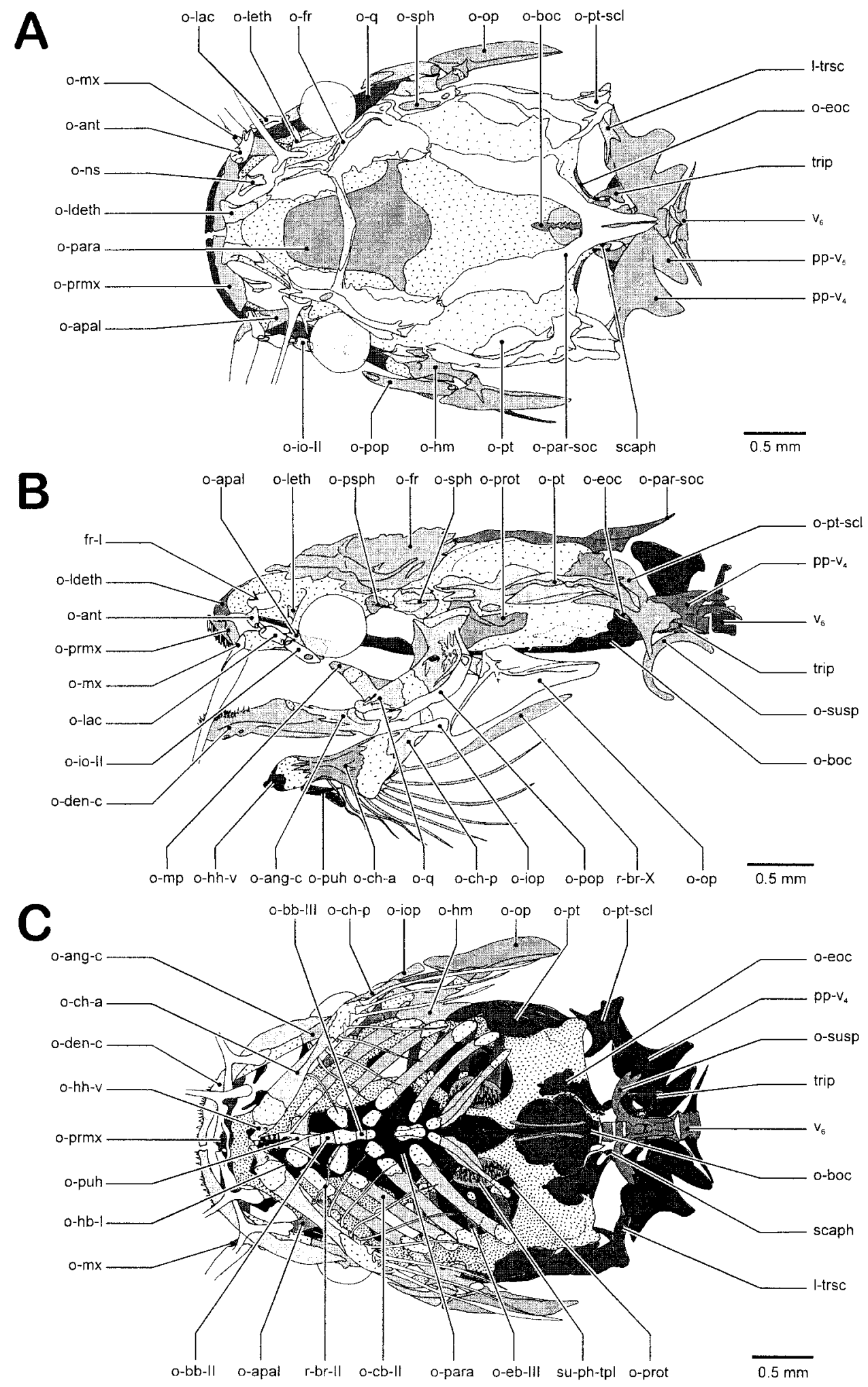

Figure 11 
surface for dentition seems to be expanded, as a kind of rostral extension of the bone has occurred. At its medial face, this bone complex bears a socket that encloses the anterior part of Meckel's cartilage. Caudally, a well-developed ventral and lateral process can be distinguished, between which fits the lateroventral process of the angulo-splenioarticulo-retroarticular complex. At the level of the coronoid process, a distinct coronomeckelian bone covers Meckel's cartilage dorsally, anterior to the coronoid process (Fig. 10D). The autopalatine is a rod-shape bone, bearing three unossified regions: (1) the anterior tip that enables the articulation with the maxillary bone, (2) the slender and elongated articular facet for the articulation with thelateral ethmoid, and (3) the posterior tip, which does not articulate with any bone (Fig. 20C). Between the mandibula and the suspensorium, the number of isolated splenial bones has increased to two, whereas in larger specimens three of them were present (Fig. 15B) (Adriaens et al., '97).

The quadrate bone bears a solid articular facet with the mandibula and is provided with a substantial dorsal, membranous outgrowth (Fig. 21C). The quadrate connects both synchondrally and through sutures with the metapterygoid bone, anteriorly, and with the hyomandibula, posteriorly (Fig. 21A). The hyomandibula also has a membranous

Fig. 11. Skull of Clarias gariepinus $(12.7 \mathrm{~mm} \mathrm{SL}$ stage). A, dorsal view; B, lateral view; C, dorsal view of the splanchnocranium. (Grey indicates bone, shaded areas indicate cartilage.) fr-l, foramen fila olfactoria; I-trsc, ligamentum transcapularis; o-ang-c, os angulosplenio-articulo-retroarticulare complex; o-ant, os antorbitale; o-apal, os autopalatinum; o-bb-II, os basibranchiale II; o-bb-III, os basibranchiale III; o-boc, os basiocci pitale; o-cb-II, os ceratobranchiale II; o-ch-a, os ceratohyale anterior; o-ch-p, os ceratohyale posterior; o-den-c, os dento-splenio-mentomeckel ium complex; o-ebIII, os epibranchiale III; o-eoc, os exoccipitale; o-fr, os frontale; o-hb-I, os hypobranchiale I; o-hh-v, os hypohyal e ventale; o-hm, os hyomandibulare; o-io-ll, os infraorbitale II; o-iop, os interoperculare; o-lac, os lacrimale (=os infraorbitale I); o-ideth, os latero-dermethmoideum; o-leth, os latero-ethmoideum; o-mp, os metapterygoideum; o-mx, os maxillare; o-ns, os nasale; o-op, os operculare; o-par-soc, os parieto-supraoccipitale; o-para, os parasphenoideum; o-pop, os praeoperculare; o-prmx, os praemaxillare; o-prot, os prooticum; o-psph, os pterosphenoideum; o-pt, os pteroticum; o-pt-scl, os posttemporosupracleithrum; o-puh, os parurohyale; o-q, os quadratum; o-sph, os sphenoticum; o-susp, os suspensorium; $\mathrm{pp}-\mathrm{v}_{4}$, parapophysis of vertebra $4 ; \mathrm{pp}-\mathrm{v}_{5}$, parapophysis of vertebra 5; r-br, radius branchiostegus; scaph, scaphium; su-ph-tpl, superior pharyngeal tooth plate; trip, tripus; $v_{6}$, vertebra 6. plate, which connects to a similar outgrowth of the quadrate (Fig. 21A). Dorsally, a cartilaginous strip is present for articulation with the neurocranium. Anterior to this strip, the bone has a distinct dorsal process, which fits into a cavity in the sphenotic bone, additionally, a ventral process of the sphenotic fits into a cavity posteri or to the hyomandibular process (Fig. 21E). Due to such a connection, the suspensorium and neurocranium are interlocked to a certain degree (see Discussion). At its posterior margin, the hyomandibula bears a substantial opercular process with a cartilaginous articular facet (Fig. 21B). At its medial face, the hyomandibula bears two foramina: (1) a small foramen just above the insertion of the ligament running to the hyoid bar, and (2) a larger one posterior and dorsal to it. This larger foramen is penetrated by the truncus hyomandibularis, whereas through the smaller foramen a blood vessel enters.

Compared to the situation in previous stages, the foramen through which the truncus leaves has shifted ventrally, due to the fact that a bony crest of the hyomandibular bone has grown ventrally, thereby covering the foramen of the hyosymplectic cartilage. At this stage, the latter foramen is bordered by both the hyomandi bula and the quadrate. Medially, the hyomandibula forms a ridge for the attachment of a stout ligament that runs to the hyoid bar (Fig. 21A) (Adriaens and Verraes, '94). The unossified part, separating the hyomandibula from the quadrate, corresponds to the part that in previous stages was connected to the interhyale and may be consi dered as an unossified symplectic. At its ventral margin, the hyomandibula interdigitates with the preopercular bone (Figs. 15B, 21A). This bone does not bear a distinct vertical and horizontal limb, as is the case in many catfish (Fig. 24A). I ts caudal margin consists of the neurodermal part encl osing the preopercular canal with two of its branches (Adriaens et al., '97). At its anterodorsal side, it bears a plate-like extension for theinterdigitation with thehyomandibula and the quadrate (Fig. 24A). The plate-like expansion has persisted in the metapterygoid and entopterygoid bone as well (Fig. 21D). As can be derived from the previous stages, the ossification of the metapterygoid initiates from a perichondral ossification of the pterygoid process, which can still be distinguished in this stage. In 

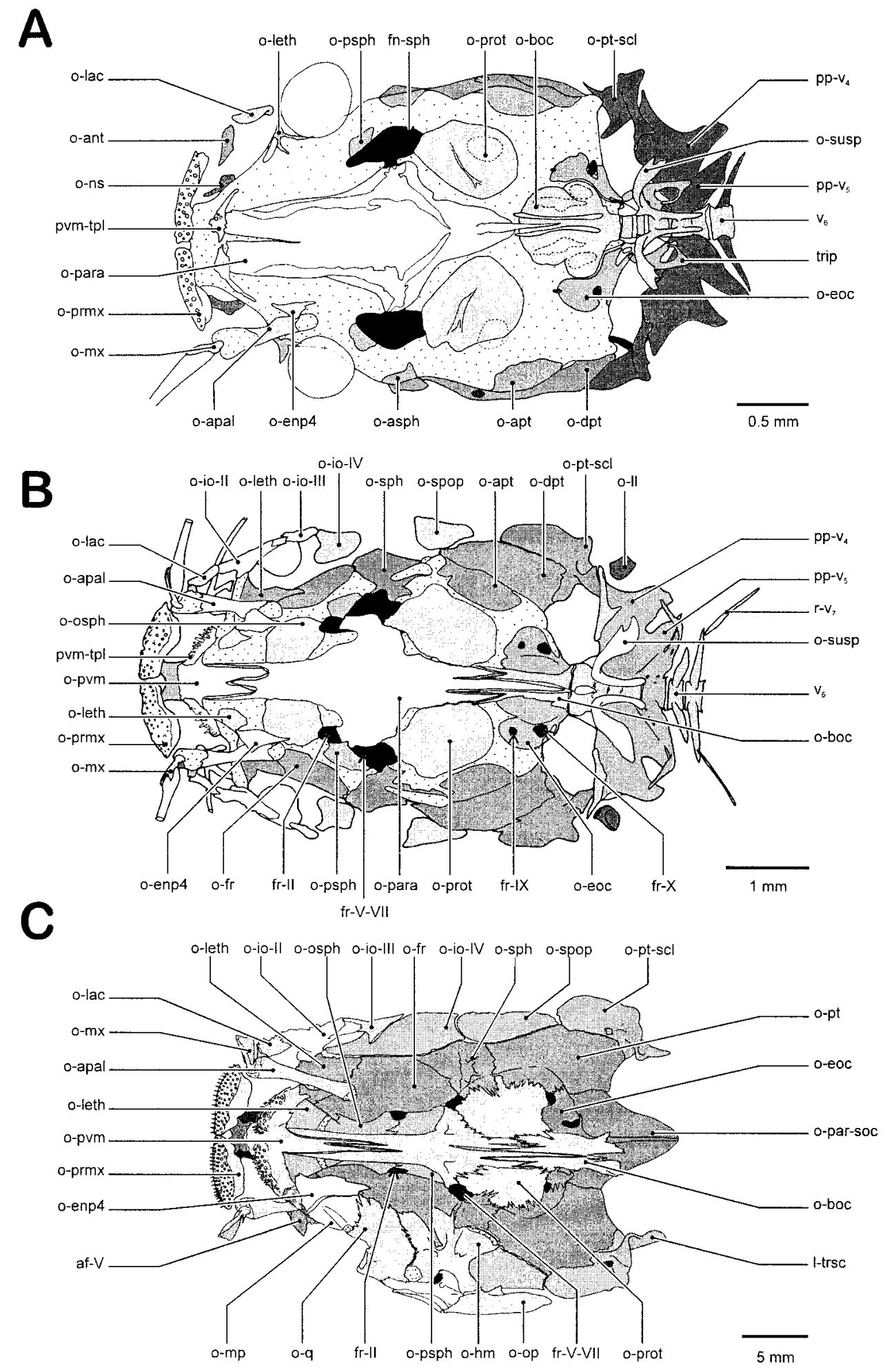

Figure 12 
this stage, both ventrally and dorsally, this central rod bears plate-like extensions. The ventral extension corresponds to the ectopterygoid process of Arratia ('92). Considerable discussion concerns the homology of the pterygoid bones in catfish and even in fish in general (Howes and Teugels, '89; Arratia, '90, '92). The metapterygoid is strongly connected to the quadrate through the ventral synchondrosis, but more strongly through the extensive suturation along the dorsal plates (Fig. 21A). Consequently, the metapterygoid no longer contacts the hyomandibula. Rostrally, the metapterygoid has a straight margin, connected to the entopterygoid through a ligamentous strip. The entopterygoid in Clarias gariepinus is ligamentously connected to a whole set of surrounding bones: (1) the metapterygoid, posteriorly, (2) the autopalatine, dorsally, (3) the prevomeral bone, anteriorly, and (4) the lateral ethmoid, anterolaterally. Caudally, the entopterygoid bone bears a distinct process (Fig. 21D).

The hyoid bar is almost completely ossified, although cartilaginous strips seem to persist between all bones (Figs. 15C, 22A). At the medial face of the ventral hypohyal, the dorsal hypohyal remains separated by cartilage from both the ventral hypohyal and the anterior ceratohyal. The ventral hy-

Fig. 12. Neurocranium of Clarias gariepinus (ventral view). A, $12.7 \mathrm{~mm} \mathrm{SL}$ stage; B, $21.5 \mathrm{~mm} \mathrm{SL}$ stage; C, $127.0 \mathrm{~mm}$ SL stage. (Grey indicates bone, shaded areas indicate cartilage.) af- $\mathrm{V}$, articulatory facet of the os lateroethmoideum with the os infraorbitale II; fn-sph, fenestra sphenoidea; fr-II, foramen fasciculus opticus: fr-IX, foramen nervus gl ossopharyngeus (=fenestra basicapsularis posterior); fr- $\mathrm{X}$, foramen nervus vagus; fr-VVII, foramen of the trigemino-facial nerve complex; Itrsc, ligamentum transcapularis; o-ant, os antorbitale; o-apal, os autopalatinum; o-apt, os autopteroticum; o-asph, os autosphenoticum; o-boc, os basioccipitale; o-dpt, os dermopteroticum; o-enp4, sesamoid "os entopterygoideum" type 4; o-eoc, os exoccipitale; o-fr, os frontale; o-hm, os hyomandibulare; o-io-II, os infraorbitale II; o-io-III, os infraorbitale III; o-io-IV, os infraorbitale IV; o-lac, os lacrimale (= os infraorbitale I); o-leth, os lateroethmoideum; o-II, lateral line ossicle; o-mp, os metapterygoideum; o-mx, os maxillare; o-ns, os nasale; o-op, os operculare; o-osph, os orbitosphenoideum; o-par-soc, os parieto-supraoccipitale; o-para, os parasphenoideum; o-prmx, os praemaxillare; o-prot, os prooticum; o-psph, os pterosphenoideum; o-pt, os pteroticum; o-pt-scl, os posttemporo-supracleithrum; o-pvm, os prevomerale; o-q os quadratum; o-sph, os sphenoticum; o-spop, os suprapraeoperculare; o-susp, os suspensorium; $\mathrm{pp}-\mathrm{v}_{4}$, parapophysis of vertebra 4; pp- $v_{5}$, parapophysis of vertebra 5; pvm-tpl, prevomeral tooth plate; $r-v_{7}$, rib of vertebra 7; trip, tripus; $v_{6}$, vertebra 6. pohyal is much larger than the dorsal. Ventromedially, the latter bone forms an interdigitation with the anterior ceratohyal bone, whereas the rest is interconnected through a synchondrosis. Mediolateral to these sutures, it is attached through a stout ligament that is connected to the anterior tips of the parurohyal bone (Fig. 4G). A basihyal bone is absent. The anterior ceratohyal bone is the largest of the hyoid bar (Fig. 22C). At its medial face, it bears a shelf against which the first six branchiostegal rays articulate (Fig. 22A). The following two rays articulate with the cartilaginous strip, which separates the anterior ceratohyal bone from the posterior one ventrally. The posterior two branchiostegal rays articulate with the ventral margin of the posterior ceratohyal bone. The posterior two branchiostegal rays articulate with the ventral margin of the posterior ceratohyal bone. The posterior ceratohyal bone tapers posteriorly and terminates as a solid cone (Fig. 22D). At the dorsal face of this cone is a stout ligament that connects the hyoid bar to the hyomandibula (Fig. 21A). Another large ligament connects the lateral face with the medial process of the mandibular retroarticular process (Fig. 20A). In this stage, the interhyal is completely reduced (Adriaens and Verraes, '94). The parurohyal bone has become more solidly ossified, with three distinct, caudal processes. Although the median process is the result of a fusion of two processes, it is more slender than the lateral processes (Fig. 4G). The two heads of the paired sternohyoi deus muscle fit nicely into the fork of the parurohyal bone (Adriaens and Verraes, '97d). The length of the ligaments, in relation to the size of the parurohyal, seems to have become reduced substantially, as the rostral tips of the parurohyal now partially fit into a small gap at the medial face of the ventral hypohyals. The main body of the parurohyal still bears a foramen, penetrated by a ventral branch of the ventral aorta (Fig. 13). The latter artery is here referred to as the parurohyal artery. It enters the parurohyal dorsally, where it splits into two arteries before it leaves the bone ventrally. Between the two rostral processes of the parurohyal, a vein (here referred to as the vena parurohyalis) branches off of the vena jugularis inferior and curves caudal ly, agai inst the ventral side of the bone and between the two branches of the artery (Fig. 13B). The branchiostegal rays differ slightly in shape, depending on 


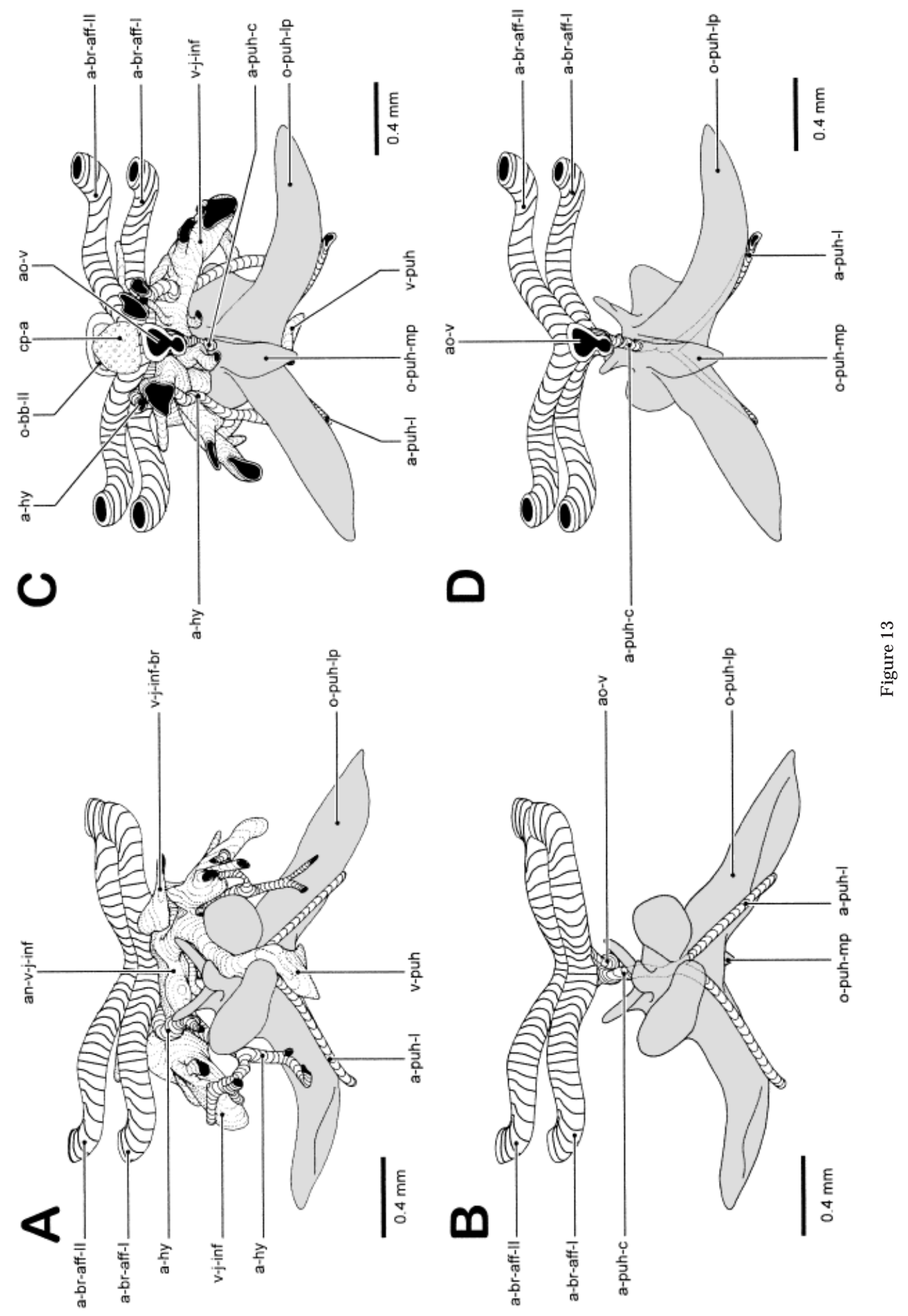


their position. The anterior ray is a slender rod with a broader articular part, whereas the posterior ray has a distinct articular facet, penetrated by a foramen (Fig. 22E), with a distal, elongated, plate-like part (Fig. 22A).

Ossification of the branchial basket seems to have completed, although several cartilaginous elements lack any bone (Fig. 15C). The anterior copula still bears two ossifications, corresponding to the second and third basibranchial bones (Fig. 23B-C). No signs of the first basibranchial could be discerned at this stage (Fig. 23A). The posteri or copula also lacks ossifications of the fourth and fifth basibranchial (Fig. 23D-E). Hypobranchial bones I and II of the previous stage have expanded, as they now cover almost half of the surface of the corresponding cartilaginous elements (Figs. 15C, 23A,B). The third hypobranchial element is still unossified. The cartilaginous fourth hypobranchial is believed to remain fused to the ceratobranchial cartilage and is unossified as well (Fig. 23D) (Adriaens and Verraes, '97c).

All five ceratobranchials are well ossified. They consist of the central, perichondral rod, which bears two caudal ridges for attachment of the gill rods, as well as for the housing of blood vessels and nerves. The tooth plate, covering the dorsal face of the fifth ceratobranchial bone, has become broader, especially at its anterior half (Fig. 23E ). The epibranchials are more el ongated, compared with the previous stage, especially epibranchials I and II (Fig. 15C). This el ongation seems to be coupled to the elongation of the third infrapharyngobranchial bone. Medially, these bones converge and attach to each other through cartilage, which most probably corresponds to the unossified remains of infrapharyngobranchials I and II

Fig. 13. Graphical, 3-D reconstruction of the parurohyal bone and related bloodvessels in Clarias gariepinus (46.8 mm SL stage). A, frontal view; B, frontal view with vena jugularis inferior and arteria hyoidea removed; C, caudal view; D, caudal view with vena jugularis inferior and arteria hyoidea removed. (Grey indicates bone.) a-br-aff-I, arteria branchialis afferens I; a-br-aff-II, arteria branchialis afferens II; a-hy, arteria hyoidea; apuh-c, arteria parurohyalis communis; a-puh-I, arteria parurohyalis lateralis; an-v-j-inf, anastomosis between left and right venae jugulares inferiores; ao- $v$, aorta ventralis; cp-a, copula anterior; o-bb-II, os basibranchialeII; o-puh-Ip, lateral process of the os parurohyale; o-puh-mp, medial process of the os parurohyale; v-j-inf, vena jugularis inferior; v-j-inf-br, branch of the vena jugularis inferior; v-puh, vena parurohyalis.
(Adriaens and Verraes, '97c). This cartilage connects these epibranchials to the anterior tip of the third infrapharyngobranchial bone (Fig. 15C). Epibranchiale III has a welldeveloped uncinate process at its caudal margin (Fig. 23C). Medially, this epibranchial articulates with the posterior tip of the third infrapharyngobranchial and the anterior margin of the fourth one (Fig. 15C). The fourth epibranchial bone bears a horizontal, plate-like extension at its middle portion, for the support of the uncinate process (Fig. 23D). Medially, this epibranchial articulates with the posterolateral margin of the fourth infrapharyngobranchial element. As mentioned, only the third and fourth infrapharyngobranchials ossify in Clarias gariepinus (Fig. 15C). The third is rod-like, with both its articular tips nonossified (Fig. 23C). The fourth one is rather triangular, with its lateral margin nonossified (Fig. 23D). The upper pharyngeal tooth plate is enlarged and is supported dorsally by the fourth infrapharyngobranchial bone, as well as the medial part of epibranchials III and IV (Fig. 15C).

The opercular series in juvenile Clarias gariepinus consists of the opercular bone, the preopercular, and interopercular bones (Fig. 15B). The subopercular bone is missing, as is the case in most siluriform fish (see Discussion). The preopercular bone attaches to the suspensorium, as mentioned above. The opercular bone is triangular and articulates with the opercular process of the hyomandibula (Fig. 15B). Consequently, at its anterior margin, the opercular bone bears a well-developed articular facet, which is in contact with a medial crest for the insertion of the levator operculi muscle and the opercular part of thehyohyoi dei adductor muscles (Fig. 24B) (Adriaens and Verraes, '97b). The ventral tip of the opercular bone attaches to the interopercular bone through a ligamentous strip (Fig. 15B). This interopercular bone remains triangular, as it tapers rostrally to become elongated in a stout ligament that is attached to the lateral process of the mandibular retroarticular process (Figs. 20A, 24C). The interopercular bone also attaches through connective tissue to the lateral face of the posterior ceratohyal bone.

\section{DISCUSSION}

Bone in Clarias gariepinus is cellular, although the number of osteocytes is low. Ostariophysans, in general, together with some other primitive teleostean lineages (Meu- 

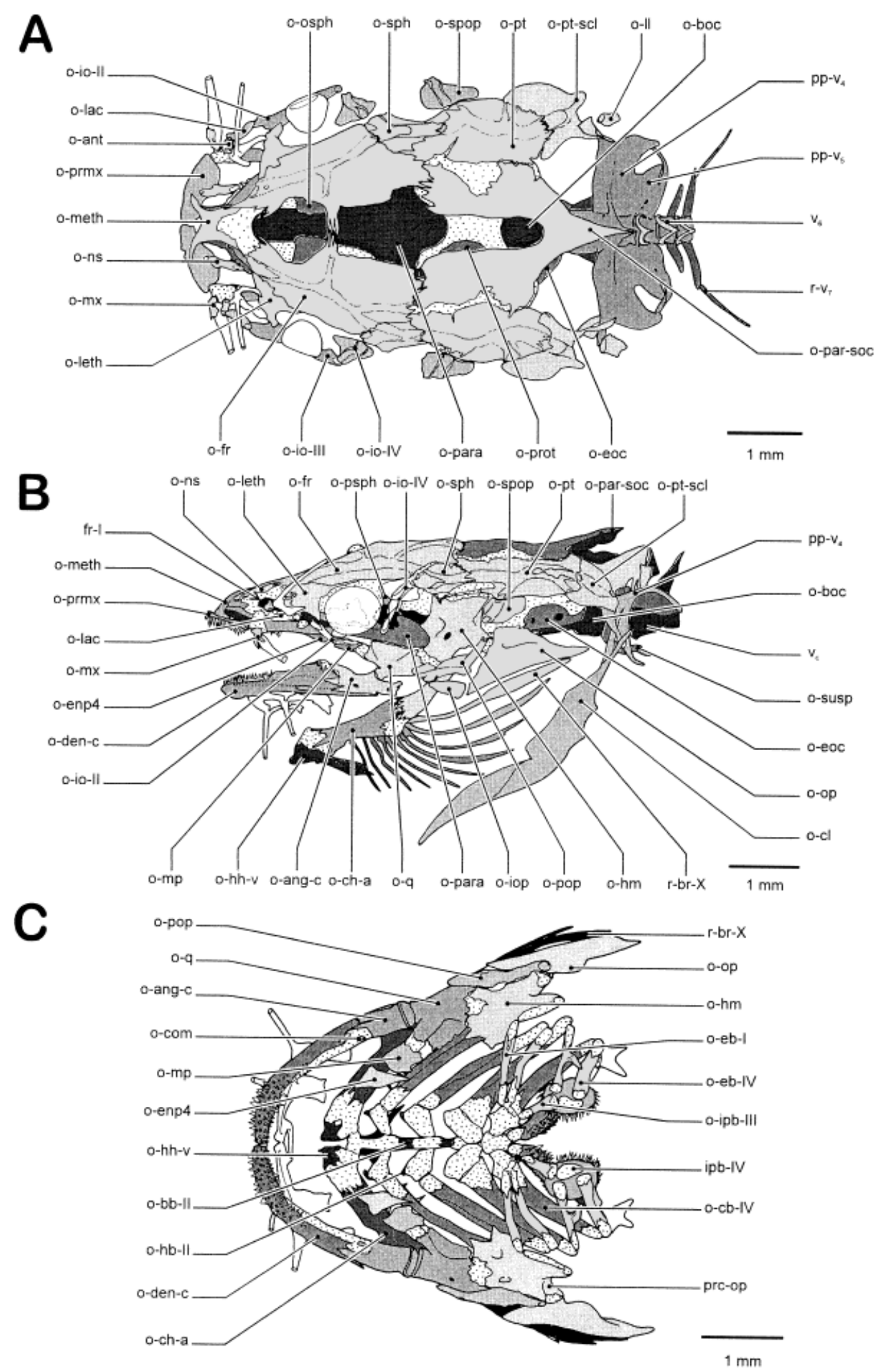

Figure 14 
nier and Huysseune, '92), are characterized by the presence of cellular bone. According to the terminology of Patterson ('77), all three bone types in fish are formed in $\mathrm{C}$. gariepinus: cartilage bones, dermal bones, and membrane bones. In C. gariepinus, all cartilage bones ossify perichondrally. True enchondral ossification was not observed but may occur in larger specimens. Bony elements are compact, lamellar ossifications early in ontogeny, whereas most of them become spongi ous in the juvenile stage. The cartilage bones, lining the cartilaginous structures, are surrounded with membranous apolamellae, which frequently are formed in a radiating manner. Most dermal bones are extremely trabecular, with the exception of the prevomeral bone and parasphenoid bone. Dermal tooth plates become spongy also. At least one type of membrane bone is also present: the sesamoid bones (coronomeckelian and entopterygoid bones). The fully developed skull of $C$. gariepinus consists of about 150 bones (both sides included), which can be subdivided into five categories: (1) 22 anamestic dermal bones, (2) 14 dermal canal bones, (3) 37 perichondral bones, (4) two sesamoid bones and (5) three bones of a compound nature.

Fig. 14. Skull of Clarias gariepinus $(21.5 \mathrm{~mm} \mathrm{SL}$ stage). A, dorsal view; B, lateral view; C, dorsal view of splanchnocranium. (Grey indicates bone, shaded areas indicate cartilage.) fr-I, foramen fila olfactoria; ipb-IV, infrapharyngobranchiale IV; o-ang-c, os angulo-splenioarticulo-retroarticulare complex; o-ant, os antorbitale; o-bb-II, os basibranchiale II; o-boc, os basioccipitale; o-cb-IV, os ceratobranchiale IV; o-ch-a, os ceratohyale anterior; o-cl, os cleithrum; o-com, os coronmeckelium; o-den-c, os dento-splenio-mentomeckelium complex; o-eb-I, os epibranchiale I; o-eb-IV, os epibranchiale IV; o-enp4, sesamoid "os entopterygoi deum" type 4; o-eoc, os exoccipitale; o-fr, os frontale; o-hb-II, os hypobranchiale II; o-hh-v, os hypohyale ventrale; o-hm, os hyomandibulare; o-io-II, os infraorbitale II; o-io-III, os infraorbitale III; o-io-IV, os infraorbitale IV; o-iop, os interoperculare; o-ipb-III, os infrapharyngobranchiale III; o-lac, os Iacrimale (=os infraorbitale I); o-leth, os latero-ethmoideum; o-ll, lateral line ossicle; o-meth, os mesethmoideum; o-mp, os metapterygoideum; o-mx, os maxillare; o-ns, os nasale; o-op, os operculare; o-osph, os orbitosphenoideum; o-par-soc, os parieto-supraoccipitale; o-para, os parasphenoideum; o-pop, os praeoperculare; o-prmx, os praemaxillare; o-prot, os prooticum; o-psph, os pterosphenoideum; o-pt, os pteroticum; o-pt-scl, os posttemporo-supracleithrum; o-q, os quadratum; o-sph, os sphenoticum; o-spop, os suprapraeoperculare; o-susp, os suspensorium; pp- $\mathrm{v}_{4}$, parapophysis of vertebra 4 ; pp- $\mathrm{v}_{5}$, parapophysis of vertebra 5; prc-op, processus opercularis; r-br, radius branchiostegus; $r-v_{7}$, rib of vertebra 7 ; $v_{6}$, vertebra $6 ; v_{c}$, vertebral complex of the Weberian apparatus.
Siluriform relationships of the osteocranium of Clarias gariepinus

Although a comparative osteology is beyond the scope of this report, some of the features used to describe the cranial osteology of Clarias gariepinus, are briefly discussed.

The paired origin of the prevomeral bone has been observed in most teleost fish (De Beer, '37; Verraes, '73). This bone is considered nonhomologous with the vomeral bone of tetrapods, although it is frequently referred to as "vomeral bone" in teleosts (de Beer, '37; Harrington, '55; Daget, '64). In Clarias gariepinus, it appears that the pre vomeral bone itself is unpaired (whether or not a fusion occurs between paired blaste mata or not could not be discerned) and becomes fused to paired tooth plates. In the closely related heteropneustid species, Heteropneustes fossilis, an unpaired prevomeral bone arises, prior to its dentition (Srinivasachar, '58). Researchers seem to come to a consensus that the toothless prevomeral bone is an unpaired, dermal bone that becomes fused to paired, autogenous toothplates, whereas the latter may be homologous with pharyngeal tooth plates of the premandibular arch (Daget, '64; Srinivasa Rao and Lakshmi, '84; Arratia, '87). The prevomeral bone in siluriform fish is generally T-shaped, bearing two patches of teeth at its lateral wings and interdigitating with the parasphenoid through very long sutures (Bhimachar, '33; Merriman, '40; Tilak, '63b, '65a; Lundberg, '82; Srinivasa Rao and Lakshmi, '84; Howes and Fumihito, '91). Both tooth patches may be fused to each other (Merriman, '40; Tilak, '61, '63b,c; Rastogi, '63; Arratia, '87; Howes and F umihito, '91) or may even be absent (Tilak, '65a, '67; Gauba, '70; Lundberg, '82; Vignes and Garcia, '87; Ferraris, '96). Fusion between both tooth plates in adult Clariidae seems to be the general trend (Tilak, '63c; Teugels, '82). In case dentition is lacking, an unpaired origin of the prevomeral bone has been observed (Kindred, '19), with its lateral wings sometimes being absent (Lundberg, '82; Howes, '83). Heavily dentate prevomeral tooth plates are present in Pangasiidae and Siluridae, where these plates become closely aligned with autogenous palatine tooth plates, or may even fuse to them (Tilak, '61; Roberts and Vidthayanon, '91). In Chacidae, the pre vomeral bone is absent as an independent ossification (Tilak, '71; Brown and Ferraris, '88). 


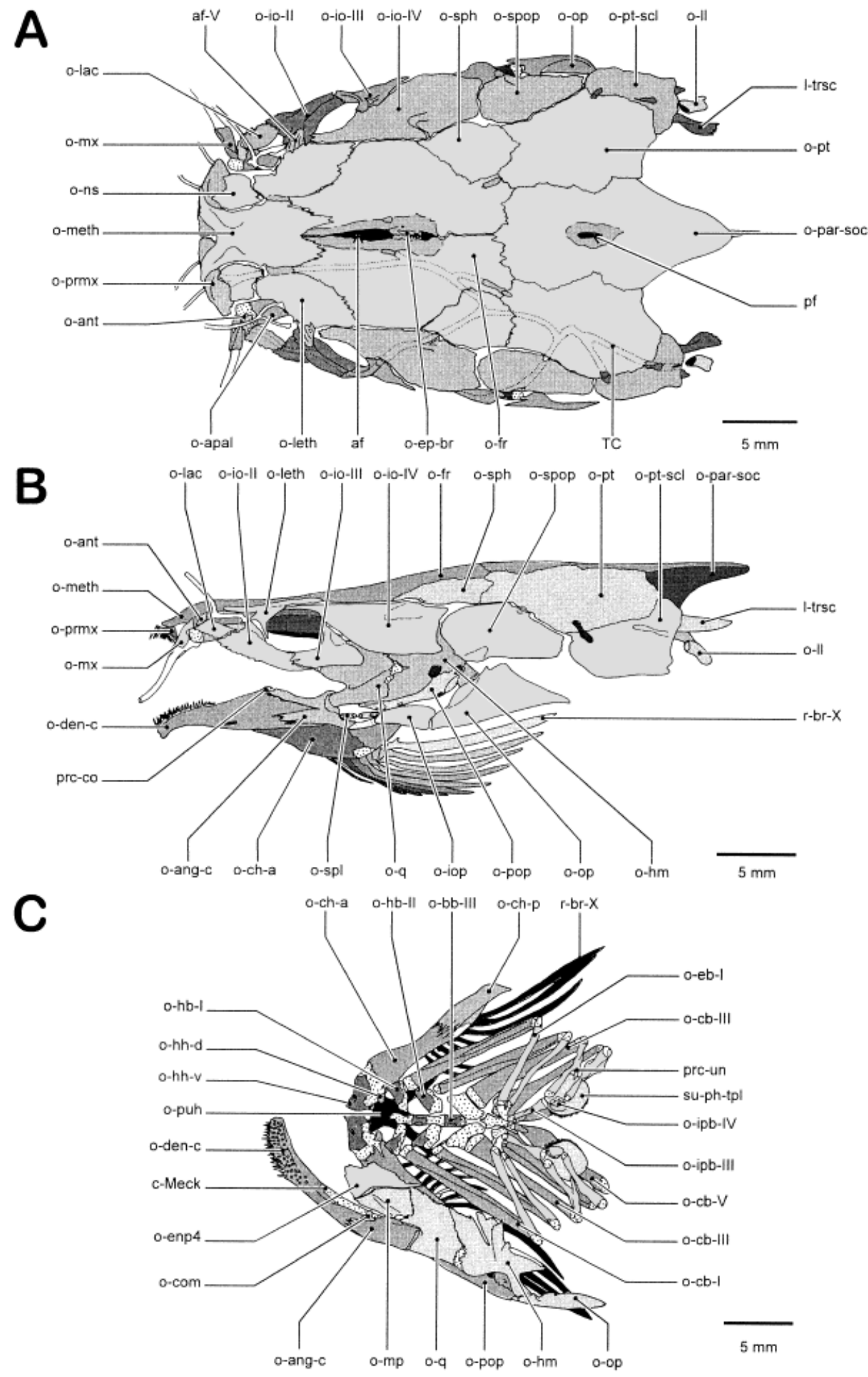

Figure 15 


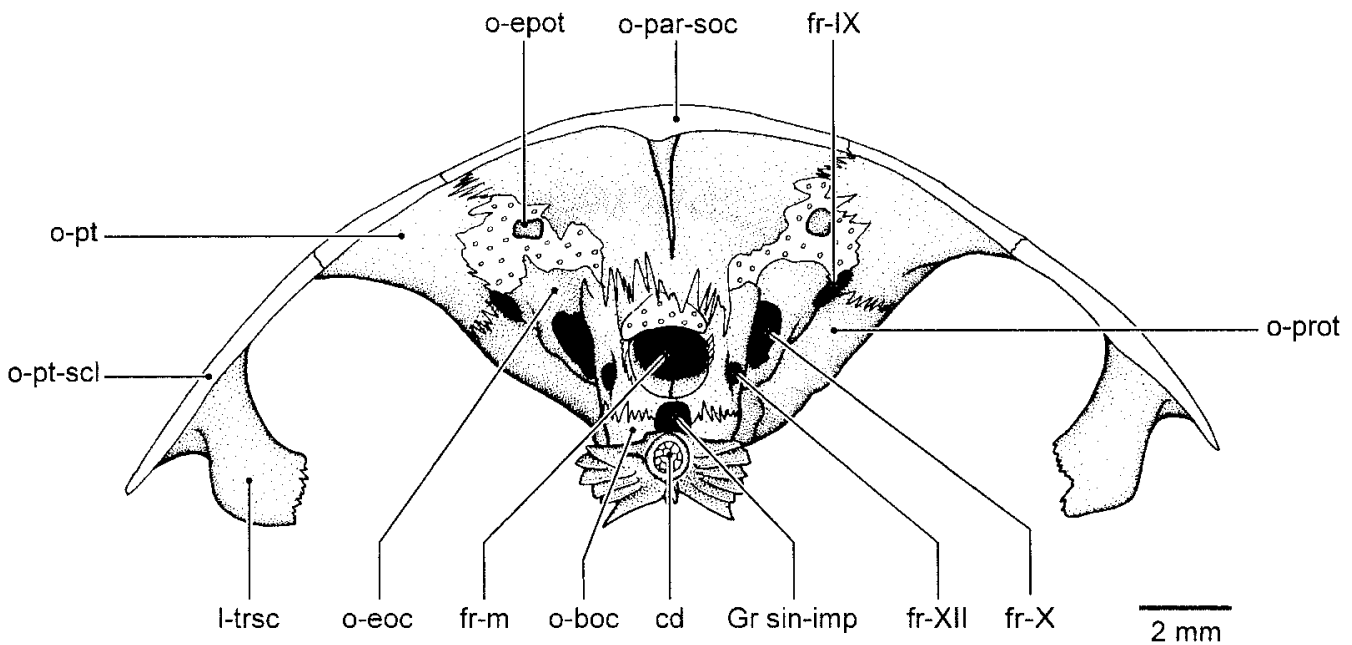

Fig. 16. Skull of Clarias gariepinus ( $140.1 \mathrm{~mm} \mathrm{SL}$ stage). Caudal view. (Small circles indicate cartilage.) cd, chorda dorsal is; fr-IX, foramen nervus gl ossopharyngeus ( $=$ fenestra basicapsularis posterior); fr- $\mathrm{m}$, foramen magnum; fr-X, foramen nervus vagus; fr-XII, foramen nervus hypoglossus; Gr sin-imp, groove for the sinus

For a discussion and in- and outgroup comparison of the parietal and supraoccipital bone complex, we refer to Fink and Fink ('81, '96) and Arratia and Gayet ('95). The

Fig. 15. Skull of Clarias gariepinus ( $127.0 \mathrm{~mm} \mathrm{SL}$ stage). A, dorsal view; B, lateral view; C, dorsal view of the splanchnocranium. (Grey indicates bone, shaded areas indicate cartilage.) af, anterior fontanella; af- $\mathrm{V}$, articulatory facet of the os lateroethmoideum with the os infraorbitale II; c-Meck, cartilago Meckeli; I-trsc, ligamentum transcapularis; o-ang-c, os angulo-splenioarticulo-retroarticulare complex; o-ant, os antorbitale; o-apal, os autopalatinum; o-bb-III, os basibranchialellI; o-cb-I, os ceratobranchiale I; o-cb-III, os ceratobranchiale III; o-cb-V, os ceratobranchialeV; o-ch-a, os ceratohyale anterior; o-ch-p, os ceratohyale posterior; o-com, os coronomeckelium; o-den-c, os dento-splenio-mentomeckelium complex; o-eb-I, os epibranchiale l; o-enp4, sesamoid "os entopterygoideum" type 4; o-ep-br, ossification of the os frontale around the epiphyseal bridge; o-fr, os frontale; o-hb-I, os hypobranchiale I; o-hb-II, os hypobranchiale II; o-hh-d, os hypohyale dorsale; o-hh-v, os hypohyal e ventrale; o-hm, os hyomandibulare; o-io-lI, os infraorbitale II; o-io-III, os infraorbital III; o-io-IV, os infraorbitale IV; o-iop, os interoperculare; o-ipb-III, os infrapharyngobranchiale III; o-ipb-IV, os infrapharyngobranchiale IV; o-lac, os lacrimale (= os infraorbitaleI); o-leth, os latero-ethmodeum; o-II, lateral line ossicle; o-meth, os mesethmoideum; o-mp, os metapterygoideum; o-mx, os maxillare; o-ns, os nasale; o-op, os operculare; o-par-soc, os parieto-supraocci pitale; o-pop, os praeoperculare; o-prmx, os praemaxillare; o-pt, os pteroticum; o-pt-scl, os posttemporo-supracl eithrum; o-puh, os parurohyale; o-q, os quadratum; o-sph, os sphenoticum; o-spl, ossa splenialia; o-spop, os suprapraeoperculare; pf, posterior fontanella; prc-co,processus processus coronoideus; prcun, processus uncinatus; r-br, radius branchiostegus; su-phtpl, superior pharyngeal tooth plate; TC, temporal canal. impar perilymphaticus; I-trsc, ligamentum transcapularis; o-boc, os basioccipitale; o-eoc, os exoccipitale; oepot, os epioticum; o-par-soc, os parieto-supraoccipitale; o-prot, os prooticum; o-pt, os pteroticum; o-pt-scl, os supracleithrum.

presence of a separate parietal ossification which has been observed in several siluriform taxa, is now generally accepted to explain the compound nature of this bone (Arratia, '87; Fink and Fink, '96).

For a discussion on the homology of the posttemporo-supradeithral bone in Siluriformes, we refer to L undberg ('75), Arratia and Gayet ('95), and Fink and Fink ('81, '96). Concerning the transscapular ligament, several constructions seem to be present in Siluriformes. In many catfish, the posttemporo-supracl eithral bone connects to the basioccipital through a bony limb, the ossified transscapular ligament, which attaches through a ligament to the lateral face of the basioccipital (Bhimachar, '33; Merriman, '40; Hubbs and Miller, '60; Tilak, '61, '63b, '65a, '67, '71; Rastogi, '63; Lundberg, '75; Poll, '77; Srinivasa Rao and Lakshmi, '84; Howes and Fumihito, '91). In others, no such a connection is observed. Then, mostly, a medial limb connects the anterior vertebrae, at the level of the vertebral center (Tilak, '63b), or contacts the parapophyses (Srinivasacher, '58; Nawar, '54; Tilak, '63c; Gauba, '70; Howes, '83; present study). Regan ('11) mentioned that a lower limb of the posttemporal (posttemporo-supracleithral bone of present study) to the basioccipital is absent in Clariidae, Loricariidae, and Callichthyidae. This author also mentioned that the posttemporal is absent in Clariidae, whereas the su- 


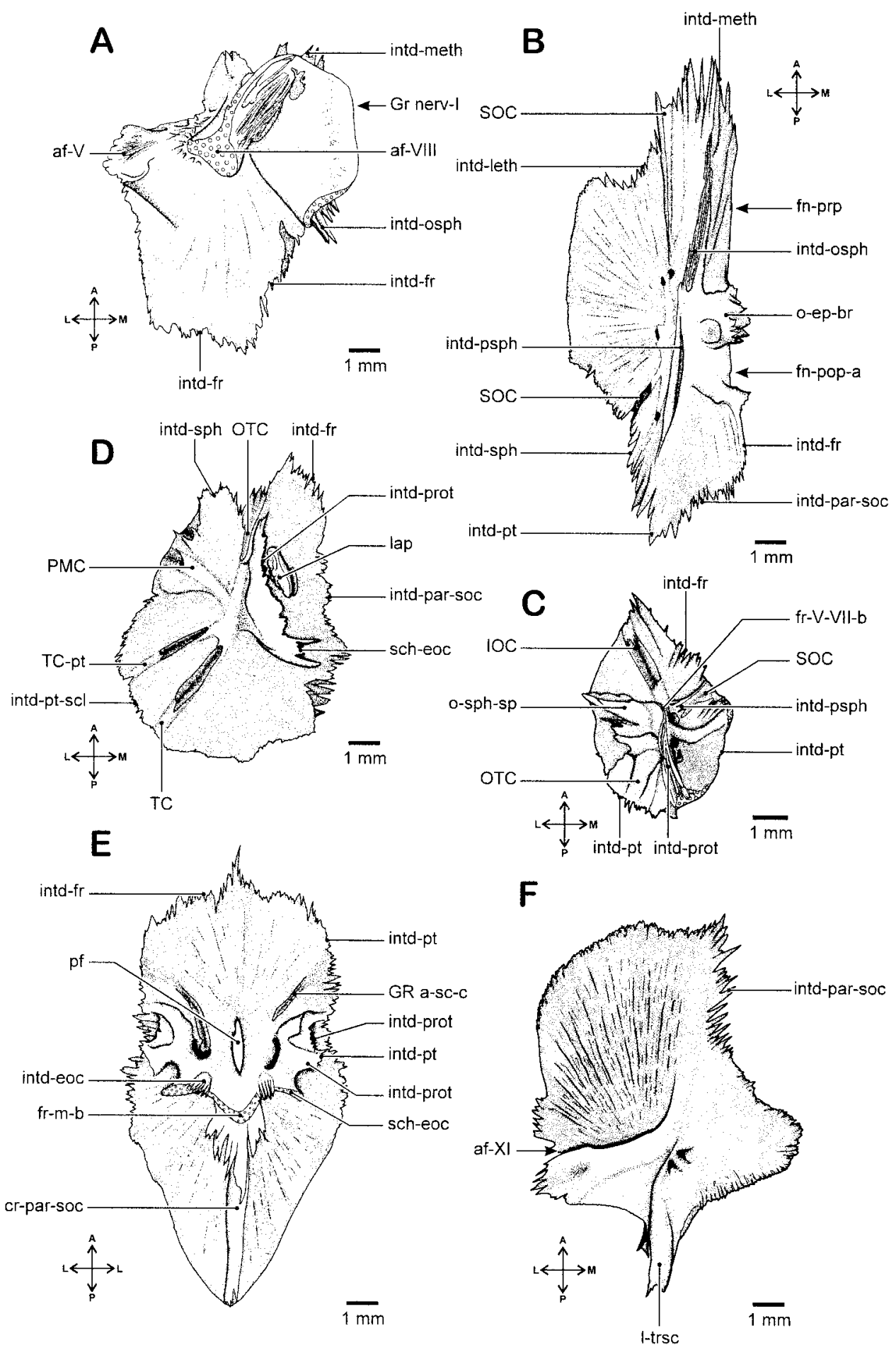

Figure 17 


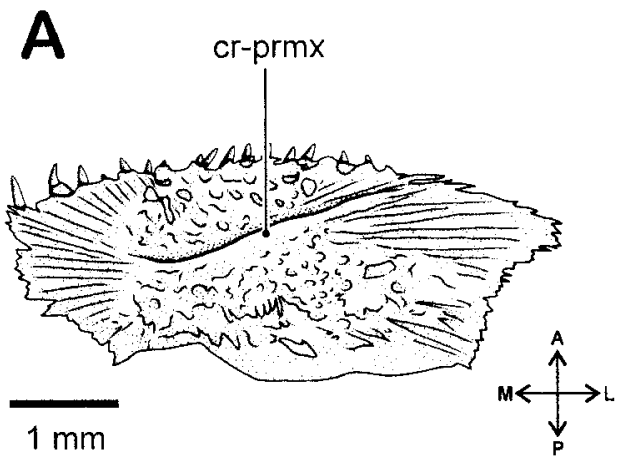

Fig. 18. Maxillary bones of juvenile Clarias gariepinus. A, premaxillary, dorsal view (125.5 mm SL stage); B, maxillary, caudal view (174.5 mm SL stage). (Orientation cross: D, dorsal, V: Ventral.) af-X, articulatory facets of the os maxillare with the os autopalatinum; $\mathrm{cr}$ -

pracleithral bone is connected "with a posterior process firmly united to the air-bladder capsule." In Dipl omystidae, Arratia ('87) observed a ventromedial process of the post-

Fig. 17. Skull roof bones of juvenile Clarias gariepinus (125.5 mm SL stage). A, lateral ethmoid, ventral view; B, frontal, ventral view; C, sphenotic, ventral view. D, pterotic, ventral view; E, Parieto-suproccipital, ventral view; F, posttemporo-supracleithral, ventral view. (Orientation cross: A: Anterior, P: Posterior, L: Lateral, M: Medial.) af-V, articulatory facet of the os later oethmoideum with the os infraorbitale II; af-VIII, articulatory facet of the os lateroethmoideum with the os autopalatinum; af-XI, articulatory facet of the os posttemporo-supracleithrum with the os cleithrum; cr-par-soc, medioventral crest of the posterior part of the os parietosupraoccipital; fn-pop-a, anterior part of the postpineal foramen; fn-prp, fenestra praepinealis; fr-m-b, border of the foramen magnum; fr-V-VII-b, border of the foramen of the trigemino-facial nerve complex; $\mathrm{Gr}$ a-sc-c, groove for the anterior semicircular canal; Gr nerv-I, groove of the fila olfactoria; intd-eoc, interdigitation with the os exoccipitale; intd-fr, interdigitation with the os frontale; intd-leth, interdigitation with the os lateroethmoideum; intd-meth, interdigitation with the os mesethmoideum; intd-osph, interdigitation with the os orbitosphenoideum; intd-par-soc, interdigitation with the os parietosupraoccipitale; intd-prot, interdigitation with the os prooticum; intd-psph, interdigitation with the os pterosphenoideum; intd-pt, interdigitation with the os pteroticum; intd-pt-scl, interdigitation with the os posttemporosupracleithrum; intd-sph, interdigitation with the os sphenoticum; IOC, infraorbital canal; I-trsc, ligamentum transcapularis; Iap, lapillus (utricular otolith); o-epbr, ossification of the os frontale around the epiphyseal bridge; o-sph-sp, sphenotic spine; OTC, otic canal; pf, posterior fontanella; PMC, preoperculo-mandibular canal; sch-eoc, synchondrosis with the os exoccipitale; SOC, supraorbital canal; TC, temporal canal; TC-pt, pterotic branch of the temporal canal.

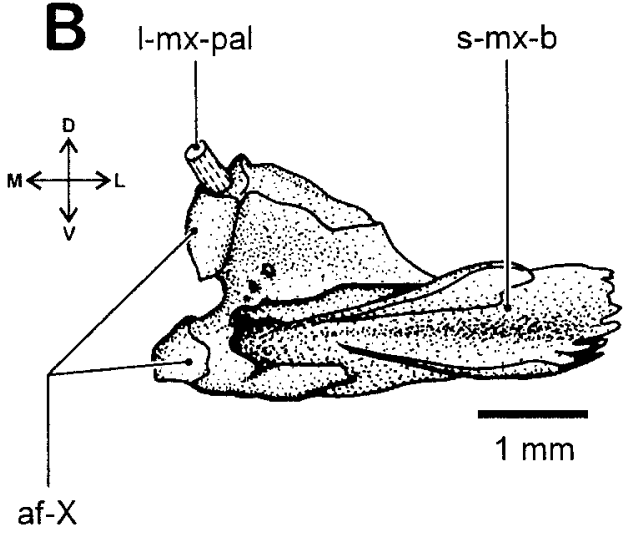

prmx, dorsal crest of the os praemaxillare, for the articulation with the cornua prae-ethmoidea; I-mx-pal, ligamentum maxillo-palatinum; s-mx-b, socket of the maxillary barbel.

temporo-supracleithral bone, which is bifurcated and attached to the cranium (at the level of the basioccipital) and to the parapophyses through ligaments.

The question raised here is whether the process, attaching to the basioccipital in most catfish corresponds to the one connecting the Weberian apparatus in others. The connection to the basioccipital is believed to be the ossified Baudelot's ligament, which generally runs from the supracleithral bone to the basioccipital in other teleosts. Lundberg ('75) considered the connection to the parapophyses of the vertebrae as a differentiation (ventral process) of the transscapular ligament of his supracleithrum (= posttemporo-supracleithrum of present study). A double connection of the posttemporo-supracleithral bone to the basioccipital and Weberian apparatus, as observed by Arratia ('87) in Diplomystidae, is considered to be a feature of the Siluriphysi (present Siluriformes and Gymnotiformes) (Fink and Fink, '81: character 98). Although such a bifurcation is absent in Clarias gariepinus, it could indicate the homology of the ventromedial process of the posttemporo-supracleithral bone with a part of the transscapular ligament in other catfish groups.

A dermopalatine is considered to be absent in ostariophysan fish. Tooth plates at the level of the autopalatine are then re garded as neomorphic, autogenous tooth plates (Fink and Fink, '81, '96; Arratia and Schultze, '91; Arratia, '92). The dermopala- 

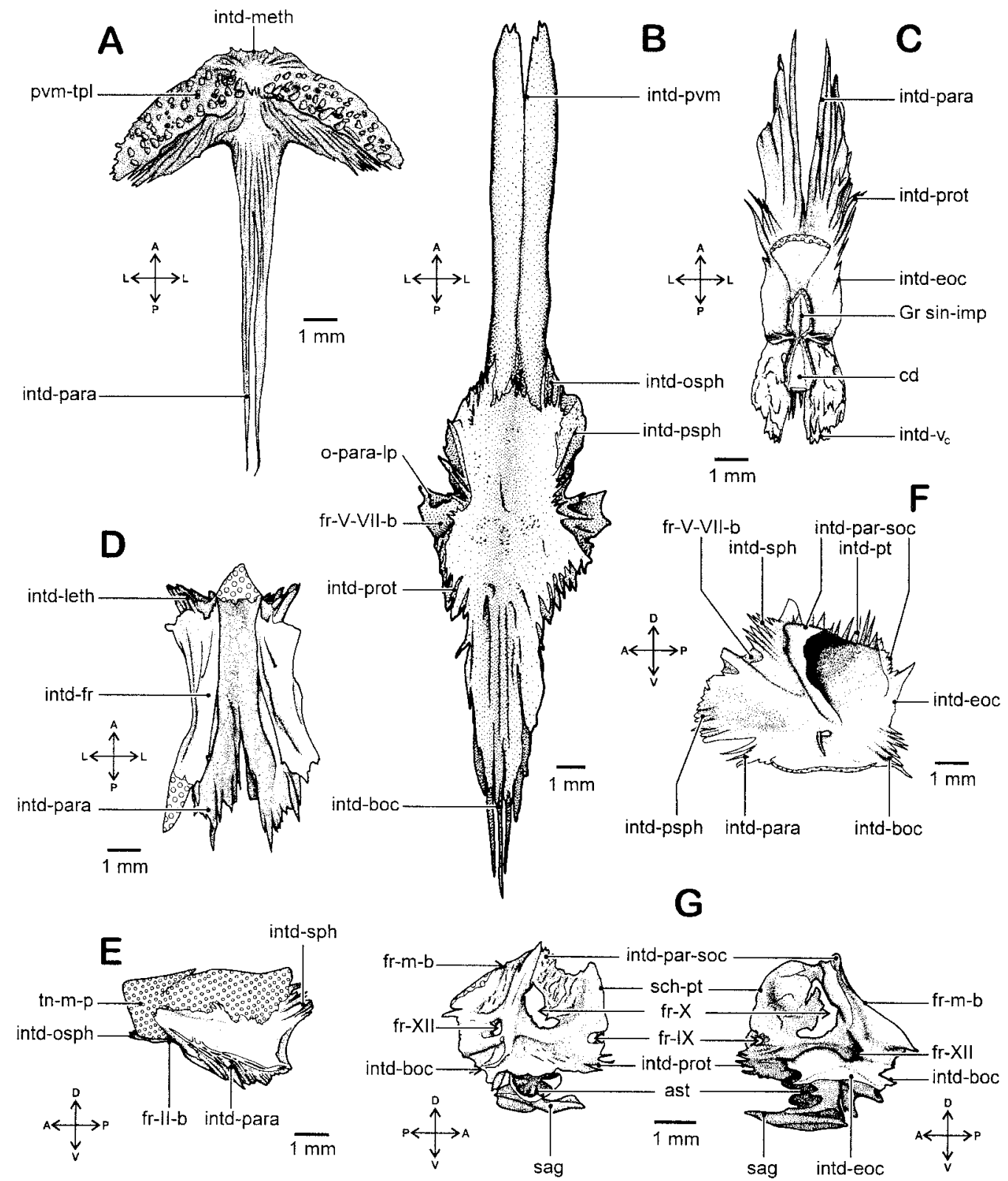

Fig. 19. Skull floor bones of juvenile Clarias gariepinus. A, prevomer, ventral view (125.5 mm SL stage); B, parasphenoid, dorsal view (174.5 mm SL stage); C, basioccipital, dorsal view (125.5 mm SL stage); D, Orbitosphenoid, dorsal view (125.5 mm SL stage); E, pterosphenoid, lateral view (125.5 mm SL stage); F, prootic, medial view (125.5 mm SL stage); G, exoccipital, lateral (left) and medial (right) view (125.5 mm SL stage). ast, asteriscus (lagenar otolith); cd, chorda dorsalis; fr-II-b, border of the foramen fasciculus opticus; $\mathrm{fr}-\mathrm{IX}$, foramen nervus glossopharyngeus ( =fenestra basicapsularis posterior); fr-m-b, border of the foramen magnum; fr-VVII-b, border of the foramen of the trigemino-facial nerve complex; fr-X, foramen nervus vagus; fr-XII, foramen nervus hypoglossus; Gr sin-imp, groove for the sinus impair perilymphaticus; intd-boc, interdigitation

with the os basioccipitale; intd-eoc, interdigitation with the os exoccipitale; intd-fr, interdigitation with the os frontale; intd-leth, interdigitation with the os lateroethmoideum; intd-meth, interdigitation with the os mesethmoideum; intd-osph, interdigitation with the os orbitosphenoideum; intd-par-soc, interdigitation with the os parieto-supraoccipitale; intd-para, interdigitation with the os parasphenoideum; intd-prot, interdigitation with the os prooticum; intd-psph, interdigitation with the os pterosphenoideum; intd-pt, interdigitation with the os pteroticum; intd-pvm, interdigitation with the os prevomerole; intd-sph, interdigitation with the os sphenoticum; intd- $\mathrm{v}_{\mathrm{c}}$, interdigitation with the vertebral complex o-para-lp, lateral wing of the os parasphenoideum; pvmtpl, prevomeral tooth plate; sch-pt, synchondrosis with the os pteroticum; tn-m-p, taenia marginalis posterior. 

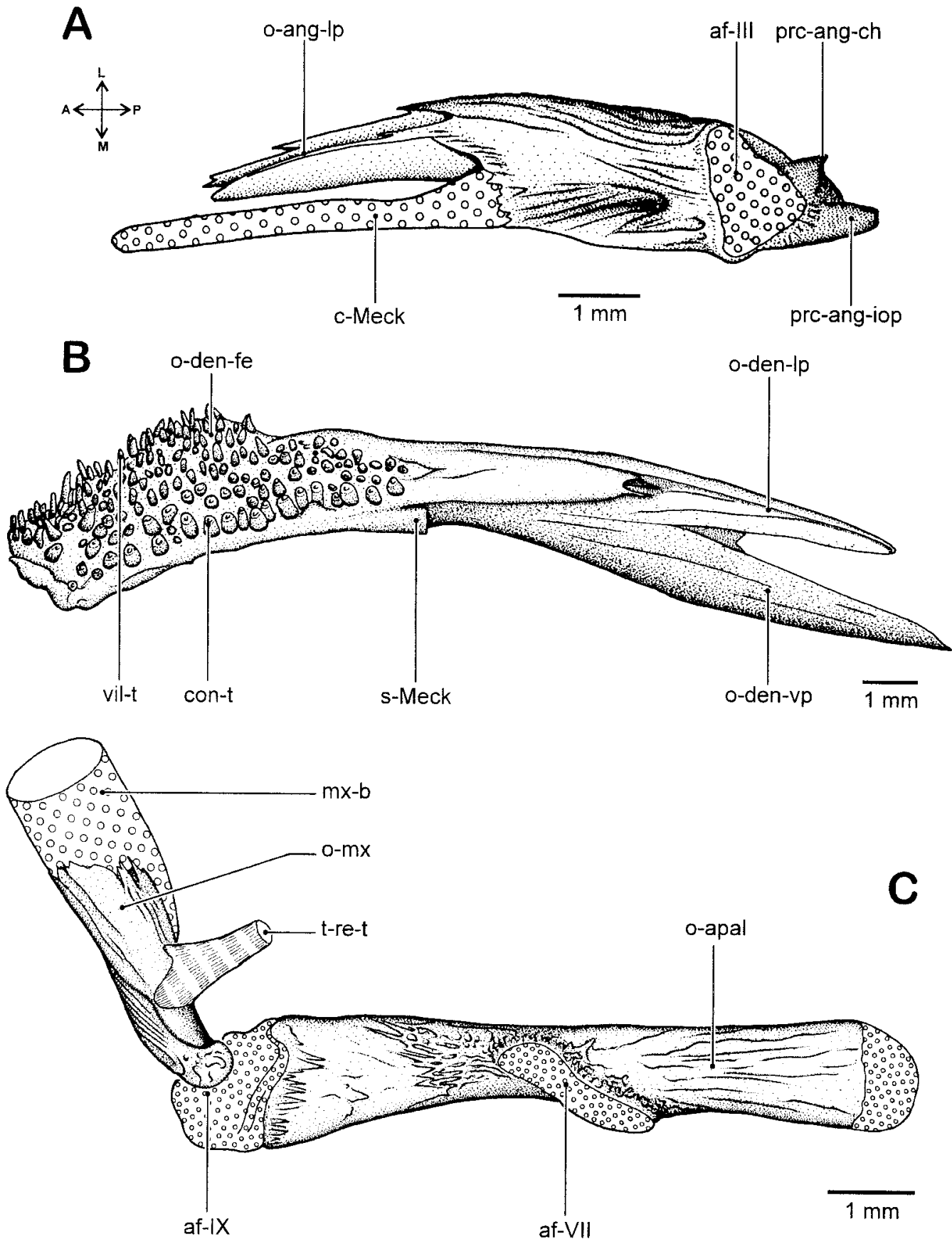

Fig. 20. Lower jaw and palatine of juvenile Clarias gariepinus. A, angulo-splenio-articulo=retroarticular bone complex with Meckel's cartilage, dorsal view (125.5 $\mathrm{mm}$ SL stage); B, dento-splenio-mentomeckelian bone complex, dorsal view (174.5 mm SL stage); C, autopalatine and maxillary, dorsal view (125.5 mm SL stage). af-III, articulatory facet of the os angulo-splenio-articuloretroarticulare with the os quadratum; af-VII, articulatory facet of the os autopalatinum with the os lateroethmoideum; af-IX, articulatory facet of the os autopalatinum with the os maxillare; c-Meck, cartilago
Meckeli; con-t, conical teeth; mx-b, maxillary barbel; o-ang-lp, lateral process of the os angulo-splenio-articuloretroarticulare complex; o-apal, os autopalatinum; o-denfe, frontal extension of the os dento-splenio-mentomeckelian complex; o-den-Ip, lateral process of the os dentosplenio-mentomeckelium; o-den-vp, ventral process of the os dento-splenio-mentomecklium complex; o-mx, os maxillare; prc-ang-ch, processus angulo-ceratohyalis; prc-ang-iob, processus angulo-interopercularis; s-Meck, socket for Meckel's cartilage; $t$-re-t, tendon of the $m$. retractor tentaculi: vil-t, villiform teeth. 
A
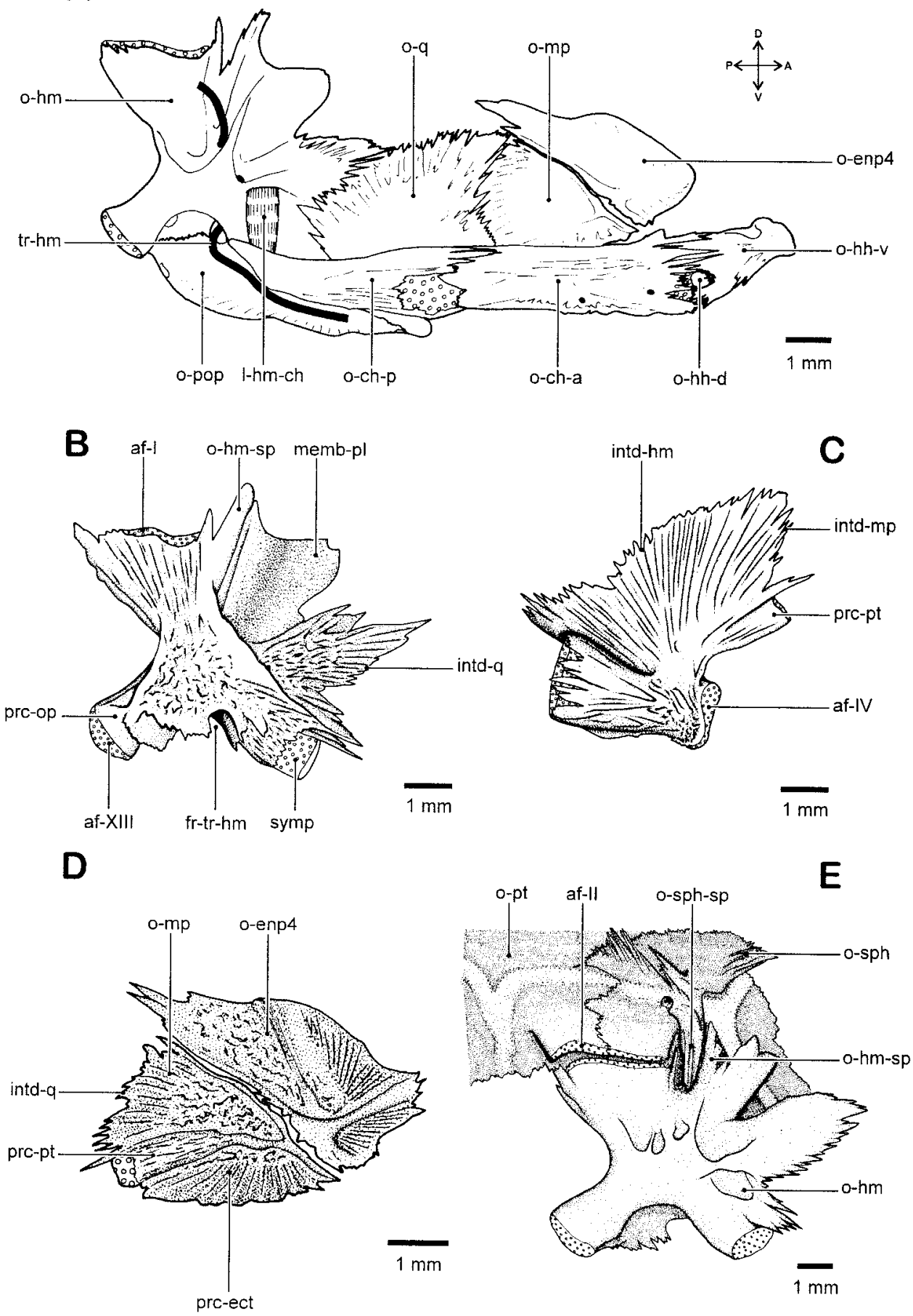

Figure 21 
tine of Vandewalle et al., ('93), observed in Clarias gariepinus, corresponds to the sesamoid entopterygoid bone of the present study. The "thin dermal plate" covering the anterior end of the cartilaginous pterygoid process probably may have been confused with the perichondral metapterygoid, which bears a dorsal and ventral membranous apolamella. The cartilagi nous connection between the metapterygoid and the entopterygoi d, as mentioned by Vandewalle et al., ('93), could not be observed. The dermopal atinein Gal edchthys felis (Ariidae), reported by Bamford ('48: Fig. 7B), seems to correspond to the prevomeral tooth plates, as they attach to the lateral ethmoids at the same spot as is the case in most siluriforms.

The homology of the urohyal bone in osteichthyan fishes has been extensively reviewed by Arratia and Schul tze ('90). I I most teleost fishes the urohyal bone is an unpaired ossification of the aponeurosis, between the contralateral sternohyoideus heads, bearing two rostral processes for the ligamentous connection with the ventral hypohyals, and a ventral, horizontal plate (de Beer, '37; Patterson, '77; Arratia and Schultze, '90). In siluriform fish, however, a perichondral ossification participates in the formation of that bone, together with a paired bone of apparent sesamoid origin. This was

Fig. 21. Suspensorium of juvenile Clarias gariepinus. A, suspensorium and hyoid bar, medial view (125.5 $\mathrm{mm} \mathrm{SL}$ stage); B, hyomandibula, lateral view $(125.5 \mathrm{~mm}$ $\mathrm{SL}$ stage). C, quadrate, lateral view (125.5 mm SL stage); D, metapterygoid and entopterygoid, lateral view (125.5 mm SL stage); E, L ocking mechanism of suspensorium and neurocranium, medio-ventral view (127.0 $\mathrm{mm} \mathrm{SL}$ stage). af-I, articulatory facet of the os hyomandibulare with the os sphenoticum; af-II, articulatory facet of the os sphenoticum with the os hyomandibulare; af-IV, articulatory facet of the os quadratum with the os angulo-splenio-articulo-retroarticulare; af-XIII , articulatory facet of the os hyomandibulare with the os operculare; fr-tr-hm, foramen truncus hyomandibularis nervus facialis; intd-hm, interdigitation with the os hyomandibulare; intd-mp, interdigitation with the os metapterygoideum; intd-q, interdigitation with the os quadratum; I-hm-ch, ligamentum hyomandibulo-ceratohyale; memb$\mathrm{pl}$, membranous plate of the os hyomandibulare; o-ch-a, os ceratohyale anterior; o-ch-p, os ceratohyale posterior; o-enp4, sesamoid "os entopterygoideum" type 4; o-hh-d, os hypohyale dorsale; o-hh-v, os hypohyale ventrale; o-hm, os hyomandibulare; o-hm-sp, hyomandibular spine; o-mp, os metapterygoi deum; o-pop, os praeoperculare; o-pt, os pteroticum; o-q, os quadratum; o-sph, os sphenoticum; o-sph-sp, sphenotic spine; prc-ect, processus ectopterygoideus; prc-op, processus opercularis; prcpt, processus pterygoideus; tr-hm, truncus hyomandibularis nervus facialis. also observed in the present study, in which development of the parurohyal bone is very similar to that observed in Trichomycterus areolatus (Trichomycteridae) (Arratia and Schultze, '90). In Clarias gariepinus, a perichondral bone appeared at the ventral margin of the cartilaginous basibranchial I (8.4 $\mathrm{mm} \mathrm{SL}$ ), after the paired elements were observed (6.6 $\mathrm{mm} \mathrm{SL})$. At $8.4 \mathrm{~mm} \mathrm{SL}$, the perichondral part was al ready fused to the sesamoid one. The chondroid bone of some catfish, however, could not be observed in C. gariepinus (Arratia and Schultze, '90).

Three hypotheses can be put forward: (1) the perichondral part corresponds to the endoskeletal urohyal of sarcopterygians, which becomes fused to dermal bones, the latter homologous with the sarcopterygian interclavicles (Patterson, '77), or (2) as Patterson ('77) in a way predicted, the perichondral part corresponds to the ventral part of the anterior basibranchial bone, which becomes fused with the paired tendon bones. A final possibility is (3) the secondary invasion of the ossification centers of the tendons of the sternohyoideus muscle into the basibranchial cartilage, which thus become perichondral, as already proposed by Arratia and Schulze ('90). H owever, they mentioned that "the parurohyal of siluroids is a novelty within teleosts in its combination of paired tendon bones with the addition of secondary cartilage or chondroid bone."I n Clarias gariepinus, no such secondary cartilage, nor chondroid bone could be observed. The cartilage involved was the basibranchial I. An ossified basibranchial I is absent in presently studied siluriforms, but could be observed in some other ostariophysans, e.g. Cyprinidae (Harrington, '55; Cubbage and Mabee, '96), Catostomiade (Cypriniformes) (Weisel, '60), Characidae (Weitzman, '62), Hemiodontidae, Parodontidae (Characiformes) (Roberts, '74). Although the parurohyal of Siluriformes is considered to be homologous with the urohyal of other ostariophysans and other teleosts (Arratia and Schultze, '90), a detailed ontogenetic study, at an ultrastructural level, of the parurohyal and basibranchial cartilage could yield conclusiveresult on the true nature of the parurohyal in siluriform fish.

Another feature related the parurohyal bone, in contrast with the teleostean urohyal bone, is the penetration of it by an artery. Arratia and Schultze ('90) noted the 

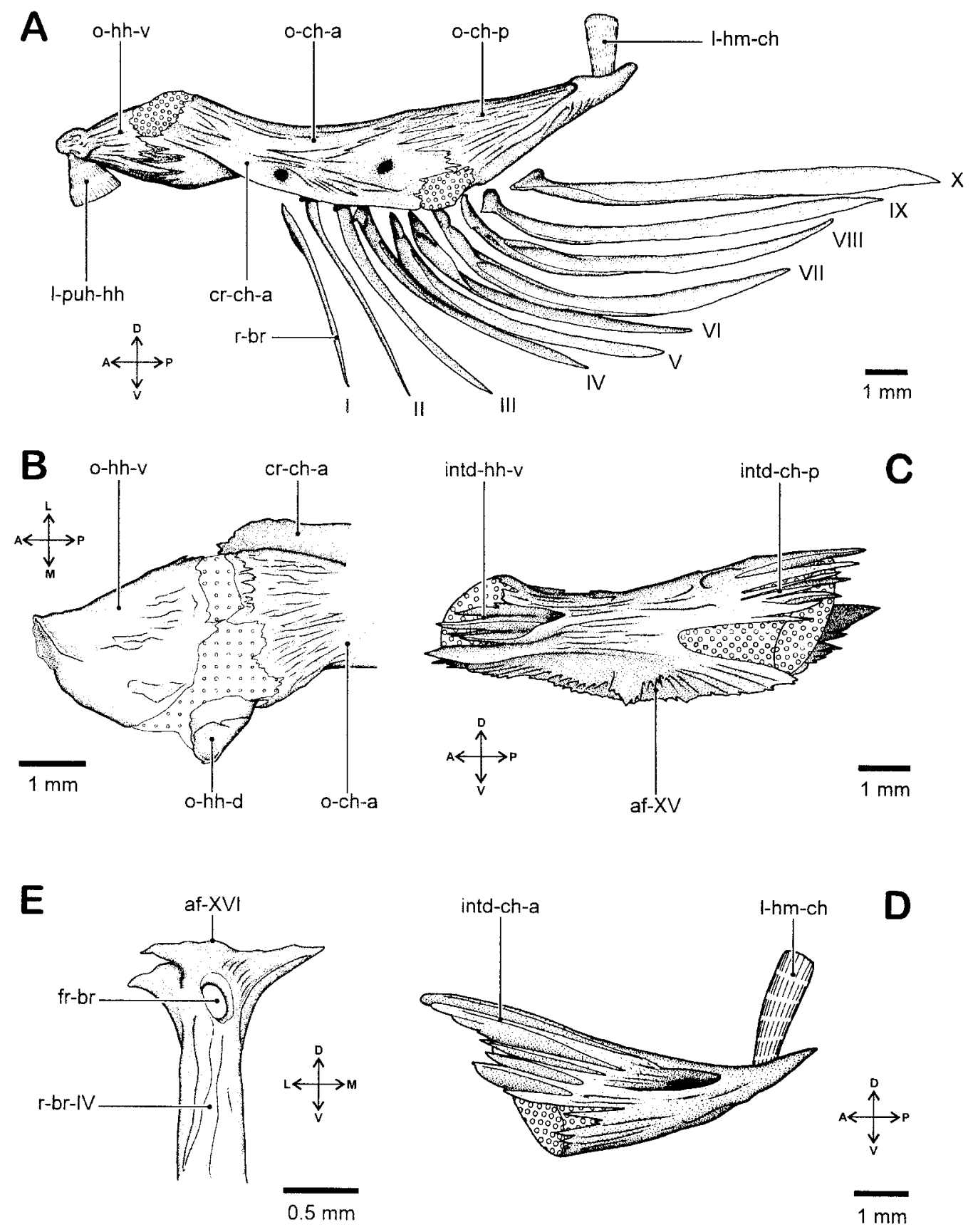

Fig. 22. Hyoid bar of juvenile Clarias gariepinus. A, hyoid bar with branchiostegal rays, lateral view (125.5 $\mathrm{mm}$ SL stage). B, hypohyals, dorsal view (127.0 mm SL stage); C, anterior ceratohyal, medial view $(125.5 \mathrm{~mm}$ SL stage); D, posterior ceratohyal, medial view (125.5 $\mathrm{mm} \mathrm{SL}$ stage); $\mathbf{E}$, detail of articular facet of a branchiostegal ray, frontal view (125.5 mm SL stage). af-XV, articulatory facet of the os ceratohyale anterior with the radii branchiostegi; af-XVI, articulatory facet of the radius branchiostegus with the os ceratohyale anterior; cr-ch-a, crest of the os ceratohyale anterior, for the

articulation with the radii branchiostegi; fr-br, foramen of the radii branchiostgi; intd-ch-a, interdigitation with the os ceratohyale anterior; intd-ch-p, interdigitation with the os ceratohyale posterior; intd-hh-v, interdigitation with the os hypohyale ventrale; I-hm-ch, ligamentum hyomandibulo-ceratohyale; I-puh-hh, ligamentum parurohyalo-hypohyale; o-ch-a, os ceratohyale anterior; o-ch-p, os ceratohyale posterior; o-hh-d, os hypohyale dorsale; o-hh-v, os hypohyal e ventrale; r-br, radius branchiostegus. 

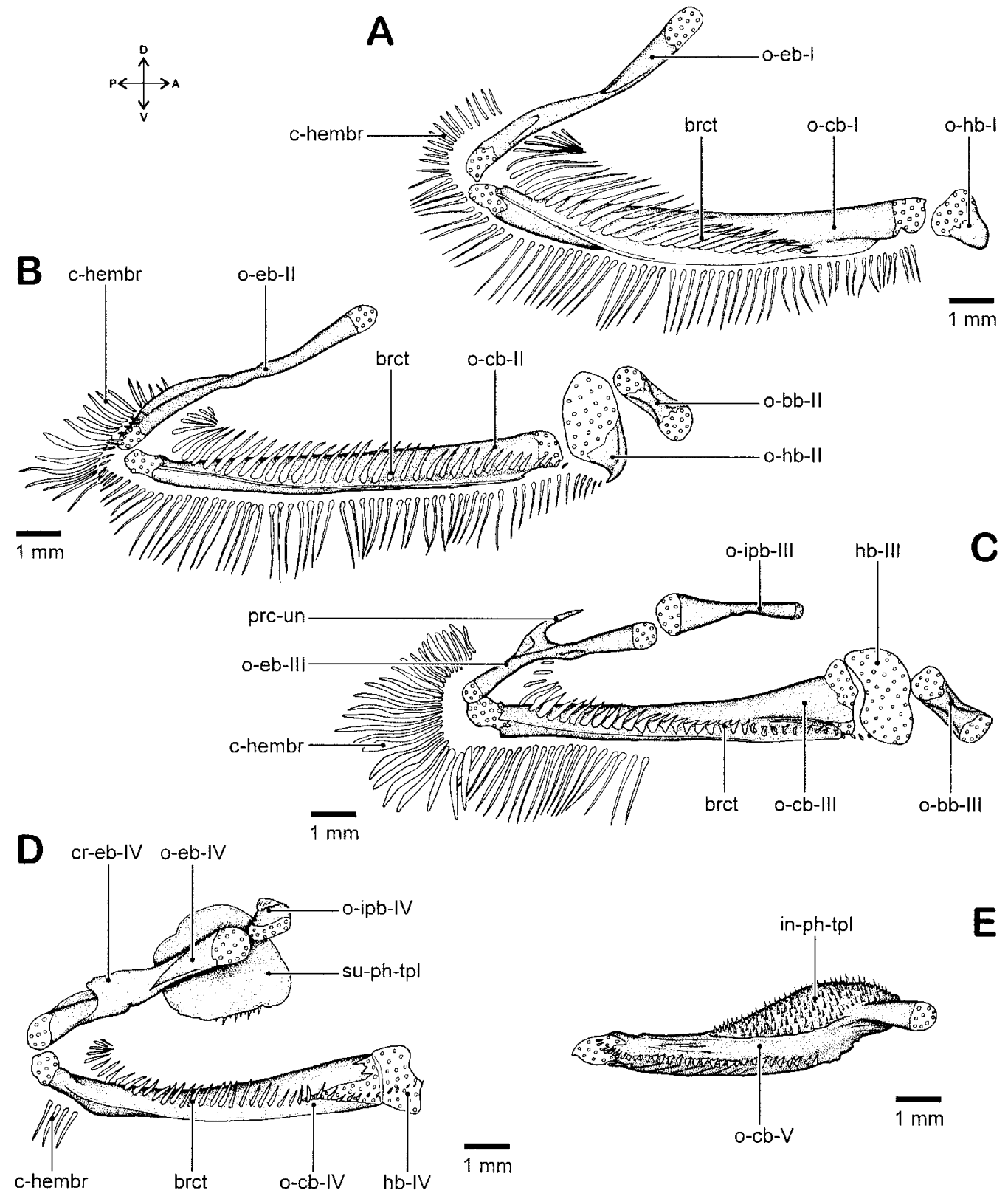

Fig. 23. Branchial basket of juvenile Clarias gariepinus (125.5 mm SL stage). A, branchial arch I, medial view; B, branchial arch II, medial view; C, branchial arch III, medial view; D, Branchial arch IV, medial view; E, branchial arch V, medial view. brct, branchictenium; c-hembr, cartilaginous supporting rods of the hemibranchia; cr-eb-IV, crest of the os epibranchiale IV, for the support of the processus uncinatus of the os epibranchiale III; hb-III, hypobranchiale III; hb-IV, hypobranchialeIV; in-ph-tpl, inferior pharyngeal toothplate; o-bb-

II, os basibranchiale II; o-bb-III, os basibranchiale III; o-cb-I, os ceratobranchial le ; o-cb-II, os ceratobranchiale II; o-cb-III, os ceratobranchialeIII; o-cb-IV, os ceratobranchialeI V; o-cb-V, os ceratobranchialeV; o-eb-I, os epibranchiale I; o-eb-II, os epibranchiale II; o-eb-III, os epibranchiale III; o-eb-IV, os epibranchiale IV; o-hb-I, os hypobranchiale I; o-hb-II, os hypobranchiale II; o-ipbIII, os infrapharyngobranchialeIII; o-ipb-IV, os infrapharyngobranchiale IV; prc-un, processus uncinatus; su-phtpl, superior pharyngeal tooth plate. 


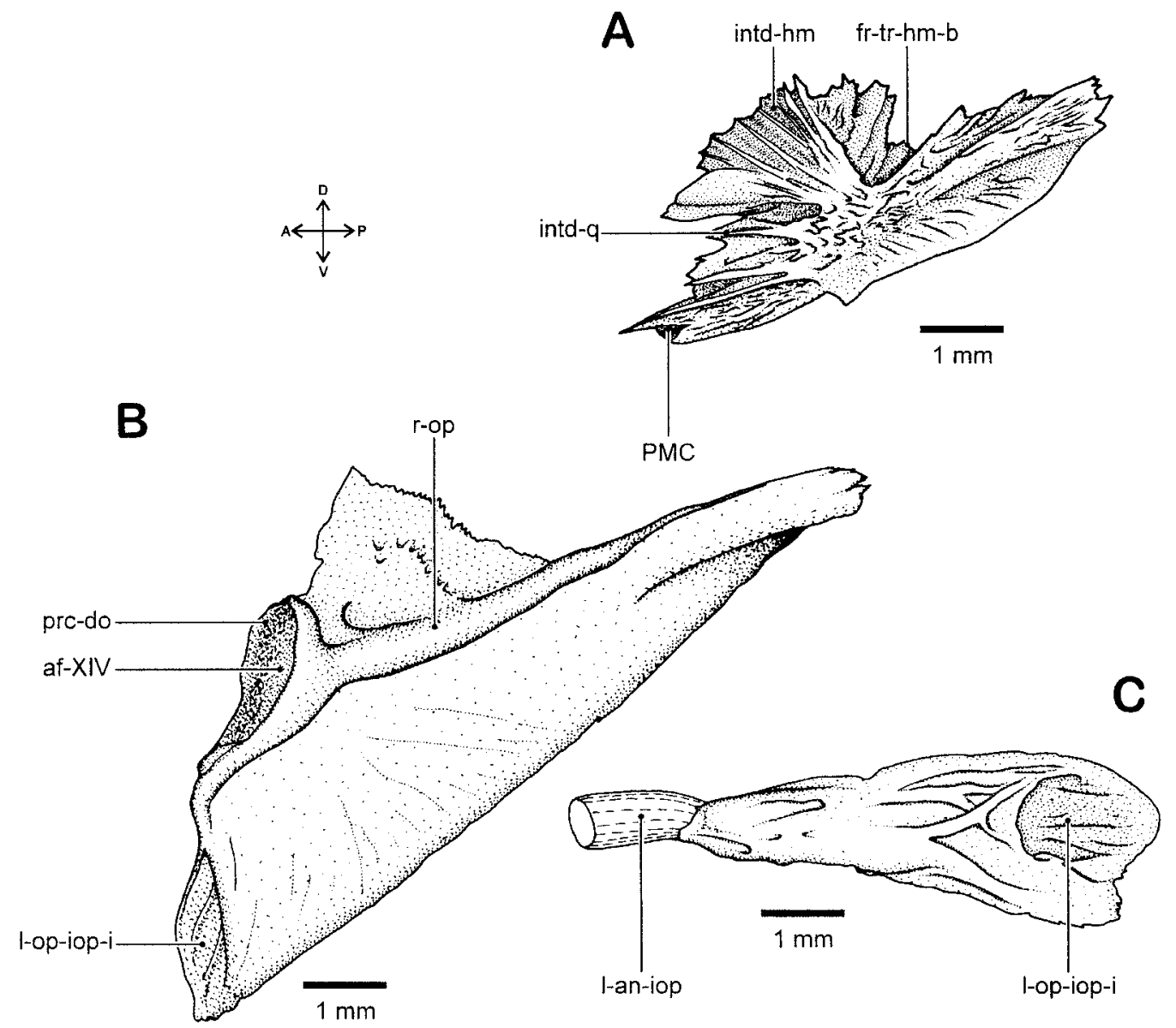

Fig. 24. Opercular bones of juvenile Clarias gariepinus. A, preopercular bone, lateral view $(125.5 \mathrm{~mm} \mathrm{SL}$ stage); B, opercular bone, medial view (174.5 mm SL stage); C, interopercular bone, medial view $(174.5 \mathrm{~mm}$ $\mathrm{SL}$ stage). af-XIV, articulatory facet of the os operculare with the os hyomandibulare; fr-tr-hm-b, border of the

passage of the hypobranchial artery, which runs anteriorly and enters the parurohyal bone dorsally, in Trichomycterus areolatus and N oturus flavus (I ctaluridae). It then penetrates the bone, leaving it ventrally. In T. areolatus, the artery runs anteriorly, splitting into three branches at the anterior margin of the hypohyals. In N. flavus, however, the artery splits into two, immediately after it leaves the parurohyal (Arratia and Schultze, '90: Fig. 19). Each branch then gives off a lateral branch at the anterior margin of the hypohyals. Thesituation in Clarias gariepinus seems to differ even more (Fig. 13): a ventral branch of the ventral aorta runs to foramen truncus hyomandibularis nervus facialis; intd$\mathrm{hm}$, interdigitation with the os hyomandibulare; intd-q interdigitation with the os quadratum; I -an-iop, Iigamentum angulo-interoperculare; PMC, preoperculo-mandibulare canal; prc-do, processus dorsalis; r-op, insertion ridge on the os operculare for the $\mathrm{m}$. levator operculi.

the dorsal face of the parurohyal bone and penetrates it through the foramen. Ventrally, it immediately spl its off two branches, as in N. flavus, but they run posteriorly, instead of anteri orly. The terminol ogy "hypobranchial artery" is not adopted in the present study, as it appears that the artery penetrating the parurohyal is not homologous with the hypobranchial artery observed in other tel eosts. In tel eosts, the hypobranchial artery always splits off from an efferent branchial artery, in most cases the second one (Bertin, '58; Goodrich, '58). In C. gariepinus, the hypobranchial artery splits off from the fourth efferent branchial artery 
(Nawar, '55). As this is not the case for the artery penetrating the parurohyal bone in C. gariepinus, it cannot be referred to as the hypobranchial artery. Consequently, theterm "arteria parurohyal is" is applied.

The absence of the subopercular bone is a synapomorphic feature of Siluriformes (Gosline, '73; Fink and Fink, '81, '96). This is also the case for Clarias gariepinus, where none of the ontogenetic stages reveal ed the presence of any subopercular primordium. Surprisingly, a "small, rudimentary suboperculum" was observed in Plotosius canius (Plotosidae) and Osteogeni osus militaris (Ariidae) (Bhimachar, '33).

\section{Sequences in boneformation as response to functional demands}

The sequences in bone formation appear to be related to functional demands that arise in developing larvae and juveniles. These demands tend to vary to a large extent during the transformation from larva to adult, with several vulnerable moments at which the functional demands, and structural adaptations to support these demands, differ only very little (Galis et al., '94).

The initiation of cranial ossification during ontogeny in teleost fish is coupled to respiratory and feeding requirements. In Clarias gariepinus, the opercular bone is the first one to appear (4.1 $\mathrm{mm} \mathrm{SL}$ ), supporting the opercular skin fold (Fig. 25). Opercular ossification starts at the articular facet of the opercular process of the hyosymplecticum, as could be observed in other teleosts (Verraes, '73; Huysseune, '85). From there on, the bone becomes a posteriorly extended rod, bearing a ventral plate (Fig. 2B). Myological data indicate that some of the muscles acting on the opercular bone arise between 5.2 and $6.8 \mathrm{~mm} \mathrm{SL}$. Although the adductor and levator operculi are present at that stage, it is only the levator muscle that already inserts onto the opercular bone (Adriaens and Verraes, '97b). However, prior to a possible muscular displacement of the opercular bone, the opercular skin fold is displaced by active respiratory movements, which al ready seem to occur at the $5.2 \mathrm{~mm}$ SL stage(Surlemont et al., '89). At this stage, opening and closing of the mouth is observed, coupled to ad- and abduction of the cheek region. A similar correlation between the onset of opercular ossification and the initiation of active respiratory movements was observed in Galeichthys fel iceps (Siluriformes, Ariidae) (Tilney and Hecht, '93), Ca- tostomus commersoni (Cypriniformes, Catostomidae) (McEIman and Balon, '80) and Gadus morhua (Gadiformes, Gadidae) (H unt von Herbing et al., '96a). In Poecilia reticuIata (Cyprinodontiformes, Poeciliidae) ossification al ready starts whilethe larva still lies within the egg membrane. Although no true active respiration, by means of gills, is performed, respiratory movements were already observed (Weisel, '67). It appears that the alternating mechanical load onto the opercular skin fold, early during ontogeny, may be related to the early ossification of the opercular bone, prior to mechanical load exerted by muscular contraction of the opercular muscles (Herring, '93). The formation of a substantial, horizontal rod in the opercular bone in C. gariepinus may well be related to the insertion of the levator operculi, as in the adult situation, this rod corresponds to the levator operculi crest (Fig. 24B) (Adriaens and Verraes, '97b).

Other ossifications related to the onset of respiratory movements are the branchiostegal rays, as they support the branchiostegal membrane in a similar way as the opercular bone supports the opercular skin fold (Fig. 25). The initiation of branchiostegal ray ossification generally follows that of the opercular bone rather rapidly, e.g., in Clarias gariepinus, Heterobranchus longifilis (Vandewalle et al., '97), Gal eichthys feliceps (Tilney and Hecht, '93), Chrysichthys auratus (Vandewalle et al., '95), Barbus barbus (Vandewalle et al., '92), Danio rerio (Cubbageand Mabee, '96), Catostomus macroche'Ius (Weisel, '67), Oncorhynchus mykiss (Verraes, '73), Poecilia reticulata (Weisel, '67), Oryzias latipes (Langille and Hall, '87). In Gadus morhua, however, a time lapse is present between the two ossifications (Hunt von Herbing et al., '96a). The gradually adding of branchiostegal rays consequently covers the support of the gradually increasing branchiostegal membrane. The early differentiation of a dorsal process of the opercular bone in C. gariepinus seems to be related to theinsertion of the dilatator operculi muscle. At $7.2 \mathrm{~mm} \mathrm{SL}$ the insertion of a very indistinct tendon of the dilatator onto the opercular bone was overlooked in a previous study (Adriaens and Verraes, '97b), as in the serial sections, the tendon appeared to be the anterior ossification of the opercular bone.

Early ossifications involve most, but not all, dentulous bones. In Clarias gariepinus the premaxilaries, dental bones, and upper 


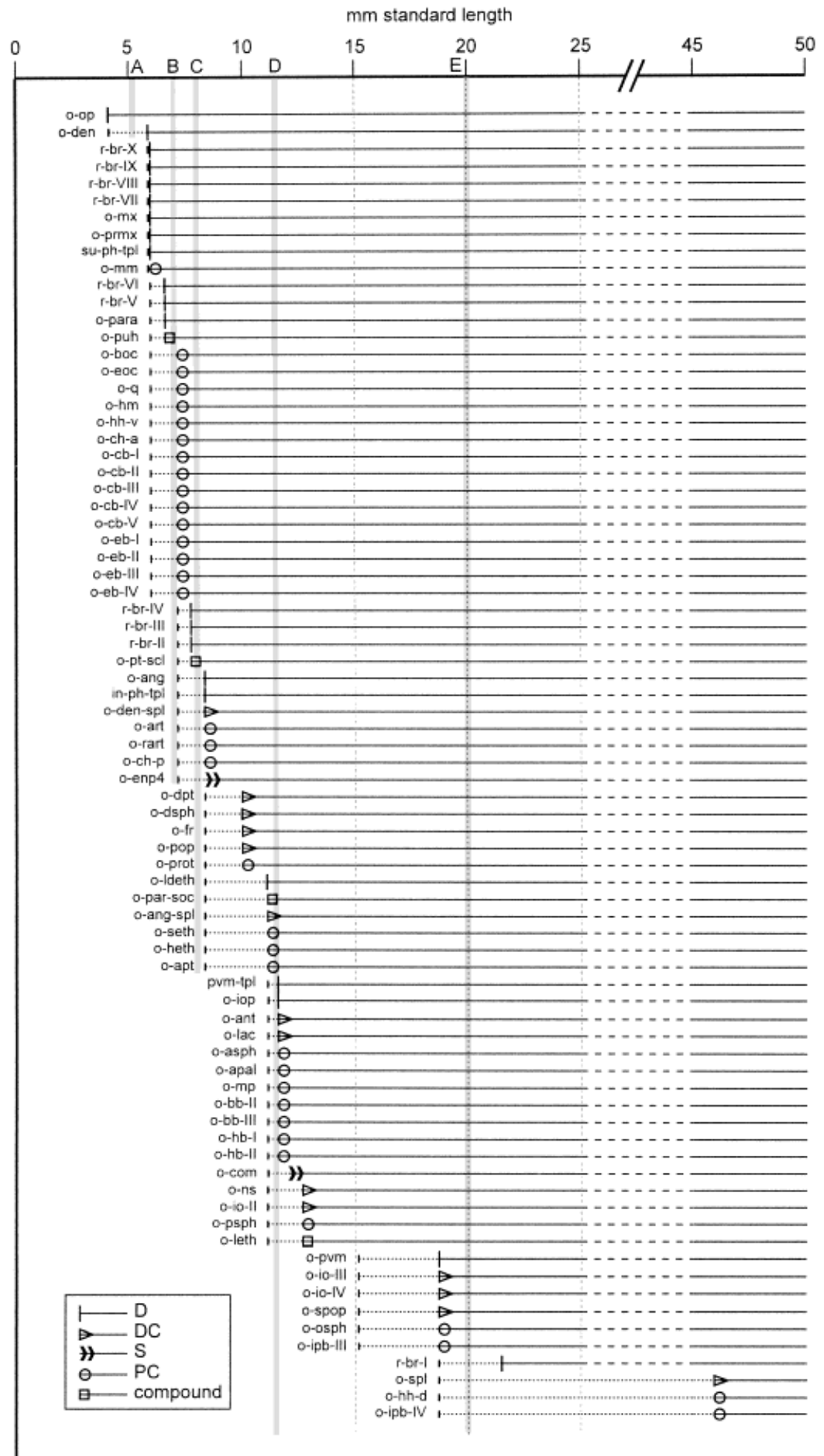

Figure 25 
pharyngeal tooth plates are present from the $6.0 \mathrm{~mm} \mathrm{SL}$ stage on, whereas the initiation of tooth formation could al ready be observed in the $5.6 \mathrm{~mm} \mathrm{SL}$ specimen. The other toothed bones, the lower pharyngeal and prevomeral tooth plates, arise at the 8.4 $\mathrm{mm}$ and $11.6 \mathrm{~mm} \mathrm{SL}$ stage, respectively (Table 2, Fig. 25). Mandibular el evation occurs from the $5.2 \mathrm{~mm} \mathrm{SL}$ stage on, as a well-developed adductor mandibulae becomes functional (Surlemont et al., '89; Adriaens and Verraes, '96). At the transition from endogenous to exogenous feeding, at $7 \mathrm{~mm} \mathrm{SL}$, most tooth-bearing bones are thus present. A rapid increase in food uptake occurs in the first few days of exogenous feeding, whereas once the feeding process has stabilized, the gastric content remains fairly constant (close to $21 \%$ of the body weight) (Haylor, '93). Early ossification of the dentate bones could also be found in the closely related Heterobranchus Iongifilis (Vandewalle et al., '97). In Chrysichthys auratus, the dentary appears prior to the premaxillaries and pharyngeal tooth plates, although its dentition arises synchronously (Vandewalle et al., '95). In Galeichthys feliceps the dentaries also appear earlier than the premaxillaries (13.9 $\mathrm{mm}$ and $18.8 \mathrm{~mm}$ $\mathrm{TL}$, respectively) (Tilney and Hecht, '93). In cypriniform fishes, which lack any dentition on either the dentary or premaxillary (homoplastic feature of Gonorhynchiformes and Cypriniformes [Fink and Fink, '81, '96; Taverne, pers. comm.]) the lower pharyngeal jaw, which is dentate, appears as one of the first ossifications, e.g., Danio rerio (Cubbage and Mabee, '96), or at least prior to the premaxillaries, e.g., Barbus barbus (Vandewalle et al., '92), Catostomus macrocheilus (Weisel, '67) and C. commersoni (McEIman and Bal on, '80). This shift in sequence is an additional support for the supposition that the sequence of cranial ossification is a reac-

Fig. 25. Chronological initiation of cranial ossifications and certain related items (grey bars) in Clarias gariepinus. Because of the doubtful and late initiation of the epiotic bone, it has not been added to the figure. A, mouth and opercular movements; B, transition from endogenous to exogenous feeding; $\mathbf{C}$, cannibal ism type I starts; D, four bar-system and digestive system become functional; $\mathbf{E}$, onset of air-breathing (first marker indicates the stage at which no ossification is observed; the second marker indicates the presence, as well as the type of ossification). D, dermal, anamestic bone; DC dermal canal bone; PC, perichondral bone; S, sesamoid bone, compound, compound bone. tion to accommodate the arising functional demands for the active uptake and manipulation of food (Vandewalle et al., '94). Additionally, it was observed in Lates calcarifer (Centropomidae, Perciformes) that dentate bones appeared only after a whole set of toothless bones (both dermal and perichondral), which seemed to be rel ated to a shift in feeding method as a response to prey size alteration during growth. I nitially, bones re lated to suction feeding appear, followed by dentulous bones at the moment prey grasping is performed (Kohno et al., '96a). In Chanos chanos (Chanidae, Gonorhynchiformes) dentition was not observed, even 150 hours after mouth opening, at which feeding appeared not to be of the suction/grasping type, but rather of the "straining" type (Kohno et al., '96b). It is believed that the morphogenesis of certain bones is, in a way, influenced by the presence or absence of teeth (Huysseune, '89). In C. gariepinus, the mentomeckelian bone is the first perichondral bone to appear (Fig. 25). Presumably, it may assist in reinforcing the dentary plate to the cartilaginous lower jaw, in order to be able to resist pressure forces more adequately.

The transition from en dogenous feeding to exogenous feeding implies that solid food particles have to be taken in and consequently transported from the oro-branchial cavity into the esophagus. Along their course, these particles pass along the hypophyseal fenestra, which is very large in platybasic skulls. It is thus not surprising that from that moment on, the overlying brain has to be protected more strongly from objects passing below than by the epithelial lining alone. A parasphenoid is formed, preventing possi ble damage to the brain, a little prior to the transition phase (Fig. 25). The supportive role of the parasphenoid, as observed in salmonids (Verraes, '74), does not seem to be as critical as could be supposed at this moment, as the trabecular bars are still intact. The resorption of the middle part of these trabecular bars occurs at $11.6 \mathrm{~mm} \mathrm{SL}$. At that stage, the parasphenoid has become broader at its lateral wings, thus interconnecting the interrupted bars. However, its role in supporting the central axis of the skull, together with the basioccipital, may not be ruled out completely (Weisel, '67). Early ossification of the parasphenoid is a general feature in tel eost fish, but when comparing its appearance in relation to the standard length, it is present in clariid species much earlier than, 
e.g., in some silurids (Kobayakawa, '92) and cyprinids (Vandewalle et al., '92). However, in some cases the parasphenoid develops even earlier, at lower standard length values (e.g., some Cyprinodontiformes) (Weisel, '67; Langille and Hall, '87). Surprisingly, in the guppy, Poecilia reticulata, the parasphenoid and several other bones are present long before hatchingstarts, and consequently long before active food uptake (Weisel, '67), whereas in the cyprinodont Oryzias latipes, the parasphenoid is formed a little prior to hatching (Langille and Hall, '87).

Exogenous feeding also requires a functional apparatus, which enables active uptake of food particles. The sternohyoideus muscle is found to insert onto the hyoid bar at the $6.8 \mathrm{~mm} \mathrm{SL}$ stage (Surlemont and Vandewalle, '91). The paired, sesamoid parts of the parurohyal bone already can be observed a little earlier (6.6 mm SL). This ossification of thetendons of the sternohyoid is an adaptation to mechanical stress resistance, indicating a possible activity of that muscle. As this is the case (Surlemont and Vandewalle, '91), a functional mouth opening mechanism is present from this stage on: contraction of the sternohyoideus results in the depression of the hyoid bar, which is coupled to the depression of the lower jaw through the protractor hyoi dei muscleand/or the ligament between the lower jaw and the hyoid bar (Osse, '69; Winterbottom, '74; Verraes, '77; Lauder, '80; Lauder and Liem, '80; Aerts, '91).

Once the primary functional demands are dealt with, the overall skull must become reinforced as it gradually becomes larger. Quite simultaneously, a whole set of perichondral bones are formed, which enable such a reinforcement (Fig. 25). These ossifications include both neurocranial elements, as well as splanchnocranial parts. The first neurocranial ones involve the reinforcement of the attachment of the skull to the notochord (basi- and exoccipital bones). Suspensorial ossifications appear at articular facets, which al ready have become functional: the quadrate for the mandibular articulation and the hyomandibula for neurocranial and the opercular articulation. All these articulations become increasingly important in feeding and respiratory movements. The ossification of the ventral hypohyal may be related to the ligamentous insertion, which connects the hyoid bar to the parurohyal, as well as the protective role of that bone for the hyoid artery (Verraes, '75). As mentioned, tension forces are already exerted onto this ligament from the $6.8 \mathrm{~mm} \mathrm{SL}$ on: a reinforcement may thus be required. The anterior ceratohyal ossification may have a supportive function for the elongated cartilaginous hyoid bar, especially at the insertion site of muscles, which are already present and inserting onto it (Adriaens and Verraes, '97d). It may also support the increasing number of articulating branchiostegal rays. A similar relation has been observed in other teleosts (Verraes, '75). The same can be suggested for thelong branchial skeletal elements: the cerato- and epibranchials. An asynchrony in epibranchial ossification in Heterobranchus longifilis is related to the formation of a suprabranchial organ (Vandewalle et al., '97). Such an asynchrony does not occur in Clarias gariepinus, which indicates that it may be absent or that it is spread over a much shorter time span.

Apart from overall reinforcement, the perichondral ossification of the above noted structures may also be coupled to a change in feeding behavior. It has been observed that Clarias gariepinus performs cannibalism extensively. Two types of cannibalistic behavior can be distinguished, based on body length and the way prey items are swallowed (Hecht and Appelbaum, '87). Type I cannibalism starts at $8 \mathrm{~mm}$ total length (corresponds to about $7.5 \mathrm{~mm} \mathrm{SL}$ ) until 45 $\mathrm{mm} \mathrm{TL}$, and is characterized by capturing the prey by the tail, swallowing it up to the head, followed by biting off of the head. This implies that large forces have to be produced by the adductor mandibulae complex, and consequently that a high mechanical stress is exerted onto the jaws. A well-developed adductor mandibulae complex is present at $7.2 \mathrm{~mm} \mathrm{SL}$ (Adriaens and Verraes, '96). The ossification of the quadrate may thus be an adaptation to resist large pressure forces during biting.

Once exogenous feeding has become obligatory and cannibalism has started, mouth opening al so becomes more and more important. The mouth-opening mechanism, noted earlier, involves the retraction of the hyoid bar through the contraction of the sternohyoideus. This muscle interconnects the hyoid bar with the pectoral girdle, at the level of the cleithral bone. During contraction of the sternohyoideus, the cleithrum is held in position, or even retracted through the hypaxials (Osse, '69; Lauder, '80; Lauder and Liem, 
'80; Muller, '87). Fixation of the cleithral bonetotheneurocranium, through an articulation, can be advantageous for this kind of mechanism. The formation of the posttemporo-supracleithral bone can consequently assist in the reinforcement of the hyoid mouth opening mechanism.

The gradual strengthening of the mandibular articulation follows the onset of the cannibalistic behavior (Fig. 25). Rather simultaneously, the angular, articular, and retroarticular bones are formed. The articular facet of the initial bony mandibula is thus reinforced in order to withstand the increasing pressure during biting off catfish heads. The transport of catfish bodies, however, is also improved, as the lower pharyngeal tooth plate is present. As the muscles acting onto them are present, both pharyngeal jaws can now become functional. This plays a crucial role in food fragmentation and transport from the orobranchial chamber into the esophagus (Vandewalle et al., '94). This transport al so requires a subsequent suction activity, in which the hyoid bar plays an important role (Liem, '90; Aerts, '91). The posterior ossification of the hyoid bar consequently contributes to its additional reinforcement, especially for the attachment of ligaments (ligamentum angulo-ceratohyale and ligamentum hyomandibulo-ceratohyale).

The ossification of the entopterygoid bone in Clarias gariepinus, and perhaps other siluriform fish, may be related to increasing tensions that are exerted onto the ligament, interconnecting the suspensorium with the ethmoid region. As is proposed by Arratia ('92), this entopterygoid is of sesamoid origin, being the ossification of the middle part of the formerly mentioned ligament. Mineralization is presumably induced by mechanical stress, whereas bone formation is induced at sites that experience an alternating mechanical load, e.g., bending, pressure, tension, torsion (Herring, '93). The increasing use of mouth opening and mouth closure, as well as orobranchial expansions for feeding and respiratory purposes, will increasingly load the suspensorium. Powerful biting will exert forces onto the suspensorium in an anteroposterior direction. As the articular facet of the suspensorium with the neurocranium is not yet secured, this ligament may contribute in restraining the suspensorium from being pulled backward, especially since in Siluriformes, in general, the direct connec- tion between suspensorium and the ethmoid region, through the pal atine, is absent (Alexander, '65; Gosline, '75; Fink and Fink, '81, '96; Arratia, '92). However, in most other teleosts, the entopterygoid appears prior to the metapterygoid (Weisel, '67; Verraes, '73; Vandewalle et al., '92; Cubbage and Mabee, '96), although it is considered not to be of sesamoid origin (Arratia, '92).

The following bones that are formed involve canal bones of the skull roof. A little earlier, canal bones of the mandibular sensory canal were already formed, possibly coupled to the early ossification of the other mandibular bones. Apparently, theskull roof bones arise in cl ose contact with the underlying cartilaginous skull, although they are of dermal origin (cfr. "parachondral bone") (Verraes, '74; Verraes and I smail, '80). I nitially, the chondrocranium becomes bordered, almost al ong its whole length: the frontal bone in the orbito-temporal region, followed by the dermosphenotic, and eventually the dermopterotic, which closes up the space between the dermosphenotic and the posttemporo-supradeithral bone. Consequently, the main sensory canal is completely enclosed and protected. Such a close synchrony be tween the ossification of these bones is found in many other teleosts (Kobayakawa, '92; Vandewalle et al., '92, '95; Cubbage and Mabbe, '96; Vandewalle et al., '97). In Oncorhynchus mykiss, the frontal appears well in front of the dermosphenotic and dermopterotic bones (Verraes, '73). The preopercular part of the preoperculo-mandibular canal is also protected at that moment, as the preopercular bone encl oses it.

Shortly after, two unpaired, bony complexes areformed, covering the left and right sides of the chondrocranium in the ethmoid region and the occipital region, respectively. In that way, the paired bones formed before are now closed off anteriorly and posteriorly by the mesethmoid and the parieto-supraoccipital bones, respectively. Again, the dermal parts of these bones arise in close contact with the cartilage, which has become perichondrally ossified. At this moment, all skull roof bones are present, and from here on, they can start enlarging medially and laterally to close off the still unprotected part of the brain. Additionally, the increased contraction load on the insertion sites of several muscles onto these bones, must play an important role (e.g., levator arcus palatini, dilatator operculi, levator operculi). 
The devel opment of the prevomeral tooth plate coincides with the formation of the opercular four bar-system, which is formed at $11.1 \mathrm{~mm} \mathrm{SL}$. This bar-system plays a crucial role in mouth opening in many adult tel eosts (Liem, '70; Aerts and Verraes, '84; Verraes, '77; Westneat, '90). A possible functional relation between an improved mouth opening for food uptake and the ossification of additional tooth plates is supported by the fact that at about this length (11.5 mm SL) the digestive system becomes completely functional (Fig. 25) (Verreth and Van Tongeren, '89; Haylor, '95). This allows improvement of the carnivorous behavior of Clarias gariepinus, as is demonstrated by the already ongoing cannibalism (at $8 \mathrm{~mm} T L$ ) (Hecht and Appel baum, '87). The increase in prey size involves, apart from an improved mouth opening, an elevated load onto several elements like the lower jaw, and the suspensorial and branchial elements. Increased tension on the tendon of the adductor mandibulae onto the lower jaw can be related to the induction of its ossification at that stage, i.e., the coronomeckelium. The suspensorium and the branchial basket elements enableorobranchial expansion, as well as aid in prey transportation to the pharyngeal jaws. Reinforcement of the pterygoid process, at the level where the ligament running to the ethmoid region is attached, also occurs through ossification of the metapterygoid. Manipulation of larger prey requires that larger forces be exerted by those elements that enable orobranchial transport. I ncreased muscular activity onto the branchial floor may be related to ossification of the basibranchials and hypobranchials at the level where muscles insert onto them.

The active hunting behavior of Clarias gariepinus, although it is also able to perform filter feeding (Groenewald, '64; Teugels, '86), involves the use of well-devel oped barbels for prey location, as well as for sampling of potential food (Alexander, '65, '66; Gosline, '73). Although the muscular control of most of these barbels is restricted (Ghiot, '78; Adriaens and Verraes, '97d), the maxillary barbel can be moved extensively, due to the palatine-maxillary mechanism (Alexander, '65; Gosline, '75; Adriaens and Verraes, '97a). In C. gariepinus, the maxillary barbel is rather large (up to $174 \%$ head length [Teugels, '86]). The protraction and retraction of it will experience a substantial drag. This implies that forces, needed for movements of the barbel, will have to increase correspondingly, which involves increasing load onto the skeletal elements of the palatine-maxillary mechanism. Themaxillary bone, encl osing the base of the barbel, bears two well-developed articular facets, for articulation with the anterior tip of the palatine (Adriaens and Verraes, '97a). The palatine itself becomes rod-like, articulating medially with the ethmoid region (at the level of the orbito-nasal lamina). Posterior to this articulation, the extensor tentaculi muscle connects the palatine to theneurocranium. It can thus be expected that autopalatine ossification provides: (1) a reinforced insertion site for the extensor tentaculi muscle, and (2) support for therigidity of the palatine, in order to withstand bending forces, which would inactivate movement of the barbel in a rotating type of palatine maxillary mechanism.

The last sensory canal to become encl osed and protected by bones is the infraorbital canal, as the antorbital and lacrimal bones are present at $11.6 \mathrm{~mm} \mathrm{SL}$. Late development of these bones is probably related to the late devel opment of the infraorbital canal itself, in relation to the other canals, as occurs in other ostariophysan fishes (Le kander, '49). However, very early ossification of the antorbital was observed in Galeichthys fel is (Siluriformes, Ariidae) (Bamford, '48). Possibly, the infraorbital canal is more protected between the eye and the mandibula than are the other canals. Ossification of infraorbital canal bones proceeds anterocaudally. In other ostariophysans, the antorbital bone develops earlier than the infraorbitals, which seems to be the case in Clarias gariepinus as well, although not so distinct (Lekander, '49). In relation to the supraorbital canal, the nasal bone is thelast to devel op (Adriaens et al., '97). The remaining exposed part of the preopercul omandibular sensory canal also becomes enclosed, as the suprapreopercular bone arises between the preopercular and the pterotic bones.

As the chondrocranium enlarges, the unossified space of the orbito-temporal region of theskull floor expands. Fortification through ossification may consequently becomenecessary, as is demonstrated by the development of the pterosphenoids, the lateral ethmoids, and later, the orbitosphenoids. Additional bridge formation between the pterosphenoid and parasphenoid contributes to reinforce- 
ment of the sphenoid fenestra, which consequently becomes subdivided into two. Such a reinforcement is present in most catfish, as mentioned above. Important to mention is that in the siluriform chondrocranium, the commissura lateralis, which forms the lateral wall of the trigemino-facial chamber and subdivides the sphenoid fenestra, is absent (de Beer, '37; Daget, '64; Alexander, '65). The absence of such a support between the skull roof and skull floor is compensated by this secondary, but bony, bridge.

The late ossifications of the third and fourth infrapharyngobranchials can be coupled to the increasing load exerted onto these elements. They play a crucial role in the support of the upper pharyngeal jaws. Additionally, muscles needed for manipulation of these jaws insert onto them. Ossification of the dorsal hypohyal does not seem to have any direct mechanical induction, as no muscles or ligaments insert onto it. Late ossification may be related to the absence of a basihyal in siluriform fishes (Arratia and Schultze, '90).

Formation of the last canal bones, the splenials, is presumably related to the increasing length of an unprotected part of the preoperculomandibar canal, with increasing body length. At $46.8 \mathrm{~mm} \mathrm{SL}$, one of these bones could be found, whereas the number reached three in larger specimens. In that way, the sensory canal becomes encl osed and protected in a manner that still allows flexibility at that point, close to the mandibular joint.

Once the essential ossifications are present, the increasing mechanical load onto the body parts, as body length and consequently also muscle size, contraction strength, prey size, etc., increase, can be supported by thickening of the bones. In juveniles, the bones become rather thick through spongy bone formation. The interdigitation becomes extremely complex, reinforcing the connection between separate bones. The skull roof becomes gradually closed off completely, as a decrease of fontanella size has been observed in larger specimens. A splendid example of additional reinforcement against mechanical load is the locking device of the suspensorium. Most ostariophysans, i.e., Characiformes, Siluriformes and Gymnotiformes, have an articular ridge, instead of two articular condyles, for articulation with the neurocranium (Arratia, '92). Two articular condyles are believed to withstand re and protraction forces to a greater extent (Barel, pers. comm.; Adriaens and Verraes, '77b). In Clarias gariepinus, however, the articular ridge is reinforced through the formation of interdigitations between the hyomandibular bone and the neurocranial bones, thus allowing lateral swinging of the suspensorium during respiration and feeding (Adriaens and Verraes, '77b) but simultaneously prohibiting anteroposterior displacement during biting. An even more extremeinterdigitation can be found in some anguilliform clariids, which also possess an enormous adductor mandibulae compl ex (Cabuy, pers. comm.).

\section{Variation in ossification sequence a result} of variation in functional demand?

In their work, Mabee and Trendler ('96) extensively described the ossification sequence of Betta splendens (Belontiidae), which they compared with data from literature of Oryzias latipes and Barbus barbus. It appeared that the ossification sequence in tel eosts comprises sequences that are conserved during evolution, whereas other sequences have altered. Consequently, different conserved sequence pairs, meaning a fixed sequence of two bones within all the tel eosts studied, were present. As they mentioned that ossification sequence statistics do not reflect a strict taxonomic coherence, other factors must be responsible. One of the possible determinants of ossification sequence can be the difference in functional demands of the different taxa. Differences in early life histories of fish, reflected, for example, by the difference in feeding type and food type, can play an inductive role in the differentiation of a certain set of bones (Kohno et al., '96a,b). For suction feeding fish, other bones will of importance during initial feeding than for those performing suction-grasping feeding. Mechanical load will act on different bones if feeding involves oral manipulation, when compared with feeding by pharyngeal jaw manipulation. Undoubtedly, the ossification sequence has a genetic basis. However, this basis is subjected to interspecific, as well as intraspecific variation (Mabee and Trendler, '96). Intraspecific variation can in turn be seen as a response to intraspecific variation in functional demands of devel oping larvae.

Toconclude, some suggestions can be made concerning the relation of ossification sequence and the presence of certain functional demands. It seems clear that early 
ossifications can be related to primordial respiration, as well as the formation of a primordial feeding apparatus during the transition phase from endogenous to exogenous feeding. As larvae grow, the overall mechanical load, related to skull support, muscle insertion, prey size, etc., will also increase. Such demands are coped with in the growing Clarias gariepinus larvae as fortifications arise, especially at the level of articulations related to the feeding apparatus. Protection of the brain from the outside initiates at the skull floor, prior to a dorsal protection, which may be related to initial food transport. Protection of the brain roof follows enclosure of the cranial lateral line system of the skull roof. Optimization of mouth opening coincides with completion of devel opment of digestive system functionality. Prey capture is also improved at this stage, as the prevomeral tooth plates are formed. Prey detection is improved, due to ossification of the palatine-maxillary mechanism.

\section{ACKNOWLEDGMENTS}

We thank Prof. Dr. F. Ollevier and Dr. F. Volckaert of the Laboratory of Ecology and Aquaculture (Catholic University of Leuven) and Mr. Fleure (Someren, the Netherlands) for providing the specimens of Clarias gariepinus. We are most grateful to $\mathrm{Dr}$. L. Taverne, for his constructive remarks on this manuscript. Also, we thank D. Vandenbroeck and G. De Wever for making the serial sections of C. gariepinus. Research was funded in part by the Institute for Science and Technology (D. Adriaens) and the National Funds for Scientific Research (W. Verraes)

\section{LITERATURE CITED}

Adriaens, D., and W. Verraes (1994) On the functional significance of the loss of the interhyal during ontogeny in Clarias gariepinus Burchell, 1822 (Teleostei: Siluroidei). Belg. J Zool. 124:139-155.

Adriaens, D., and W. Verraes (1996) Ontogeny of cranial musculature in Clarias gariepinus (Siluroidei: Clariidae): The adductor mandibulae complex. J . Morphol . 229:255-269.

Adriaens, D., and W. Verraes (1997a) Ontogeny of the maxillary barbel muscles in Clarias gariepinus (SiIuroidei: Clariidae), with some notes on the palatinemaxillary mechanism. J . Zool. (Lond.) 241:117-133.

Adriaens, D., and W. Verraes (1997b) Ontogeny of the suspensorial and opercular muscles in Clarias gariepinus (Siluriformes: Clariidae), and the consequences for respiratory movements. Neth. J . Zool. 47:1-29.

Adriaens, D., and W. Verraes (1997c) Ontogeny of the chondrocranium in Clarias gariepinus (Siluriformes: Clariidae): trends in siluroids. J. Fish Biol. 50:12211257.
Adriaens, D., and W. Verraes (1997d) Ontogeny of the hyoid and musculature in Clarias gariepinus, an African catfish (Burchell, 1822) Siluroidel: Clariidae). Zool . J. Linn. Soc 120:105-128.

Adriaens, D., W. Verraes, and L. Taverne (1997) The cranial lateral-line system in Clarias gariepinus (Burchell, 1822) Siluroidei: Clariidae): morphology and development of canal related bones. European J. Morphol. 35:1-28.

Aerts, P. (1991) Hyoid morphology and movements relative to abducting forces during feeding in Astatotilapia el egans (Tel eostei: Cichlidae). J . Morphol. 208:323345.

Aerts, P., and W. Verraes (1984) Theoretical analysis of a planar bar system in the teleostean skull: the use of mathematics in biomechanics. Annls. Soc. r. Zool. Belg 114:273-290.

Alexander, R. McN. (1965) Structure and function in catfish.J . Zool. (Lond.) 148:88-152.

Alexander, R. McN. (1966) The functions of the protrusible upper jaws of two species of cyprinid fish. J . Zool. (Lond.) 149:288-296.

Arratia, G. (1987) Description of the primitive family Diplomystidae (Siluriformes, Teleostei, Pisces): morphology, taxonomy and phylogenetic implications. Bonn. Zool. Monogr. 24:1-120.

Arratia, G. (1990) Development and diversity of the suspensorium of trichomycterids and comparison with Ioricarioids Teleostei: Siluriformes). J . Morphol. 205: 193-218.

Arratia, G. (1992) Development and variation of the suspensorium of primitive catfishes (Tel eostei: Ostariophysi) and their phylogenetic relationships. Bonn. Zool. Monogr. 32:1-148.

Arratia, G., and H.-P. Schultze (1990) The urohyal: development and homology within osteichthyans. J . Morphol. 203:247-282.

Arratia, G., and H.-P. Schultze (1991) Palatoquadrate and its ossifications: development and homology within osteichthyans. J . Morphol. 208:1-8.

Arratia, G., and M. Gayet (1995) Sensory canals and related bones of tertiary siluriform crania from Bolivia and North America and comparison with recent forms. J . Vert. Pal. 15:482-505.

Arratia, G., and L. Huaquin (1995) Morphology of the lateral line system and of the skin of diplomystid and certain primitive loricarioid catfishes and systematic and ecological considerations. Bonn. Zool. Monogr. 36:5-109.

Bamford, B.T.W. (1948) Cranial devel opment of Galeichthys felis (Ariidae). Proc. Zool. Soc. (Lond.), 118:364391.

Bertin, L. (1958) Appareil circulatoire. In P. Grassé (Ed.): Agnathes et Poissons, Anatomie, Éthologie, Systématique. Traité de Zoologie. Paris 13(2):1399-1458.

Bhimachar, B.S. (1933) On the morphology of the skull of certain Indian catfishes. J . Mysore Univ. 7:1-35.

Brown, B.A., and C.J . Ferraris, J r. (1988) Comparative osteology of the Asian catfish family Chacidae, with the description of a new species from Burma. Am Mus. Nov. 2907:1-16.

Burchell, W. (1822). Travels in the interior of Southern Africa. Volume I. London: The Batchworth Press.

Chardon, M. (1967) Reconnaissance d'un groupe nature de six families de Siluriformes Sud-Américains grace a l'étude anatomique de l'appareil de Weber au sens large. Ann. Soc. r. Zool. Belg. 97:35-58.

Chen, X., and J.G. Lundberg (1995) Xiurenbagrus, a new genus of amblycipitid catfishes (Teleostei: Siluriformes), and phylogenetic relationships among the genera of Amblicipitidae. Copeia 4:780-800. 
Cubbage, C.C., and P.M. Mabee (1996) Development of the cranium and paired fins in the zebrafish Danio rerio (Ostariophysi, Cyprinidae). J . Morphol . 229:121160.

Daget, J . (1964) Le crâne des Téléostéens. Mém. Mus. Natn. Hist. Nat. serieA 31:163-341.

de Beer, G.R. (1937) The Devel opment of the Vertebrate Skull. Oxford: Clarendon Press.

de Pinna, M.C.C. (1988) A new genus of trichomycterid catfish (Siluroidei, Glanapteryginae), with comments on its phylogenetic relationships. Rev. Suisse Zool. 95:113-128.

de Pinna, M.C.C., and R.P. Vari (1995) Monophyly and phylogenetic diagnosis of the family Cetopsidae, with synonymization of the Helogeneidae (Tel eostei: Siluriformes). Smiths Contr. Zool. 571:1-26.

Ferraris, C.J.J r. (1996) Denticetopsis, a new genus of South American whale catfish (Siluriformes: Cetopsidae, Cetopsinae), with two new species. Proc. Calif. Acad. Sci. 49:161-170.

Fink, S.V., and W.L. Fink (1981) Interrelationships of ostariophysan fishes (Teleostei). Zool. J. Linn. Soc. 72:297-353.

Fink, S.V., and W.L. Fink (1996) Interrelationships of the ostariophysan fishes (Teleostei). In M.L.J . Stiassny, L.R. Parenti and G.D. J ohnson (eds.): Interrelationships of Fishes. New York: Academic Press, pp. 209249.

Galis, F., A. Terlouw, and J .W.M. Osse (1994) The relation between morphology and behavior during ontogenetic and evolutionary changes. J . Fish Biol . 45(suppl. A):13-26.

Gauba, R.K. (1966) Studies on the osteology of Indian sisorid catfishes: II. The skull of Glyptothorax cavia. Copeia 4:802-810.

Gauba, R.K. (1970) On the cranial osteology of two Indian catfishes of the genus Laguvia. Zool. Anz. 185: 55-67.

Ghiot, F. (1978) The barbel movements of three South American pimel odid catfishes. Zool. Anz. 200:395-401. Goodrich, E.S. (1958) Studies on the Structure and Devel opment of Vertebrates, Vol. II. New York: Dover, $352 \mathrm{pp}$.

Gosline, W.A. (1973) Considerations regarding the phylogeny of cypriniform fishes, with special reference to structures associated with feeding. Copeia 4:761-776.

Gosline, W.A. (1975) The palatine-maxillary mechanism in catfishes with comments on the evolution and zoogeography of modern siluroids. Occ. Pap. Calif. Acad. Sci. 120:1-31.

Greenwood, P.H. (1956) A new species of Clariallabes (Pisces, Clariidae), from the Nile. Proc. Zool. Soc. Lond. 127:555-564.

Groenewald, A.A.v.J . (1964) Observations on the food habits of Clarias gariepinus Burchell, the South African Freswater Barbel (Pisces: Clariidae) in Transvaal. Hydrobiologia 13:287-291.

Hanken, J ., and R. Wassersug (1981) The visible skeleton. A new double-stain technique reveals the nature of the "hard" tissues. Funct. Photogr. 16:22-26.

Harrington, R.W. J r. (1955) The osteocranium of the American cyprinid fish, Notropis bifrenatus, with an annotated synonymy of teleost skull bones. Copeia 4:267-290.

Haylor, G.S. (1993) Controlled hatchery production of Clarias gariepinus (Burchell, 1822): an estimate of maximum daily feed intake of $\mathrm{C}$. gariepinus larvae. Aquaculture Fish. Manag. 24:473-482.

Haylor, G.S. (1995) Terminology for the early developmental stages of the African catfish, Clarias gariepinus (Bruchell): working definitions for aquaculture. Aquaculture Fish. Manag. 23:511-514.
Haylor, G.S., and O. Oyegunwa (1993) Onset of air breathing and development of accessory breathing organs in relation to temperature in the African catfish, Clarias gariepinus (Burchell): working definitions for aquaculture. Aquaculture Fish. Manag. 24: 253-260.

Hecht, T., and S. Appel baum (1987) Notes on the growth of Israeli sharptooth catfish (Clarias gariepinus) during the primary nursing phase. Aquaculture 63:195204.

Herring, S.W. (1993) Epigenetic and functional influences on skull growth. In J. Hanken and B.K. Hal (eds.): The Skull, Vol. 1. Devel opment. Chicago, London: University of Chicago Press, pp. 153-206.

Howes, G.J . (1983) Problems in catfish anatomy and phylogeny exemplified by the Neotropical Hypophthalmidae (Teleostei: Siluroidei). Bull. Br. Mus. nat. Hist. (Zool.) 45:1-39.

Howes, G.J ., and G.G. Teugels (1989) Observations and homology of the pterygoid bones in Corydoras paleatus and some other catfishes. J . Zool. (Lond.) 219:441456.

Howes, G.J ., and A. Fumihito (1991) Cranial anatomy and phylogeny of the South-East Asian catfish genus Belodontichthys. Bull. Br. Mus. nat. Hist. (Zool.) 57 133-160.

Hubbs, C.L., and R.R. Miller (1960) Potamarius, a new genus of ariid catfishes from the fresh waters of Middle America. Copeia 2:101-112.

Hunt von Herbing, I., T. Miyake, B.K. Hall, and R.G. Boutilier (1996a) Ontogeny of feeding and respiration in larval Atlantic cod Gadus morhua (Tel eostei, Gadiformes): I. Morphology. J . Morphol. 227:15-35.

Hunt von Herbing, I., T. Miyake, B.K. Hall, and R.G. Boutilier (1996b) Ontogeny of feeding and respiration in Iarval Atlantic cod Gadus morhua (Teleostei, Gadiformes): II. Function. J. Morphol. 227:37-50

Huysseune, A. (1985) The opercular cartilage in Astatotilapia elegans. Fortschr. Zool. 30:371-373.

Huysseune, A. (1989) Morphogenetic aspects of the pharyngeal jaws and neurocranial apophysis in postembryonic Astatotilapia el egans (Trewavas, 1933) (Tel eostei: Cichlidae). Acad. Anal. 51:11-35.

Kamler, E., M. Szlaminska, M. Kuczynski, J. Hamáckova, J . Kouril, and R. Dabrowski (1994) Temperature-induced changes of early devel opment utilization in the African catfish Clarias gariepinus. J. Fish Biol. 44:311-326.

Kindred, J. (1919) The skull of Amiurus. III. Biol. Monogr. 5:1-120.

Kobayakawa, M. (1992) Comparative morphology and development of bony elements in the head region in three species of J apanese catfishes (Silurus: Siluridae; Siluriformes). J pn. J . I chthyol. 39:25-36.

Kohno, H., R. Ordonio-Aguilar, A. Ohno, and Y. Taki (1996a) Osteol ogical development of the feeding apparatus in early stage larvae of the seabass, Lates calcarifer. I chthyol. Res. 43:1-9.

Kohno, H., R. Ordonio-Aguilar, A. Ohno, and Y. Taki (1996b) Morphological aspects and improvement in feeding ability in early stage larvae of the milkfish, Chanos chanos. I chthyol. Res. 43:133-140.

Langille, R.M., and B.K. Hall (1987) Development of the head skeleton of the $\mathrm{J}$ apanese medaka, Oryzias latipes (Tel eostei ). J . Morphol. 193:135-158.

Lauder, G.V., J r. (1980) The suction feeding mechanism in sunfishes (Lepomis): an experimental analysis. J . Exp. Biol. 88:49-72.

Lauder, G.V., J r., and K.F. Liem (1980) The feeding mechanism and cephalic myol ogy of Salvel inus fontinalis: form, function, and evolutionary significance. In 
E.K. Balon (ed.): Charrs, Salmonid Fishes of thegenus Salvelinus, The Netherlands: Dr. W. J unk.

Lekander, B. (1949) The sensory line system and the canal bones in the head of some Ostariophysi. Act. Zool. 30:1-131.

Liem, K.F. (1970) Comparative functional anatomy of the Nandidae (Pisces: Teleostei). Zool. Ser. Field Mus. Nat. Hist. 56:1-166.

Liem, K.F. (1990) Aquatic versus terrestrial feeding modes: possible impacts on the trophic ecol ogy of vertebrates. Am. Zool . 30:209-221.

Lundberg, J .G. (1975) Homologies of the upper shoulder girdle and temporal region bones in catfishes (Order Siluriformes), with comments on the skull of the Helogeneidae. Copeia 1:66-74.

Lundberg, J.G. (1982) The comparative anatomy of the toothless blindcat, Trogloglanis pattersoni Eigenmann, with a phylogenetic analysis of the ictalurid catfishes. Misc. Publ. Mus. Zool., Univ. Mich. 163:1-85.

Mabee, P.M., and T.A. Trendler (1996) Development of the cranium and paired fins in Betta splendens (Tel eostei: Percomorpha): intraspecific variation and interspecific comparisons. J. Morphol. 227:249-287.

Mangakis, N., E. Böwe, and Z.D. Pikova-Müllerova (1964) Vorschlag für ein Erfahrungsgemäss guter und schnell arbeitends trichromverfahren. Zentbl. allg. Path. path. Anat. 105:289-292.

McEIman, J .F., and E.K. Balon (1980) Early ontogeny of white sucker, Catostomus commersoni, with steps of saltatory devel opment. Env. Biol. Fishes 5:191-224.

McMurrich, J.P. (1884) On the osteology of Amiurus catus (L.) Gill. Zool . Anz. 168:296-299.

Merriman, D. (1940) Morphological and embryological studies on two species of marine catfish, Bagre marinus and Galeichthys felis. Zool ogica, N.Y. 25:221-248.

Meunier, F.J ., and A. Huysseune (1992) The concept of bonetissue in Osteichthyes. N eth. J. Zool . 42:445-458.

Muller, M. (1987) Optimization principles applied to the mechanism of neurocranium levation and mouth bottom depression in bony fishes (Halecostomi ). J . Theor. Biol. 126:343-368.

Nawar, G. (1954) On the anatomy of Clarias lazera: I. Osteology. J . Morphol. 94:551-585.

Nawar, G. (1955) On the anatomy of Clarias lazera: III. The vascular system. J. Morphol. 97:179-214.

Osse, J.W.M. (1969) Functional morphology of the head of the perch (Perca fluviatilis L.): an electromyographic study. Neth. J . Zool. 19:289-392, PhD thesis, The Netherlands.

Patterson, C. (1977) Cartilage bones, dermal bones and membrane bones, or the exoskel eton versus the endoskel eton. In S.M. Andrews, R.S. Miles, and A.D. Walker (eds.): Problems in VertebrateE volution. London: Academic Press, pp. 77-121.

Poll, M. (1957) Redescription du Gymnallabes tihoni Poll 1944, Clariidae microphthalme du Stanley-Pool (Congo Bel ge). Rev. Zool. Bot. Afr. 55:237-248.

Poll, M. (1977) Les genres nouveaux Platyallabes et Platyclarias comparés au genre Gymnallabes GTHR. Synopsis nouveau des genres de Clariidae. Bull. Classe Sci. 5:122-149.

Radermaker, F., C. Surlemont, P. Sanna, M. Chardon, and P. Vandewalle (1989) Ontogeny of the Weberian apparatus of Clarias gariepinus (Pisces, Siluriformes). Can. J . Zool. 67:2090-2097.

Rastogi, M. (1963) The head skeleton of Indian schilbeid, Clupisoma garua (Ham.). J . Morphol. 113:205214.

Regan, C.R. (1911) The classification of the teleostean fishes of the order Ostariophysi-2. Siluroidea. Ann. \& Mag. N. Hist. Ser. 8, 8:37-577.
Roberts, T.R. (1974) Osteology and classification of the neotropical characoid fishes of the families Hemiodontidae (including Anodontinae) and Parodontidae. Bull. Mus. Comp. Zool. 146:411-472.

Roberts, T.R., and C. Vidthayanon (1991) Systematic revision of the Asian catfish family Pangasiidae, with biological observations and descriptions of three new species. Proc. Acad. Nat. Sci. (Phil.) 143:97-144.

Srinivasachar, H.R. (1958) Development of the skull in catfishes: Part V: Development of skull in Heteropneustes fossilis (Bloch). Proc. Natl. Inst. Sci. India 24B:165-190.

Srinivasa Rao, K., and K. Lakshmi (1984) Head skel eton of the marine catfish Arius tenuispinnis Day (Osteichthyes: Siluriformes, Ariidae). J . Morphol. 181:221-238.

Surlemont, C., and P. Vandewalle (1991) Dével oppement postembryonnaire du sequellette et de la musculature de la tête de Clarias gariepinus (Pisces, Siluriformes) depuis l'éclosion jusqu'à 6,8 mm. Can. J . Zool. 69:10941103.

Surlemont, C., M. Chardon, and P. Vandewalle (1989) Skel eton, muscles and movements of the head of a 5.2 $\mathrm{mm}$ fry of Clarias gariepinus (Burchell) (Pisces: Siluriformes). Fortschr. Zool. 35:459-462.

Taverne, L., and A. Aloulou-Triki (1974) Étude anatomique, myol ogique et ostéol ogique du genre Synodontis Cuvier (Pisces: Siluriformes: Mochocidae). Ann. Mus. r. Afr. Centr. Sci. Zool. 210:1-69.

Teugels, G.G. (1982) A systematic outline of the African species of the genus Clarias (Pisces; Clariidae), with an annotated bibliography. Ann. Mus. r. Afr. Centr. Sci. Zool. 236:1-249.

Teugels, G.G. (1986) A systematic revision of the African species of the genus Clarias (Pisces; Clariidae). Ann. Mus. r. Afr. Centr. Sci. Zool. 247:1-199.

Teugels, G.G., L. Risch, L. De Vos, and D.F.E. Thys van den Audenaerde (1991) Generic review of the African bagrid catfish genera Auchenoglanis en Parauchenoglanis with description of a new genus. J . Nat. Hist. 25:499-517.

Tilak, R. (1961) The osteocranium and Weberian apparatus of Eutropiichthys vacha (Ham.) and E. murius (Ham.): a study of interrelationships. Zool. Anz. 167: 413-430.

Tilak, R. (1963a) The osteocranium and the Weberian apparatus of the fishes of the family Sisoridae (Siluroidea): a study in adaptation and taxonomy. Zeitschr. Wiss. Zool. Leipzig 168:281-320.

Tilak, R. (1963b) The osteocranium and Weberian apparatus of a few representatives of the family Siluridae and Plotosidae (Siluroidea): A study of interrelationships. Zool. Anz. 171:424-439.

Tilak, R. (1963c) Relationships between the osteocranium and weberian apparatus in two Indian catfishes of the genus Clarias (Siluridae). Copeia 4:623-629.

Tilak, R. (1964) The osteocranium and the Weberian apparatus of the fishes of the family Schilbeidae (Siluroidea). Proc. Zool. Soc. Lond. 143:1-36.

Tilak, R. (1965a) The comparative osteol ogy of the osteocranium and the Weberian apparatus of the Tachysuridae (Pisces: Siluroidei). J . Zool. (L ond.) 146:150-174.

Tilak, R. (1965b) The osteocranium and the Weberian apparatus of the fishes of the family Bagridae. Morph. J ahrb. 107:415-443.

Tilak, R. (1967) The osteocranium and Weberian apparatus of Amblyceps mangois (Hamilton) (Pisces: Siluroidei) in relation to taxonomy. Zool. Anz. 178:61-74.

Tilak, R. (1971) A study of the osteocranium, the Weberian apparatus and the girdles of Chaca chaca (Hamil- 
ton): family Chacidae, Siluroidei. Zool. Anz. 186:417435.

Tilney, R.L., and T. Hecht (1993) Early ontogeny of Galeichthys feliceps from the south east coast of South Africa. J . Fish Biol. 43:193-212.

Vandewalle, P., B. Focant, F. Huriaux, and M. Chardon (1992) Early development of the cephalic skeleton of Barbus barbus (Teleostei, Cyprinidae). J. Fish Biol. 41:43-62.

Vandewalle, P., C. Surlemont, and M. Chardon (1993) About the early larval development of the anterior suspensorial ossifications of Clarias gariepinus (Burchell, 1822). Zool. Anz. 231:11-19.

Vandewalle, P., A. Huysseune, P. Aerts, and W. Verraes (1994) The pharyngeal jaws in teleost feeding. In Advances in Comparative and Environmental Physiology 18. Berlin: Springer-Verlag, pp. 59-92.

Vandewalle, P., P. Laleye, and B. Focant (1995) Early development of cephalic bony elements in Chrysichthys auratus (Geofrey Saint-Hilaire, 1808) (Pisces, Siluriformes, Claroteidae). Belg. J . Zool. 125:329-348.

Vandewalle, P., I. Gluckmann, E. Baras, F. Huriaux, and B. Focant (1997) Postembryonic development of the cephalic region in Heterobranchus Iongifilis. J. Fish Biol. 50:227-253.

Verraes, W. (1973) Bijdrage tot de functioneel-morfologische studie der koponderdelen van Salmo gairdneri Richardson, 1836 (Pisces, Teleostei) gedurende de postembryonale ontogenie, met bijzondere aandacht voor het cranium en de kopspieren, Ph.D. thesis, University of Ghent, 2 vols. 242pp., (in Dutch).

Verraes, W. (1974) Discussion on some functionalmorphological relations between some parts of the chondrocranium and the osteocranium in the skull base and the skull roof, and some soft head parts during postembryonic development of Salmo gairdneri Richardson, 1836 (Teleostei: Salmonidae). Forma et Functio 7:281-292.

Verraes, W. (1975) Some functional aspects of ossifications in the cartilaginous ceratohyale during postembryonic development in Salmo gairdneri Richard- son, 1836 (Teleostei: Salmonidae). Forma et Functio 8:27-32.

Verraes, W. (1977) Postembryonic ontogeny and functional anatomy of the ligamentum mandibulo-hyoideum and the ligamentum interoperculo-mandibulare, with notes on the opercular bones and some other cranial elements in Salmo gairdneri Richardson, 1836 (Teleostei: Salmonidae). J . Morphol. 151:111-119.

Verraes, W., and M.H. Ismail (1980) Development and functional aspects of the frontal bones in relation to some other bony and cartilaginous parts of the head roof in Haplochromis elegans Trewavas, 1933 (Tel eostei: Cichlidae). Neth. J . Zool. 30:450-472.

Verreth, J ., and M. Van Tongeren (1989) Weaning time in Clarias gariepinus (Burchell) larvae. Aquaculture 83:81-88.

Vignes, O.E., and M.M. Garcia (1987) Estudio comparado del craneo de tres especies del genero Pimelodus (Siluriformes, Pimel odidae) y su posible significacion taxonomica. Rev. Mus. Arg. Ci, nat. "Bernardino Rivadavia"I nst. Nac. Inv. Ci. nat. 14:39-54.

Volckaert, F.A.M., P.H.A. Gal busera, B.A.S. Hellemans, C. Van den Haute, D. Vanstaen, and F. Ollevier (1994) Gynogenesis in the African catfish (Clarias gariepinus). I. Induction of melogenesis with thermal and pressure shocks. Aquaculture 128:221-233.

Weisel, G.F. (1960) The osteocranium of the catostomid fish, Catostomus macrocheilus: a study in adaptation and natural relationship. J . Morphol. 106:109-129.

Weisel, G.F. (1967) Early ossification in the skeleton of the sucker (Catostomus macrochelius) and the guppy (Poecilia reticulata). J. Morphol. 121:1-18.

Weitzman, S.H. (1962) The osteol ogy of Brycon meeki, a generalized characid fish, with an osteological definition of the family. Stanf. Ichth. Bull. 8:1-77.

Westneat, M.W. (1990) Feeding mechanics of teleost fishes (Labridae; Perciformes): a test of four-bar linkage models. J. Morphol. 205:269-295.

Winterbottom, R. (1974) A descriptive synonymy of the striated muscles of the teleostei. Proc. Acad. Nat. Sci. (Phil.) 125:225-317. 